\author{
UNIVERSIDADE DE SÃO PAULO \\ FACULDADE DE ODONTOLOGIA DE BAURU
}

\author{
MAX LAURENT ALBARRACÍN
}
Avaliação da deformação do intermediário e região peri-implantar em função da carga aplicada em coroas unitárias implantossuportadas parafusadas





\section{Avaliação da deformação do intermediário e região peri-implantar em função da carga aplicada em coroas unitárias implantossuportadas parafusadas}

Dissertação apresentada a Faculdade de Odontologia de Bauru da Universidade de São Paulo para obtenção do título de Mestre em Ciências no Programa de Ciências Odontológicas Aplicadas, na área de concentração Reabilitação Oral.

Orientador: Prof. Dr. José Henrique Rubo

Versão Corrigida 


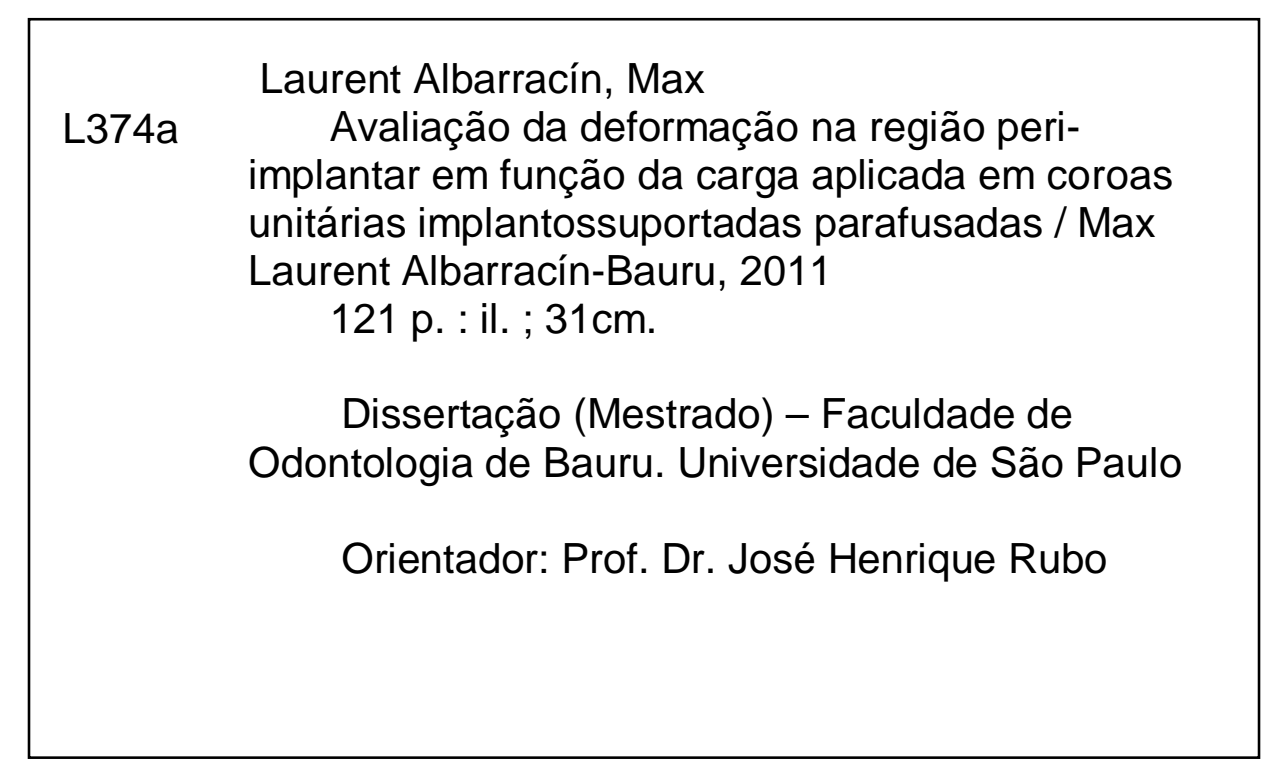

Nota: A versão original desta dissertação encontra-se disponível no Serviço de Biblioteca e Documentação da Faculdade de Odontologia de Bauru - FOB/USP.

Autorizo, exclusivamente para fins acadêmicos e científicos, a reprodução total ou parcial desta dissertação, por processos fotocopiadores e outros meios eletrônicos.

Assinatura:

Data: 
FOLHA DE APROVAÇÃO 



\section{DEDICATÓRIA}

A Deus pela vida e pela saúde.

Aos meus pais Jacques, e Maria Helda ("in memoriam").

A minha namorada Milena, pelo amor, apoio e ajuda permanente. Sua companhia e dedicação ao meu lado têm sido muito importantes para meus sonhos se tornarem realidade.

Aos meus irmãos: Jacqueline, Jacques e Paulette. 



\section{AGRADECIMENTO ESPECIAL}

Os meus sinceros agradecimentos:

Ao meu orientador: Prof. José Henrique Rubo

Pela sua disponibilidade sempre comigo, aconselhando, e mostrando o caminho certo para obter os resultados deste trabalho, nunca esquecerei a confiança que depositou em mim.

Seu método e dedicação serão para mim exemplo no meu desenvolvimento como profissional

Muito Obrigado! 



\section{AGRADECIMENTOS}

Aos Professores do Departamento de Prótese, pelos ensinamentos e orientações.

Ao Prof. Edson Capello de Souza, do Departamento de Engenharia Mecânica da UNESP pela amizade e disponibilidade com a qual sempre nos recebeu durante o planejamento e execução dos experimentos desta Dissertação.

Ao Prof. Dr. José Roberto Pereira Lauris, pela valiosa assessoria na realização da parte estatística deste trabalho.

Aos Prof. Dr. Luiz Fernando Pegoraro, Prof. Dr. Accácio Lins do Valle e Profa. Dra. Ana Lucia de Almeida pela paciência, consideração e incentivo. Suas presenças nas clínicas do mestrado transmitindo seus conhecimentos e experiências me ajudaram em toda minha vida profissional.

Aos Prof. Dr. Gerson Bonfante e Prof. Dr. Pedro Cesar Garcia de Oliveira pelas orientações e conselhos durante os seminários do PAE.

Ao meu colega de Mestrado Max Doria pela paciência e ajuda permanente na realização desta pesquisa com sucesso e pela amizade e companheirismo que tem sido de muito valor para mim.

A minha amiga Fernanda pela amizade e por abrir as portas para compartilhar com toda sua

Família. 

Aos colegas de mestrado, não tenho palavras para expressar o carinho que tenho por todos vocês sempre fui acolhido como igual. Ao Luiz, Vitor, Hugo, Matheus e todas as meninas, Lívia Lopes, Carol, Mírian, Luana, Lívia Aguiar, Lívia Maria, Ana Sílvia, Mônica e Eloisa cada um de vocês teve detalhes muitos bons comigo por isso agradeço sua amizade e companheirismo, suas ajudas foram de muito valor para mim. É um privilegio ter estudado e aprendido ao lado de todos vocês.

Aos colegas Jorge e a Mércia pela ajuda na clinica com as cirurgias.

Aos meus colegas de doutorado Vinícius e Marcelo que sempre tem estado presentes para me ajudar e aconselhar.

Aos colegas Valdey e Rafael pela ajuda com as orientações no inicio desta pesquisa.

Ao Prof. Dr. Ricardo Marins de Carvalho e Thiago Pegoraro que acreditaram em mim desde o começo desde meu país sem me conhecer, minha gratidão.

Às secretárias do Departamento de Prótese, Déborah e Cláudia que sempre me receberam com consideração.

A Cleusa e Hebe pela ajuda e colaboração nas clínicas de Pós-Graduação. Aos funcionários do Serviço de Biblioteca e Documentação em especial a Rita Paglione, pela colaboração e disponibilidade.

Às funcionárias da Secretária de Pós-Graduação, sempre me ajudaram com disposição e rapidez e isto foi de grande valia para minha adaptação como estrangeiro.

A Capes, pela bolsa de estudo que permitiu com que eu realizasse este Mestrado.

Ao programa de aperfeiçoamento e ensino PAE. 

Ao CIP da FOB-USP, e ao Renato pela ajuda e colaboração.

À Facultad de Odontologia da Universidad Nacional de Colombia e especialmente à professora Dra. Maria Clemencia Vargas que sempre acredito em mim e deu apoio durante toda minha formação como dentista.

A mis grandes amigos colombianos Gustavo, Carlina, Gustavo Eduardo y Gabriel Machado Toquica. (Su amistad es muy importante para mí. Gracias por creer y apoyarme en todos los momentos de mi vida. A su lado siempre me he sentido muy querido; mi eterna gratitud y cariño).

Gostaria também de agradecer a cada pessoa que, por um motivo ou outro, fez parte da minha vida em Bauru, e que por ventura eu não tenha lembrado de citar.

À Faculdade de Odontologia de Bauru, através de seu Diretor, Prof. Dr. José Carlos Pereira, à Comissão de Pós-Graduação, através do seu Presidente Prof. Dr. Paulo César Rodrigues Conti, à Coordenação do Curso de Pós-Graduação em Reabilitação Oral, através de seu coordenador Prof. Dr. Guilherme Janson, minha gratidão e agradecimentos!!! 

"Quando recebemos um ensinamento devemos recebê-lo como um valioso presente e não como uma dura tarefa. Eis aqui a diferença que transcende." 



\section{RESUMO}

As coroas unitárias metalocerámicas implantossuportadas são amplamente utilizadas na reabilitação de pacientes desdentados. O comportamento mecânico destas coroas é muito importante para entender o processo de transmissão de forças mastigatórias e suas reações no intermediário e na estrutura óssea periimplantar, mas estes processos ainda não estão totalmente compreendidos. 0 objetivo deste trabalho foi verificar a deformação gerada no intermediário e no osso peri-implantar de coroas unitárias implantossuportadas após aplicação de carga. Foi utilizado um modelo mestre de poliuretano, simulando o osso mandibular, com um implante hexágono externo de $3,75 \mathrm{~mm} \times 13 \mathrm{~mm}$ de comprimento, no qual foi fixado um intermediário multi-unit (Nobel Biocare, Göteborg, Sweden). O trabalho apresentou 3 grupos com quatro corpos de prova cada, divididos de acordo com o tipo de cilindro e liga de fundição (Cilindro de ouro sobrefundidos com a liga de $\mathrm{PdAg}$, cilindro de $\mathrm{CoCr}$ usinado sobrefundidos com a liga de $\mathrm{NiCoCr}$, cilindro de acrílico fundido com a liga de $\mathrm{NiCoCr}$ ). Cada corpo de prova foi submetido cinco vezes a aplicação de carga axial de $300 \mathrm{~N}$ em uma máquina de ensaio universal. $\mathrm{A}$ força foi aplicada no centro da oclusal de cada coroa. Foram realizadas leituras das deformações geradas no intermediário e no poliuretano com o uso de extensômetros lineares elétricos os quais foram colados em três faces do intermediário e nas superfícies mesial, vestibular, distal e lingual do osso simulado ao redor do implante. Os dados obtidos foram submetidos a análise de variância (ANOVA) e teste de Tukey $(p<0,05)$. Os resultados do estudo demonstraram que a utilização dos três tipos de cilindro não alteram o resultado final de distribuição de tensão no intermediário após o carregamento. Adicionalmente as coroas confeccionadas com cilindro de CoCr usinado, tiveram o comportamento mais estável com relação a uniformidade na distribuição das tensões no intermediário e no osso simulado quando comparados com os outros dois grupos (cilindros de Au e Calcinável).

Palavras-chave: Coroa unitária implantossuportada, Extensômetro, Biomecânica, Implante dentário 



\section{Evaluation of the deformation in the abutment and peri-implant region according to the load applied in screwed implant-supported single crowns}

The metal-ceramic crowns implant-supported are widely used in the rehabilitation of edentulous patients. The mechanical behavior of these crowns is very important to understand the process of transmission of masticatory forces and their reactions at abutment and peri-implant bone structure, but these processes are not fully understood yet. The aim of this study was to verify the deformation in the abutment and peri-implant bone in implant-supported single crowns after load application. Was used a master model of polyurethane simulating the jawbone with an external hexagon implant of $3.75 \mathrm{~mm}$ of diameter and $13 \mathrm{~mm}$ of length, which was fixed a multi-unit abutment (Nobel Biocare, Göteborg, Sweden). The study presented three groups with four samples each, divided according to type of cylinder and casting alloy (gold cylinder smelting with the PdAg alloy, CoCr cylinder machined cast-on with the league $\mathrm{NiCoCr}$, cast acrylic cylinder with alloy NiCoCr). Each sample was subjected to five times the application of vertical load of $300 \mathrm{~N}$ on a universal testing machine. The force was applied in the center of the occlusal surface of each crown. Readings were taken of the deformations generated in the abutment and polyurethane with the use of strain gages which were glued on three sides of the abutment and mesial, buccal, lingual and distal surfaces of simulated bone around the implant. The datas were submitted to ANOVA and Tukey test $(p<0.05)$. The study results demonstrated that the use of three types of cylinder does not change the final result of stress distribution in the intermediate after axial loading. Additionally crowns made with machined cylinder $\mathrm{CoCr}$, had more stable with respect to uniform distribution of stresses in the intermediate and the simulated bone when compared with the other two groups (Au and burnout cylinders).

Keywords: Single unit implant-supported crown, Strain gage, Biomechanics, Dental implant. 



\section{LISTA DE ILUSTRAÇÕES}

\section{- FIGURAS}

Figura 4. 1 - Vista ântero-superior da matriz metálica com a tampa de acrílico e os dois implantes posicionados.

Figura 4.2 - Vista interna da tampa com os implantes posicionados.......................68

Figura 4.3 - Vista superior do modelo de PU, com os implantes ............................69

Figura 4.4 - Vista anterior do modelo de PU, com os implantes..............................69

Figura 4.5 - Padronização dos corpos de prova. Matriz em silicona e enceramento do pré-molar terminado

Figura 4.6 - Corpos de prova cilindro protético de ouro - liga de paládio prata.

Figura 4.7 - Corpos de prova cilindro protético usinado - liga de cobalto-cromo.

Figura 4.8 - Corpos de prova cilindro protético de acrílico - liga de cobalto-cromo.

Figura 4.9 - Grupo 1: Cilindro de ouro, sobre-fundidos com a liga de paládio-prata e cobertura cerâmica ${ }^{*}$ Pors-on ${ }^{\circledR} 4-$ Degussa S.A., São Paulo, Brasil.....

Figura 4.10 - Grupo 2: Cilindro de acrílico fundido com a liga de $\mathrm{NiCoCr}$ e cobertura cerâmica *Dan Ceramalloy, Nihon Shika Kinzoku CO....

Figura 4.11 - Grupo 3: Cilindro de $\mathrm{CoCr}$ usinado, sobre-fundidos com a liga de NiCoCr e cobertura cerâmica *Dan Ceramalloy, Nihon Shika Kinzoku CO.

Figura 4.12-Imagem da base metálica visualizando o local de assentamento do modelo de PU com os três parafusos de retenção e estabilização.

Figura 4.13-Imagem da base metálica com o modelo de PU posicionado, notando o perfeito assentamento da superfície lingual do modelo na superfície interna da base metálica 

Figura 4.14 - Imagem do torquimetro eletrônico Nobel Biocare Torque Controller ${ }^{\mathrm{TM}}$

Figura 4.15 - Superfícies interna e externa dos extensômetros lineares elétricos

Figura 4.16-Modelo de PU com os intermediários e com os extensômetros lineares elétricos colados na superfície oclusal do modelo ao redor dos dois implantes

Figura 4.17 - Placa de circuito com extensômetros soldados. 78

Figura 4.18 - Imagem do dispositivo de aquisição de dados com os canais de extensometria conectados

Figura 4.19 - Imagem da Maquina de ensaio univeral da empressa EMICTM

Figura 4.20-Imagem superior do modelo experimental na base colocado na maquina de ensaio universal EMIC ${ }^{\mathrm{TM}}$

Figura 4.21 - Imagem lateral do modelo experimental na sua base colocado nas maquina de ensaio universal EMIC ${ }^{\mathrm{TM}}$

Figura 4.22 - Imagem da aplicação de carga com a ponta de aço

Figura 4.23 - Desenho representativo da disposição dos extensômetros lineares elétricos no intermediário (I) no modelo de PU .82

Figura 4.24 - Fases das variações dos valores de deformação 85

Figura 4.25 - Vista panorâmica de toda a montagem para a aplicação de carga e a aquisição dos dados 



\section{- GRÁFICOS}

Gráfico 5.1-Gráfico de médias e desvio padrão de microdeformação $(\mu \varepsilon)$ para todos os corpos de prova no intermediário e no poliuretano

Gráfico 5.2 -Gráfico das médias de microdeformação $(\mu \varepsilon)$ captadas pelos canais de extensometria no intermediário e no poliuretano para o grupo de cilindro de Au. 90

Gráfico 5. 3 -Gráfico das médias de microdeformação $(\mu \varepsilon)$ captadas pelos canais de extensometria no intermediário e no poliuretano para o grupo de cilindro Calcinável 91

Gráfico 5. 4 -Gráfico das médias de microdeformação $(\mu \varepsilon)$ captadas pelos canais de extensometria no intermediário e no poliuretano para o grupo de cilindro de $\mathrm{CoCr}$. 



\section{LISTA DE TABELAS}

Tabela 4.1 - Especificações das ligas utilizadas, segundo os fabricantes

Tabela 5.1 - ANOVA a dois critérios para as duas variáveis pesquisadas, material e localização. Valor da probabilidade menor que 0,05 significa estatisticamente significante $(p<0,05)$

Tabela 5.2 - TESTE DE TUKEY. Os valores localizados em cada linha com a mesma letra não apresentam diferença estatisticamente significante (nível de significância de 0,05). A interação foi apenas observada no SG vestibular com valores estatisticamente significantes. 92 



\section{LISTA DE ABREVIATURA E SIGLAS}

\begin{tabular}{|c|c|}
\hline PdAg & paládio-prata \\
\hline $\mathrm{CoCr}$ & cobalto-cromo \\
\hline $\mathbf{N i}$ & Niquel \\
\hline $\mathrm{Au}$ & Ouro \\
\hline SG & canal de extensometria \\
\hline PU & poliuretano \\
\hline I & implante \\
\hline${ }^{\circ} \mathrm{C}$ & grau Celsius \\
\hline g & gramas \\
\hline $\mathbf{T}$ & tensão \\
\hline $\mathbf{P}$ & carga aplicada \\
\hline $\mathbf{S}_{0}$ & seção transversal \\
\hline $\mathbf{E}$ & módulo de elasticidade \\
\hline $\mathbf{L}$ & comprimento final \\
\hline $\mathrm{L}_{0}$ & comprimento inicial \\
\hline$\Delta \mathrm{L}$ & variação do comprimento \\
\hline $\mathbf{m m}$ & milímetros \\
\hline $\mathbf{c m}^{3}$ & centímetro cúbico \\
\hline $\mathrm{Ncm}$ & Newton centímetro \\
\hline rpm & rotações por minuto \\
\hline$\varepsilon$ & tensão \\
\hline$\mu \varepsilon$ & microstrains \\
\hline$\mu \mathrm{m}$ & micrometros \\
\hline MHz & mega hertz \\
\hline GPa & giga pascal \\
\hline
\end{tabular}





\section{SUMÁRIO}

1 INTRODUÇÃO 13

2 REVISÃO DE LITERATURA. 19

2.1 BIOMECÂNICA E AVALIAÇÕES CLÍNICAS EM PRÓTESES IMPLANTOSSUPORTADAS

2.2 BIOLOGIA ÓSSEA E TENSÕES AO REDOR DOS IMPLANTES .

$3 \quad$ PROPOSIÇÃO 61

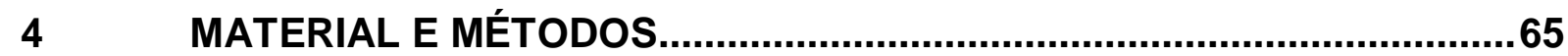

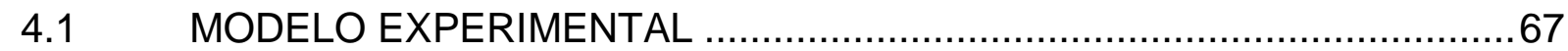

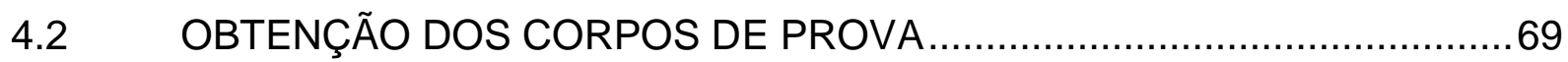

4.2.1 Enceramento e inclusão dos corpos de prova............................................70

4.2.2 Sobrefundição dos corpos de prova ....................................................71

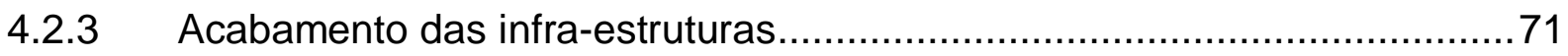

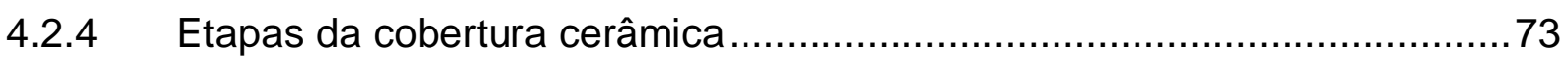

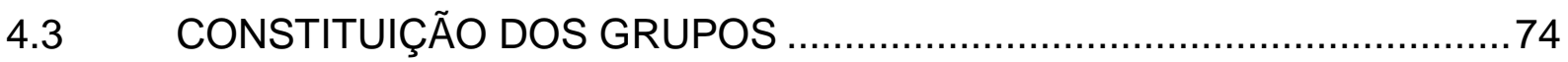

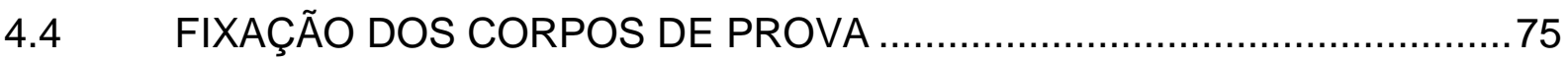

4.5 COLAGEM DOS EXTENSÔMETROS LINEARES

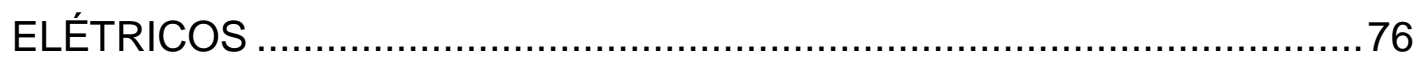

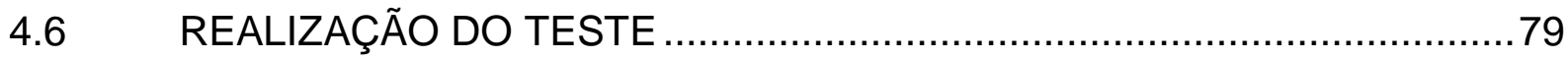

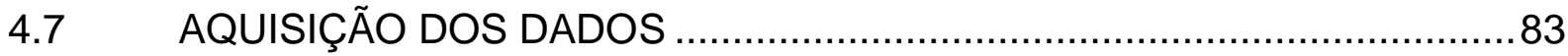

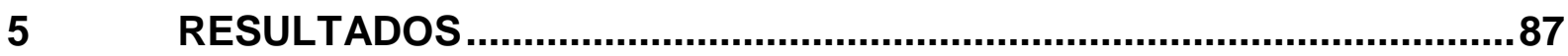

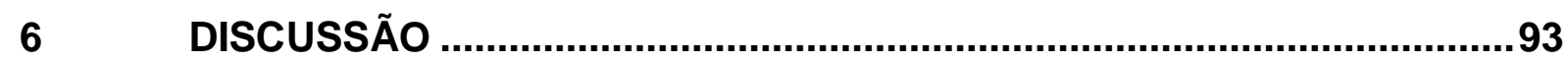

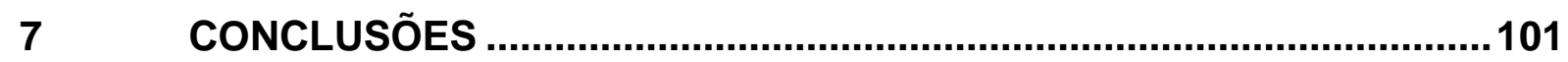

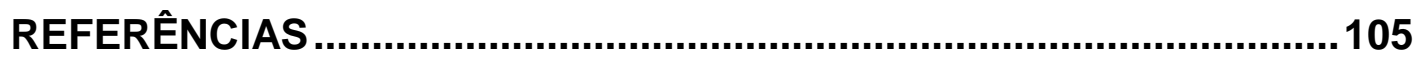

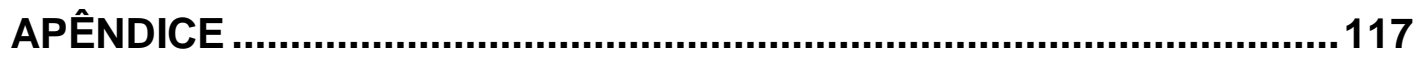



1- Introducão 



\section{INTRODUÇÃO}

Implantes ósseo integrados são amplamente utilizados para pacientes desdentados, aumentando as opções de tratamento na reabilitação oral. O sucesso e o grande número de pacientes tratados nos últimos anos atraíram o interesse de clínicos e pesquisadores no mundo todo. Apesar dos excelentes resultados em longo prazo proporcionado pelo uso de implantes no tratamento odontológico, estes não são livres de complicações mecânicas.

Os aspectos biomecânicos dos implantes dentários são bastante diferentes dos dentes naturais, devido à capacidade do ligamento periodontal de absorver forças e permitir micro movimentações, comparado com os implantes ósseointegrados. Existe a possibilidade que a carga transferida para o implante e ao osso peri-implantar exceda os limites fisiológicos resultando no fracasso e perda do conjunto prótese-implante (EKFELDT; CARLSSON; BÖRJESSON, 1994; RANGERT et al., 1994; SKALAK, 1983).

Assim, a literatura ressalta que o sucesso em longo prazo do tratamento com implantes depende do prudente controle da carga biomecânica (ÇEHRELI; IPLIKÇIOGLU; BILIR, 2002). Geralmente as falhas são observadas após as próteses serem instaladas nos pacientes e estão principalmente relacionadas a complicações biomecânicas, porém ainda não são totalmente compreendidas e a literatura sobre estas falhas é inconclusiva (TAYLOR; AGAR; VOGIATZI, 2000).

O conjunto prótese implante apresenta uma conexão rígida que induz tensões em cada um dos seus componentes expostos às forças. Quando as cargas mastigatórias funcionais e parafuncionais se sobrepõem, são geradas tensões adicionais que afetam o conjunto formado pelo osso, implante e prótese. É assim que o maior desafio para o dentista será realizar uma prótese aceitável que não comprometa o tratamento ao longo prazo (JEMT, 1996).

Na presença de forças funcionais aplicadas ao conjunto prótese-implante são induzidas tensões e deformações que afetam a remodelação do osso peri-implantar (BIDEZ; MISCH, 1992; BRÅNEMARK; ZARB; ALBREKTSSON, 1987). Porém o 
efeito de uma excessiva e constante deformação e a manutenção da ósseointegração não tem sido esclarecido ainda completamente (MILLINGTON; LEUNG, 1995).

O estresse mecânico gerado pelo esforço de tensão/deformação, pode ter conseqüências positivas e negativas ao tecido ósseo e as forças oclusais podem atuar sobre os implantes orais em diferentes magnitudes podendo levar à perda óssea marginal e à perda da osseointegração (ISIDOR, 2006). Segundo a literatura a carga excessiva na interface osso/implante seria uma das grandes responsáveis por essa perda, motivando o estudo das microdeformações, através do qual, podemos definir parâmetros que constatem níveis considerados prejudiciais a esta interface (HEKIMOGLU, 2004).

Para poder correlacionar as forças transmitidas pela sobrecarga oclusal com os diferentes graus de remodelação óssea sofrida pelos tecidos peri-implantares, a teoria "mecanostática", proposta por Frost, pode ser utilizada para quantificar qual a tensão máxima suportada pelo osso. Frost sugere, que certos hormônios e agentes bioquímicos podem "enganar" o sistema, alterando os limites das janelas fisiológicas, permitindo, que o uso mecânico normal aumente a densidade e resistência óssea significantemente (DUNCAN; TURNER, 1995).

Além disso, a teoria proposta por Frost (1994) afirma que a remodelação óssea pode induzir a reabsorção ou conservação do osso, mas não pode acrescentar mais osso à estrutura. Também estabeleceu a existência de uma taxa mínima de tensão, a "tensão mínima efetiva" (TME), acima da qual a resposta adaptativa ocorreria, enquanto abaixo dela o osso permaneceria estável. Onde a deformação óssea permanecer abaixo de $50 \mu \varepsilon$ (micro strain - unidade de deformação) se observam os efeitos do desuso. Entre $50 \mu \varepsilon$ e $1500 \mu \varepsilon$ ocorre o equilíbrio (remodelação óssea) e se a deformação ultrapassar $1500 \mu \varepsilon$, a modelação óssea pode ocorrer. Deformações acima de $3000 \mu \varepsilon$ podem gerar reabsorção.

A distribuição de forças entre os componentes do sistema prótese/implante/osso, a reação de cada parte componente deste sistema e a mensuração destas forças transmitidas são de fundamental importância para 
entendimento de todo o processo biomecânico de distribuição de cargas funcionais e parafuncionais (SAHIN; ÇEHRELI; YALÇIN, 2002; JACQUES et al., 2009).

Para a análise desta dinâmica de fatores, tem sido utilizadas diversas técnicas para se compreender o comportamento das estruturas quando são submetidas às cargas oclusais, sendo assim as principais: a fotoelasticidade, a análise com os elementos finitos e a extensometria linear. A extensometria é uma técnica de medição de deformações que encontra aplicação em pesquisas científicas e tecnológicas. Esta técnica torna possível a obtenção de dados reais em relação às forças exercidas sobre os implantes e transferidas às estruturas de suporte (SPIEKERMANN et al., 1995, CLELLAND; VAN PUTTEN, 1996).

Quando aplicamos uma força (tensão) a um material, ocorre a deformação na sua estrutura. A deformação, expressa em " $\varepsilon$ " (epsilon), pode ser quantificada por meio da razão entre as dimensões do objeto sob estresse e suas dimensões originais, gerando valores absolutos e sem unidade (VASCONCELLOS, 2005). Os valores obtidos são muito pequenos, e assim a compressão ou o alongamento relativo são expressos em $\mu \varepsilon$ (microdeformação), sufixo empregado no presente estudo e que corresponde a $10^{-6} \varepsilon$. Mil unidades de microdeformação $(1.000 \mu \varepsilon)$ correspondem ao alongamento ou compressão de $0,1 \%$ da estrutura em questão (FROST, 1994; WISKOTT; BELSER, 1999).

Analisando os resultados encontrados na literatura, desenvolvemos este estudo in vitro com o objetivo de avaliar as deformações que ocorrem na região periimplantar e no intermediário sob aplicação de carga axial estática, para coroas unitárias parafusadas usinadas confeccionadas a partir de cilindros de três tipos diferentes de ligas. 

2- Revisão de Literatura 



\section{REVISÃO DE LITERATURA}

\subsection{BIOMECÂNICA E AVALIAÇÕES CLÍNICAS EM PRÓTESES IMPLANTOSSUPORTADAS}

A realização desta revisão, não tem a pretensão de esgotar o assunto, tem por objetivo abordar algumas das mais relevantes pesquisas que precederam nossa linha de pesquisa.

Adell et al. (1981), com um estudo de 15 anos, (1965-1980) avaliaram 2.768 implantes instalados em 191 maxilas e 219 mandíbulas, em um total de 371 pacientes. Com 405 maxilares operados, próteses foram instaladas nos implantes e foram feitos controles anuais. Os pesquisadores encontraram complicações mecânicas como fratura de parafusos, de implantes e das próteses, e complicações biológicas como perda óssea marginal. Foi considerado pelos autores, que concentrações inadvertidas de estresse, devido à ausência de um ajuste absoluto entre a prótese fixa e as conexões, como a causa mais provável para as complicações ocorridas, recomendando esforços intensos com o objetivo de aumentar a precisão na adaptação entre estes componentes.

Depois, Skalak (1983) fez uma das primeiras considerações sobre biomecânica publicando um artigo enfocando a importância desta nas próteses implanto-suportadas. Ele afirmou que o sucesso ou a falha desse tipo de prótese tem como fatores críticos a incidência e a transferência de estresses mecânicos sobre os implantes e destes para o tecido ósseo adjacente. Sugeriu também que tanto o tecido ósseo como os implantes deveriam ser submetidos somente a forças aos quais estariam aptos a receber. O pesquisador salientou que a união rígida da prótese com o implante osseointegrado constitui uma unidade e, consequentemente, qualquer desalinhamento, entre a prótese fixa e o implantes, resultaria em um estresse interno da prótese, implante e osso afirmando que esse estresse possa não ser detectado visual ou clinicamente e pode ocasionar falhas, mesmo sem a presença de forças externas. Salientou também a importância da utilização de materiais que absorvam e distribuam melhor as cargas, como a resina acrílica dos 
dentes artificiais. Foi analisado pelo autor que esse conjunto permitiria uma infraestrutura rígida com uma proteção externa para a absorção de impactos. Considerou também que uma conexão adaptada firmemente da prótese parcial fixa com as fixações fornece uma estrutura combinada que pode agir junto com o osso proporcionando uma resistência maior do que apenas a fixação.

Rangert, Jemt e Jörneus (1989), afirmaram que a geometria das próteses tem influência significativa na distribuição de cargas aos implantes. Definiram a pré-carga como a força gerada no momento do aperto dos parafusos e que mantém os componentes unidos. Esta pré-carga deve ser suficiente para suportar as forças externas, que podem provocar a separação dos componentes e, em consequência, o afrouxamento dos parafusos. Assim dessa forma, duas condições básicas devem ser seguidas para o sucesso do tratamento: obtenção de adequada pré-carga e adaptação precisa da prótese. Os autores confirmam que os parafusos de retenção protética são a parte frágil deste sistema reabilitador, podendo ser considerados mecanismos de segurança. A principal causa do afrouxamento ou fratura destes parafusos é a falta de adaptação protética. $O$ desenho das próteses e 0 posicionamento dos implantes têm importante influência no estresse que é transmitido para os implantes e para o tecido ósseo. Discutiram sobre os parâmetros biomecânicos que determinam as forças que incidem sobre os implantes e sugeriram princípios clínicos a serem adotados para minimizar problemas.

Setz et al. (1989) estudaram o padrão de mastigação e o estresse nos implantes suportando barras protéticas para fixação de sobredentaduras. Foram utilizados dezoito pacientes portadores de próteses totais inferiores conectadas a uma barra protética apoiada em dois implantes, na região anterior da mandíbula, foram submetidos a avaliações com eletrognatografia e extensometria, com e sem a barra protética implantossuportada. $O$ fato de ter barra determinou importantes incrementos na força mastigatória, e conseqüentemente reduziu o tempo para a trituração do bolo alimentar. Foram feitas avaliações com a técnica da extensometria in vivo que demonstraram estresses nos implantes no momento da fixação da barra protética, que podem exceder as forças mastigatórias. Todos os implantes também foram submetidos a estresses durante a deglutição. As forças encontradas atingiram a metade do valor das forças mastigatórias. 
Através de um estudo de análise bidimensional de elemento finito, Williams et al. (1990) verificaram que uma infraestrutura para prótese fixa implanto-suportada em liga de cobalto-cromo permitiu a distribuição mais uniforme de estresse ao longo de sua extensão em relação à liga de ouro. Apesar de ter um alto módulo de elasticidade, proporcionou uma transmissão de carga mais eficaz e duradoura. Foi sugerido pelos autores a possibilidade de utilização da liga de cobalto-cromo em substituição às ligas de ouro em próteses sobre implantes.

No mesmo ano, Zarb e Schmitt (1990) em um estudo longitudinal sobre a efetividade clínica de implantes ósseo-integrados descreveram os aspectos clínicos e complicações encontradas em 46 pacientes com próteses implanto-suportadas. Em um período de 4 a 9 anos, os problemas e complicações encontrados foram observados e registrados em todas as etapas do tratamento. Encontraram que a fratura do parafuso de ouro foi a falha protética mais frequente. Foi sugerido pelos autores que esse problema poderia ser consequência de sobrecargas ou ausência de adaptação passiva da infraestrutura. Também afirmaram que a maioria dos problemas encontrados foram de natureza iatrogênica, embora alguns fossem inerentes ao próprio método utilizado.

O estudo realizado por Jemt (1991) apresentou um acompanhamento de 1 ano de 391 próteses parciais fixas sobre implantes, relatando um sucesso de $99,5 \%$ com o tratamento protético. Embora tiverem sido relatadas poucas complicações, a maioria ocorreu na maxila. Entre as complicações encontradas com mais freqüência foram: problemas com a fala $(31,2 \%)$, mordida do lábio e bochecha $(6,6 \%)$, irritação causada pelo cantilever (3,1\%), problemas gengivais (fístula, hiperplasia, inflamação $1,7 \%)$, fratura da estrutura metálica $(0,8 \%)$. O pesquisador relatou que não houve fratura de nenhum dos componentes. O estudo mostrou que 271 próteses $(69,3 \%)$ apresentaram os parafusos estáveis no primeiro controle (após 1 semana), não havendo necessidade de apertamento. A instabilidade dos parafusos de ouro foi maior na maxila, sendo esta diferença estatisticamente significante. Afirmou que quando o desenho da prótese é adequado, sendo esta rígida e com adaptação passiva, o risco de fratura dos componentes é baixo e a incidência dessa falha é maior no primeiro ano de função. Foi sugerido pelo autor um protocolo para análise de adaptação de próteses sobre implantes. Considerando uma prótese fixa suportada por 5 implantes, numerados de 1 a 5 da direita para a esquerda, a prótese 
deve ser posicionada e o parafuso 1 apertado totalmente. Com este procedimento, observa-se a adaptação dos demais componentes. O procedimento deve ser repetido com outro parafuso distal (parafuso 5). Uma vez verificada a adaptação, prossegue-se com o apertamento dos parafusos, um de cada vez, iniciando-se pelo parafuso 2, depois na seqüência os parafusos 4, 3, 1 e, por último, o parafuso 5 . Cada parafuso era apertado até sua primeira resistência, anotando-se a posição da chave e um máximo de $1 / 2$ volta $\left(180^{\circ}\right)$ deveria ser dado na chave para o aperto final. O pesquisador utilizou outro método para avaliar a adaptação e foi a quantidade de voltas dadas durante o aperto dos parafusos. Foi considerada a prótese mal adaptada quando mais de meia volta era necessária para apertar completamente um parafuso, por este motivo, esta deveria ser separada e soldada.

No mesmo ano, Jemt et al. (1991), realizaram um estudo piloto in vivo comparando as forças desenvolvidas e transmitidas para os implantes, por uma sobredentadura e uma prótese fixa do tipo protocolo, utilizando um caso clínico com 6 implantes na maxila ocluindo contra dentes naturais, até pré-molares. Os autores confeccionaram 2 próteses, uma fixa do tipo protocolo e uma sobredentadura com sistema barra-clip (1 anterior e 2 nas extensões posteriores), ambas consideradas clinicamente adaptadas. Utilizaram para medir as deformações, 3 extensômetros fixos no intermediário direito mais distal, as cargas oclusais foram controladas através de um garfo medidor da força de mordida, sendo que o paciente ocluía no garfo em 5 posições diferentes: sobre o intermediário, anterior e posteriormente do mesmo lado e sobre o intermediário contralateral. Posteriormente, o paciente mastigava um pedaço de parafina por 20 minutos, enquanto as forças transmitidas eram continuamente registradas. Foi avaliada primeiro a prótese fixa e, em seguida, o mesmo procedimento foi realizado com a sobredentadura. Os resultados indicaram que uma maior força de tensão foi desenvolvida durante a instalação da intraestrutura da prótese fixa. Apesar das forças de compressão e tensão terem sido menores com a sobredentadura, quando submetida às forças oclusais, maiores forças laterais eram geradas no intermediário em questão. Ainda se tratando de um estudo com um único paciente, os autores consideraram que a força desenvolvida com o apertamento dos parafusos da prótese fixa poderia estar relacionada com a adaptação ou mesmo com a rigidez da barra. No estudo as forças tensionais e compressivas foram menores na sobredentadura, indicando que esta se move 
contra os implantes, distribuindo as forças também para a mucosa. Como o estudo teve limitações, os resultados obtidos não podem ser generalizados.

O propósito do estudo de Millington e Leung (1992) foi analisar a possível relação entre o estresse gerado na superfície das infraestruturas e a discrepância de adaptação em prótese fixa implantossuportada, através de análise de fotoelasticidade. Foi confeccionado um modelo experimental contendo quatro intermediários do Sistema Brånemark e uma infraestrutura em liga de ouro tipo IV foi fundida. Os autores criaram, através de anéis metálicos, desadaptações verticais de 6 a $140 \mu \mathrm{m}$ em diferentes locais, entre o intermediário e o cilindro de ouro correspondente. Ainda nas menores discrepâncias, de $6 \mu \mathrm{m}$, houve a indução de estresse. Foram observadas as maiores concentrações de estresse nos intermediários mais centrais, e não nos terminais, independente do local da desadaptação.

Jornéus, Jemt e Carlsson (1992), utilizando diferentes tipos de parafusos observaram a sua estabilidade através da aplicação de forças oclusais em coroas unitárias implanto-suportadas. A partir do cálculo das forças oclusais máximas (140 a 390N) observadas em pacientes com implantes unitários associadas a parâmetros geométricos, tentaram determinar a resistência de 4 tipos de parafuso: (1) de titânio com cabeça cônica com roscas do tipo 1; (2) de titânio com cabeça plana e roscas do tipo 1; (3) de titânio com cabeça plana e roscas do tipo 3 e (4) de ouro com cabeça plana. Foram apertados os parafusos em um implante de $10 \mathrm{~mm}$ com diferentes torques, entre 20 a $35 \mathrm{Ncm}$, através de um torquímetro. Foi utilizado o torque necessário para causar a rotação do intermediário no hexágono do implante como medida da estabilidade da articulação parafusada. Cada tipo de parafuso foi testado antes e imediatamente após o apertamento 5 vezes, sendo que em cada teste novos componentes foram utilizados. O torque necessário para rotacionar o cilindro do intermediário no implante foi medido no sentido horário e anti-horário, sendo observado visualmente e ao se ouvir um estalo produzido pelo cilindro ao mudar de posição. Foi aplicada uma força de $70 \mathrm{~N}$ perpendicularmente ao longo-eixo do implante por 100 vezes e as amostras também foram submetidas a testes de carga cíclica. O afrouxamento é um problema potencial de todos os tipos de parafuso e o apertamento insuficiente e a geometria do parafuso são as causas 
principais, pois a força de tensão age a partir da cabeça para as roscas do parafuso. A pré-carga deve ser a maior possível para propiciar uma força de contato entre 0 intermediário e o implante. Quanto mais rígidos forem os materiais, mais estável é a união. Além disso, todos os materiais têm certo grau de elasticidade e o parafuso sofre um alongamento quando submetido a forças de tensão durante o apertamento. Quanto maior o alongamento, melhor a estabilidade final do parafuso. Foi enfatizado pelos pesquisadores a importância do desenho da cabeça do parafuso na transmissão do torque máximo para a haste e roscas. Observaram a ocorrência de 2 mecanismos de afrouxamento do parafuso: por flexão e pelos efeitos de assentamento. Uma força de flexão acima da resistência do parafuso resulta em sua permanente deformação, causando a redução das forças de contato entre o intermediário e o implante. Por conseguinte, o parafuso afrouxa com mais facilidade. Outro mecanismo da perda do parafuso baseia-se no fato de que nenhuma superfície é completamente lisa. Ainda superfícies cuidadosamente torneadas são rugosas quando vistas microscopicamente. Por isso, não entram em contato completamente. Quando a interface do parafuso é sujeita a cargas externas, ocorrem micromovimentos entre as superfícies, podendo causar um desgaste nas áreas de contato, mas, ao mesmo tempo, aproximando mais as duas superfícies. Os pesquisadores destacaram que a qualidade do assentamento depende da aspereza inicial da superfície e da rigidez, bem como da magnitude das forcas incidentes. As superfícies rugosas e cargas externas mais pesadas aumentam o assentamento. Quando o efeito de assentamento completo é maior que o alongamento elástico do parafuso, o mesmo afrouxa porque não existem forças de contato para segurar o parafuso. Foi considerado que os testes de carga utilizados representaram uma situação extrema, raramente ocorrendo em situações clínicas. Portanto, os autores sugeriram que a utilização de parafusos de titânio possibilita uma boa margem de segurança na maioria das situações clínicas.

O estudo realizado por Shackleton et al. (1992) verificou a causa e a incidência dos problemas protéticos após a instalação de próteses fixas implantossuportadas em um grupo de 25 pacientes tratados com prótese total fixa mandibular do Sistema Brånemark. Foi analisada a história clínica dos pacientes para obter informações sobre tratamentos adicionais, num período de acompanhamento de 10 a 70 meses. Os problemas mais frequentes foram a fratura 
de componentes protéticos individuais ou da própria prótese $(34,2 \%)$; em seguida, 0 afrouxamento dos parafusos de ouro ou do intermediário ( $25,5 \%$ ), problemas dos tecidos moles $(9,6 \%)$, queixas em relação à fonética $(8,2 \%)$ e queixas estéticas (6,8\%). Em longo prazo, a análise dos resultados também mostrou que cantilevers de $15 \mathrm{~mm}$ ou menos são significativamente melhores que os mais extensos. De acordo com os resultados desse estudo, os autores concluíram que mais de $50 \%$ dos problemas protéticos são relacionados aos fatores de estresse que atuam sobre a prótese. Os autores sugeriram que o comprimento do cantilever não deveria exceder $15 \mathrm{~mm}$ para minimizar os problemas mecânicos.

O estudo realizado por Glantz et al. (1993) utilizou a extensometria para registrar deformações funcionais in vivo e in vitro em uma prótese fixa suportada por cinco implantes osseointegrados. Foram colados quatro extensômetros lineares elétricos em cada conexão protética, e os sinais foram transferidos para um computador por um conversor de sinal analógico/digital. Para coleta e análise dos dados obtidos foi utilizado um programa de computador. Baseados nas informações obtidas com vários testes in vitro, experimentos in vivo foram desenvolvidos, com o paciente realizando máximo aperto dos dentes, bem como durante o ciclo mastigatório. Com os resultados obtidos foram demostradas diferenças entre as condições clínicas e laboratoriais. Os pesquisadores alertaram para as altas concentrações de estresse durante o aperto dos parafusos de retenção da prótese às conexões. Afirmaram que a técnica de mensuração de deformações com o emprego da extensometria permite a precisa coleta de dados, permitindo estudos com implantes ósseointegrados com uma grande variedade de condições.

No mesmo ano Weinberg (1993) descreveu as diferenças entre os aspectos biomecânicos da distribuição de forças em próteses implantossuportadas e dentosuportadas. O relacionamento complexo entre os componentes do sistema assim como as diferenças na rigidez relativa das estruturas envolvidas são responsáveis pela absorção e distribuição de forças. A distribuição das forças nas próteses sobre implantes depende do grau de deformação dos parafusos de retenção (do intermediário e de ouro), do intermediário, da própria prótese, do implante e do tecido ósseo, uma vez que a osseointegração não conta com a presença do ligamento periodontal, portanto, a distribuição de forças é consideravelmente restrita. 
O ligamento periodontal tem uma resiliência de aproximadamente $500 \mu \mathrm{m}$, enquanto a parte mais flexível do sistema de implantes, o osso, permite uma deformação máxima de $100 \mu \mathrm{m}$. No caso de não poder estabelecer uma pré-carga suficiente e/ou uma adaptação adequada entre o intermediário e o cilindro de ouro, o parafuso de ouro pode sofrer deformação ou fratura. Assim quando o estabelecimento da précarga nessa interface, com o apertamento adequado do parafuso, com torque de $10 \mathrm{Ncm}$, pode minimizar a força de cisalhamento que sobre ele ocorre. Porém, quando existe uma desadaptação na interface intermediário/cilindro de ouro, a força de cisalhamento gerada no parafuso pode ser maior do que ele é capaz de suportar, podendo causar a fadiga do metal e até sua falha. Em uma prótese unitária, o afrouxamento ou falha do parafuso de ouro é facilmente detectável. Em uma prótese extensa, a falta de adaptação e a subsequente falha do parafuso alteram a distribuição da força oclusal para outros pontos A quantidade de distribuição para as fixações remanescentes depende do grau de deformação do osso de suporte, fixação, pilar protético, parafuso de retenção e da prótese. A distribuição da força depende de alguma deformação do complexo: parafuso de retenção - pilar protético devido à interface osseointegrada não permitir movimentação.

Tan et al. (1993) analisaram a distorção tridimensional em infraestruturas confeccionadas em liga de paládio-prata fundida em monobloco sobre um modelo com cinco implantes. Confrontaram duas formas de infraestruturas: "L" e "U" (recomendada pelo grupo de Toronto). Os pesquisadores sopesaram 0 deslocamento dos cilindros de ouro das amostras em relação aos intermediários do modelo mestre quanto aos deslocamentos de translação e de rotação. Empregaram medidas de coordenadas com auxílio de uma máquina de medidas de coordenadas acoplada ao programa de microcomputador AVAIL (Advanced Validator Interfacing Language), o qual armazenava e calculava os dados geométricos. Não encontraram diferenças entre as formas das infraestruturas. A localização dos cilindros no arco foi associada a deslocamentos de translação e rotação com direção e magnitude específicas. Pequenas distorções rotacionais promoveram fendas verticais amplas quando realizaram o teste de adaptação inicial com apertamento de um parafuso. Porém, tais distorções podem ser camufladas quando o torque de apertamento é dado nos parafusos fazendo a infraestrutura parecer adaptada, provocando no sistema tensões externas de pré-carga. 
Burguete et al. (1994), analisando fatores responsáveis pelo afrouxamento e fratura de parafusos protéticos, conferiram que espaços verticais na interface conexão-prótese, como não existe um assentamento passivo, determinam um contato irregular das roscas do parafuso e consequente perda da força de travamento destes, além de estabelecer estresse desnecessário na interface ossoimplante, mesmo antes que a carga oclusal venha a ser aplicada. Nenhuma proteção contra a fadiga é obtida nestas situações, uma vez que as forças externas ao sistema, que podem provocar a separação dos componentes, geram mais estresse nos parafusos, que não é dissipado em função do encaixe inadequado dos componentes do sistema.

Yanase (1994) analisou aspectos sobre adaptação de próteses sobre implantes, e discorreu sobre a opinião de vários autores, os quais relataram como realizavam o teste de adaptação da infraestrutura de uma prótese total fixa. A verificação da adaptação da infraestrutura segundo Jemt é um dos procedimentos mais críticos durante a confecção de uma prótese implantossuportada, pois nenhuma fundição apresentará uma adaptação completamente passiva micrometricamente. Ele ressaltou que a adaptação deve ser observada em um nível clinicamente aceitável, onde pequenas interfaces ou fendas entre a peça fundida e os implantes, antes do aperto dos parafusos, podem ser aceitas. Por sua vez, Gulbransen destacou que as possíveis fontes de imperfeições inerentes aos procedimentos de confecção da prótese devem ser observadas, como os procedimentos de transferência, de inclusão e fundição, as propriedades das ligas e dos materiais de moldagem e, ainda, as características dos componentes de implantes utilizados. Parel salientou que é impossível a obtenção de uma adaptação realmente passiva, apesar de se dispor de vários métodos para melhorar os procedimentos de fundição e da confecção da prótese como um todo. Também sugeriu que a inspeção visual e o apertamento do parafuso são as melhores formas de se avaliar a adaptação, ao se apertar o parafuso mais distal de um lado e observar a adaptação do outro lado da peça. Esta técnica é facilmente realizada, tanto no laboratório como clinicamente, embora não seja possível ser observada quando a interface está localizada subgengivalmente. O autor recomenda neste caso, observar a quantidade de voltas necessárias para apertar o parafuso e, caso um parafuso exigir mais voltas, pode indicar um desajuste vertical. Foi ainda 
ressaltado pelos autores, a necessidade de verificação da fidelidade do modelo obtido e consideraram esse procedimento fundamental para a obtenção de uma peça bem adaptada e para já no próprio modelo permitir a verificação da adaptação.

Através de análise fotoelástica Waskewickz, Ostrowski e Parks (1994) discorreram a respeito da necessidade da obtenção de próteses com adaptação passiva, compararando os tipos de estresse gerados ao redor de implantes durante o aperto dos parafusos de infraestruturas com adaptação passiva e com desadaptação sobre os intermediários. Foi utilizado um modelo fotoelástico simulando a curva da mandíbula, com 5 implantes Nobelpharma $(3,75 \mathrm{~mm} \times 10 \mathrm{~mm})$, numerados de 1 a 5 no sentido horário. Utilizaram intermediários convencionais de $4 \mathrm{~mm}$ (Nobelpharma), que receberam um torque de $20 \mathrm{Ncm}$ através de um torquímetro. Foram utilizados para a confecção da infraestrutura em liga de ouropaládio, cilindros de ouro de $3 \mathrm{~mm}$ (Nobelpharma), os quais foram posicionados sobre os intermediários, e seus parafusos receberam um torque de $10 \mathrm{Ncm}$. Depois, os cilindros foram unidos entre si com resina autopolimerizável para o enceramento da infraestrutura. Os autores constataram uma adaptação inadequada após a fundição da peça, com ausência de contatos íntimos entre cilindros de ouro e intermediários. Essa peça sem adaptação passiva foi analisada fotoelasticamente ao ser parafusada em posição com um torque de $10 \mathrm{Ncm}$ através de três diferentes sequências de aperto dos parafusos de ouro: (a) 1, 2, 3, 4, 5; (b) 5, 4, 3, 2, 1 e (c) 3, $2,4,1,5$. A peça foi seccionada entre cada intermediário após todas as análises, e em seguida, submetida à soldagem com a finalidade de se obter uma infraestrutura adaptada passivamente. Cada parafuso de ouro foi apertado com um torque de $10 \mathrm{Ncm}$ e as partes foram unidas com resina acrílica Duralay. O aperto da infraestrutura sem adaptação passiva promoveu uma concentração de estresse ao redor dos implantes, o que pôde ser observado através da presença de franjas no modelo fotoelástico. Quando a peça adaptada (após a solda) foi parafusada, não houve a produção de estresse nos implantes. A produção de estresse na peça sem adaptação passiva foi indiferente nas 3 sequências de aperto testadas. Os implantes 1 e 5 (nas extremidades) mostraram uma maior concentração de franjas. A concentração de estresse foi maior no terço médio de cada implante e menor nos terços cervical e apical dos mesmos. Foi recomendado pelos autores 0 seccionamento e soldagem das infraestruturas de próteses fixas sobre implantes a 
fim de se obter uma adaptação o mais passiva possível, baseando-se no fato de que é impossível prever a resposta biológica dos implantes em relação a uma força estática quando uma prótese sem adaptação passiva é parafusada.

Conforme pesquisa de Carlson e Carlson (1994) uma prótese com adaptação passiva significa que esta pode ser parafusada sem causar estresse ou tensão. Entretanto ressaltaram que não existe uma adaptação absolutamente passiva já que todo aperto de parafuso gera uma certa deformação da prótese e/ou do osso, induzindo algum estresse ao sistema. $O$ estresse e tensão são a consequência de uma prótese mal adaptada e são fatores que afetam a longevidade dos componentes. Os pesquisadores sugeriram duas formas de medir o grau de desadaptação de um sistema: medindo as forças introduzidas durante o aperto dos parafusos, ou através da medida de extensão da desadaptação por meio de um microscópio de medição. Salientaram que devido as características do Sistema Brånemark, uma desadaptação de $50 \mu \mathrm{m}$ não gera tensão ao sistema; já uma desadaptação angular de mesmo tamanho pode gerar um deslocamento angular no ápice do implante para aliviar a tensão gerada.

Hulterström e Nilsson (1994), em um estudo clínico fizeram um acompanhamento de 3 anos, no qual 66 pacientes receberam próteses fixas sobre implantes com infraestruturas confeccionadas em liga de cobalto-cromo. Por motivos econômicos, visaram buscar alternativas que substituíssem o ouro para a confecção de infraestrutura para próteses fixas implantossuportadas. Duas ligas de cobaltocromo foram utilizadas: (1) Wironit (BEGO) e (2) Formula Super Cast (Williams Dental Service $A B$ ). Nas infraestruturas, parte da face lingual, vestibular e proximais foram confeccionadas em cobalto-cromo, enquanto as outras partes foram confeccionadas em resina acrílica. Os pesquisadores realizaram três tipos de conexões entre a infraestrutura e os cilindros de ouro: no grupo 1, os cilindros de ouro foram conectados à infraestrutura através de resina acrílica autopolimerizável; no grupo 2, os cilindros de ouro foram parcialmente soldados à infraestrutura, combinados com conexões em resina acrílica autopolimerizável e, no grupo 3, os cilindros de ouro foram completamente soldados à infraestrutura. Foram avaliadas as próteses clinicamente por um período de 6 meses a 3 anos. Nenhuma complicação em relação aos materiais foi observada, assim como nenhuma reação 
tecidual. Os pesquisadores salientaram que, das três técnicas apresentadas, a soldagem parcial, usada no Grupo 2, seria o método mais recomendado. As ligas de cobalto-cromo foram consideradas como um material conveniente para a confecção de infraestruturas de prótese fixa implantossuportada por oferecerem uma combinação favorável de biocompatibilidade, resistência à corrosão, boa fusibilidade, baixo peso específico, alta rigidez e custo reduzido. Recomendaram seu emprego, onde não há problemas estéticos principalmente nos casos de mandíbula totalmente edêntula.

Spiekermann (1995) descreveu os diferentes métodos de investigação e análise biomecânica em prótese sobre implantes, relatando que os principais são: a análise do elemento finito, análise de birrefringência (fotoelasticidade), a mensuração de cargas in vivo e in vitro e estudos da resistência de união entre implante e tecido ósseo. O autor salientou que, a análise de elemento finito oferece uma maneira de calcular a distribuição e concentração de estresse e deformações dentro dos implantes e no tecido de suporte circunvizinho, através de uma estrutura bi ou tridimensional computadorizada em forma de grade. Porém, a descrição matemática da interface é problemática. A técnica de análise de birrefringência é realizada através de cargas aplicadas em implantes ancorados em modelos plásticos, utilizando uma luz monocromática polarizada. Como os implantes são muito largos em relação à espessura necessária para este procedimento, observase fenômenos de sobreposição, tornando esse método raramente aplicado atualmente. Com o método de mensuração de cargas in vivo e in vitro pode-se obter dados mais precisos em relação às forças exercidas sobre implantes ou dentes e transferidas às estruturas de suporte. Porem experimentos in vivo são, contudo, de difícil execução porque é complicado incorporar sensores apropriados (extensômetros) em aparatos intra-orais, tanto do ponto de vista técnico, como biológico. No caso dos estudos in vitro têm obtido resultados valiosos. O pesquisador descreve também os estudos da resistência de união entre implante e tecido ósseo, os quais realizados através de testes de cisalhamento, tração e compressão. Os resultados desses estudos sofrem uma influência significativa das condições experimentais.

De acordo com Isa e Hobkirk (1995), através de um estudo in vitro foi verificado o efeito do aperto do parafuso de ouro na instalação de estrutura metálica 
fundida em ouro com perfeito assentamento, bem como com diferentes graus de desajuste marginal. Utilizaram um modelo com cinco implantes do Sistema Brånemark (Nobelpharma), dispostos linearmente em uma base metálica rígida. Foram realizadas mensurações de deformação com 0 uso de um par de extensômetros lineares elétricos fixados longitudinalmente em cada intermediário.

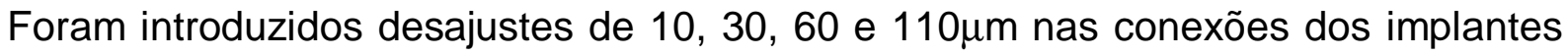
terminais e do implante central, utilizando-se arruelas de aço inoxidável entre intermediários e cilindros de ouro. Nos resultados obtidos demonstraram que 0 aperto do parafuso de ouro produziu altos valores de estresse estático no sistema, ainda com a estrutura metálica apresentando desajustes marginais inferiores a $10 \mu \mathrm{m}$.

Analisando in vitro, as forças e momentos de torção transmitidos através dos intermediários a partir da prótese até os implantes, Patterson et al. (1995) fixaram cinco implantes de $3.75 \mathrm{~mm}$ por $13 \mathrm{~mm}$ de comprimento em uma mandíbula humana desdentada, sobre cada pilar protético foram colados dois extensômetros lineares diametralmente opostos. A supra estrutura foi fundida em ouro. Em seguida os

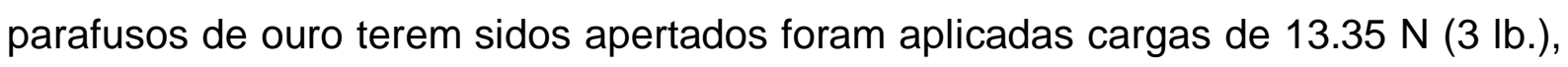
$55.59 \mathrm{~N}$ (12 lb.) e $106.78 \mathrm{~N}$ (24 lb.) . Os resultados obtidos foram comparados com análises teóricas, observando que os momentos de torção foram maiores nos intermediários adjacentes às extremidades livres, o que poderia levar a falhas do parafuso de ouro. Foi analisado que a força máxima de compressão no intermediário adjacente ao da extremidade aumenta proporcionalmente com a extensão do cantilever apresentando, por outro lado, um efeito reduzido na força de tração axial nos intermediários localizados anteriormente. Os pesquisadores observaram que quando um parafuso de ouro foi removido para simular a influência da fratura ou perda, a tensão máxima e as cargas compressivas axiais estavam aumentadas, mas o momento de flexão estava praticamente imutável. Observaram que a remoção de parafusos adjacentes aos pilares da extensão distal teve o pior efeito. Os autores concluíram que os momentos de torção podem ter uma importância relevante em relação às falhas em próteses implantossuportadas.

Usando fotoelasticidade, Millington e Leung (1995) avaliaram a relação existente entre o tamanho e localização das desadaptações e a distribuição de 
forças na superfície de infraestruturas sobre implantes observando a adaptação individual de uma infraestrutura confeccionada em liga de ouro do tipo IV, parafusada em 4 intermediários ( $A, B, C$ e D) sobre implantes. Após foram introduzidas discrepâncias verticais em um intermediário colocando-se folhas metálicas nos outros 3 intermediários e apertando os parafusos com torque de $10 \mathrm{Ncm}$. Para estabelecer o tamanho da fenda, a altura da superfície superior da infraestrutura sobre o local da fenda foi monitorado com um transdutor, antes e após a instalação das discrepâncias verticais. Os efeitos de 9 alturas de discrepância $(6,17,27,40,55,68,81$ e $104 \mu \mathrm{m})$ foram testados individualmente no intermediário mais distal (D) e no intermediário $C$. Os pesquisadores encontraram que o nível de aumento do estresse com o aumento da fenda não foi proporcionalmente linear. Os intermediários evidenciaram a maior incidência de estresse, indiferente do local da desadaptação. Porém, observaram que o nível de estresse mostrou um rápido aumento chegando a um platô com a fenda de $55 \mu \mathrm{m}$. Nas fendas maiores que $55 \mu \mathrm{m}$, o parafuso de ouro não desenvolvia força suficiente para aproximar a infraestrutura na união das partes da junção, ou seja, a pré-carga não era alcançada com o torque utilizado. No intermediário em que a discrepância era criada sofria um efeito significativo quanto à magnitude e direção da transmissão do estresse. Entre o tamanho da desadaptação e a magnitude do estresse houve uma relação positiva na infraestrutura em discrepâncias verticais maiores que $104 \mu \mathrm{m}$ no intermediário mais externo e desadaptações maiores que $55 \mu \mathrm{m}$ no intermediário central.

Carr; Brunski e Hurle (1996) mediram e compararam a pré-carga gerada com a utilização de cilindros de ouro, cilindros produzidos a partir de cilindro de ouro préfabricados, cilindros de plástico fundidos e cilindros de plástico fundidos após acabamento e polimento. Foram utilizadas para as fundições, ligas de alta e baixa fusão e assim verificar a influência da temperatura na medida da pré-carga. Foi desenvolvida maior pré-carga nos cilindros pré-fabricados quando comparada com os confeccionados a partir de cilindros de plástico. Os autores encontraram que os cilindros plásticos fundidos com a liga de baixa fusão produziram uma pré-carga significativamente maior que os fundidos com a liga de alta fusão. Houve um aumento significante na pré-carga dos cilindros de plástico, em relação aos efeitos do acabamento e polimento, porem o mesmo não foi observado nos cilindros metálicos. Os autores determinaram que quando comparados com o cilindro pré- 
fabricado a escolha do tipo de cilindro, da liga metálica, do revestimento, das técnicas de acabamento e de polimento podem afetar a pré-carga resultante.

Kansu e Aydin (1996) realizaram um experimento preocupados com a biocompatibilidade das ligas metálicas utilizadas em próteses dentárias, onde sete categorias de ligas odontológicas foram avaliadas por meio de uma análise histopatológica. Incluíram no estudo ligas de alto e baixo conteúdo de ouro, à base de paládio, paládio-prata, níquel-cromo, cobalto-cromo e ouro 22 quilates. Com a técnica de implantação subcutânea, discos fundidos de cada material foram implantados em ratos, por 15, 30 e 60 dias. Os autores encontraram a resposta tecidual mais severa e foi verificada com as amostras em liga de níquel-cromo e a mais leve, com a liga de ouro de 22 quilates. Embora de estar no grupo das ligas de metais básicos, a liga de cobalto-cromo apresentou respostas teciduais menos severas que a liga de níquel-cromo. Concluíram que deveria ser evitado o uso de ligas que contenham níquel em sua composição.

Os pesquisadores Carr; Gerard e Larsen, (1996) examinaram o efeito que próteses desajustadas exerciam na osseointegração de implantes e no volume de osso no qual foi usado um modelo animal. Este estudo comparou preliminarmente a resposta óssea ao redor de dois grupos de implantes. Um grupo de próteses foi rigidamente conectado aos implantes com um bom assentamento e o outro grupo foi conectado com um pobre assentamento. Para a realização do estudo foram utilizadas seis fêmeas adultas de babuínos que tiveram seus dentes posteriores extraídos e após dois meses de cicatrização foram instalados os dois implantes com $3,8 \times 10 \mathrm{~mm}$ de dimensões. O segundo estágio cirúrgico foi realizado após três meses de cicatrização, onde foram colocados intermediários cônicos. As próteses foram confeccionadas, instaladas sobre os implantes e os animais sacrificados após 24 e 48 horas, 1, 2, 3, e 4 semanas para a remoção das peças que seriam processadas e examinadas. Esta investigação focou sua atenção somente na resposta óssea para as cargas induzidas com a fixação das próteses. Os resultados obtidos falharam em distinguir uma diferença na resposta óssea entre os dois níveis de assentamento protético. Os dados sugeriram uma resposta oposta a que era clinicamente esperada. Por causa do desenho do estudo, ele não permitiu imitar a aplicação clínica dos desajustes das próteses. Sendo assim, não pode ser inferido em condições clínicas se a forma de assentamento das próteses pode ou não alterar 
a interface osso-implante. Segundo os autores, o estudo apresentou muitas limitações e dentro deste contexto puderam concluir que: a avaliação clínica da estabilidade dos implantes não revela diferença estatisticamente significante entre os dois grupos de próteses; a avaliação radiográfica não quantitativa não revelou diferença estatisticamente significante entre os dois grupos de próteses; análises de resposta óssea incluindo porcentagem de osseointegração e área óssea não revelaram diferença estatisticamente significante entre os dois tipos de próteses e por fim por causa do desenho do estudo não representar a aplicação clínica das próteses desadaptadas, onde as cargas funcionais dinâmicas são somadas à carga do desajuste, não se pode concluir que, em situações clínicas, o modo com que as próteses são assentadas não altera a osseointegração.

Sertgöz (1997) simulou através de um estudo de análise tridimensional de elemento finito uma situação de prótese total fixa no arco mandibular, suportada por 6 implantes localizados na região anterior e com extensões em cantilever bilaterais de $16 \mathrm{~mm}$. O pesquisador queria determinar a melhor combinação de materiais para a confecção da restauração protética quanto à infraestrutura e ao material da superfície oclusal. Foi utilizada resina acrílica, resina composta e porcelana como materiais para a superfície oclusal e ligas de ouro, prata-paládio, cobalto-cromo e titânio, como materiais para a infraestrutura. Utilizando uma carga vertical total de $172 \mathrm{~N}$, o que correspondia à média de força durante a mastigação em uma prótese fixa implantossuportada mandibular, com duas unidades em cantilever posterior bilaterais, ocluindo contra prótese total superior. Os pontos de aplicação estavam localizados no centro dos implantes terminais, no final das extremidades livres, à meia distância entre o centro dos implantes terminais e o final dos cantilevers e também em 4 pontos distribuídos na região anterior, entre os implantes distais. Encontraram que o estresse gerado no tecido ósseo ao redor dos implantes foi de pequena magnitude. Os estresses máximos foram bem inferiores aos limites de tração e compressão do osso cortical e medular. A utilização de materiais mais resilientes para a confecção da infraestrutura não alterou o prognóstico biológico das próteses fixas implantossuportadas, não havendo efeito deletério no tecido ósseo. A utilização de um material mais rígido para a confecção da infraestrutura diminuiu o estresse gerado nos parafusos de ouro. Foi sugerido que a utilização de materiais mais rígidos poderia prevenir as falhas protéticas. A melhor combinação de materiais 
encontrada foi biomecanicamente, a infraestrutura em liga de cobalto-cromo com a superfície oclusal em porcelana.

Rangert, Sullivan e Jemt (1997) analisaram as diferenças biomecânicas inerentes no tratamento de implantes em pacientes completamente desdentados e os desdentados parciais na região posterior.Salientaram que as próteses parciais não são beneficiadas pela estabilização cruzada entre arcos e portanto são mais susceptíveis as flexões. A mesma prótese com a mesma carga oclusal pode exercer diferentes níveis de tensão nos implantes e no osso de suporte dependendo do número de implantes e da sua configuração geométrica na sua instalação. Em uma prótese de três implantes o momento de flexão pode ser reduzido de 20 a $60 \%$ se houver um desalinhamento (offset ou compensado) de 2 a $3 \mathrm{~mm}$ no implante central.Os autores salientaram que implantes alinhados induzem a um fator de carregamento de risco. Afirmaram que uma prótese unitária sobre implante pode ter uma flexão em qualquer direção e uma prótese sobre dois implantes proporciona somente um eixo de rotação. Porém ambas situações provocam um fator de carregamento de risco para o complexo.

Clelland e Van Putten (1997) utilizando extensômetros mediram e compararam a deformação gerada por infraestruturas parafusadas e cimentadas e somente parafusada. Foi utilizado um modelo de resina fotoelástica com 5 implantes. Os pesquisadores instalaram 2 extensômetros do tipo roseta no modelo, posicionados no sentido vertical e paralelos aos implantes das 2 extremidades (direita e esquerda), a $2 \mathrm{~mm}$ de distância para vestibular, em uma altura correspondente à crista óssea. Foram confeccionadas 6 infraestruturas de paládioprata fundidas em monobloco, a partir da moldagem de transferência do modelo mestre, divididas em 2 grupos: cimentadas e parafusadas. Somente uma foi considerada clinicamente desadaptada, sendo então seccionada e soldada para ser incluída no experimento. O critério de aceitação clínica quanto à adaptação foi a avaliação do apertamento de apenas 1 parafuso de ouro em diferentes intermediários, sendo a peça considerada desadaptada quando nos demais intermediários desadaptações eram visualizadas. As infraestruturas cimentadas com cimento resinoso dual foram previamente tratadas com jatos de óxido de alumínio e agente adesivo. Após a aplicação do cimento, os parafusos foram apertados seguindo-se a fotopolimerização. As amostras dos 2 grupos foram parafusadas com 
$10 \mathrm{Ncm}$, na seguinte ordem de intermediários: 3, 1, 5, 2, 4. A leitura dos extensômetros foi padronizada, sendo os dados armazenados a partir do apertamento inicial de cada infraestrutura. Cada amostra foi submetida ao teste 3 vezes. Os resultados mostraram uma maior consistência no grupo 1, enquanto o grupo 2 mostrou uma maior variação das medidas fornecidas pelos 2 extensômetros. No grupo 2, a deformação foi consideravelmente maior no lado esquerdo, o que os autores atribuíram à sequência de apertamento dos parafusos. Todos os parafusos foram parcialmente apertados manualmente e depois apertados com o torquímetro. Provavelmente, a maior pré-carga foi desenvolvida no primeiro parafuso apertado e, consequentemente, maior concentração de estresse nessa região do modelo. Os autores concluíram que infraestruturas cimentadas e parafusadas minimizam a transmissão de estresse além de promoverem uma distribuição mais equilibrada.

Analisando a possibilidade de influência da deflexão mandibular na transmissão de forças ao complexo tecido ósseo / implante / infraestrutura Hobkirk e Havthoulas (1998), utilizaram uma réplica de mandíbula humana edêntula, confeccionada em resina acrílica termopolimerizável, na qual foram posicionados verticalmente seis implantes do Sistema Bränemark (Nobel Biocare), de 3,75mm x $10 \mathrm{~mm}$, distribuídos entre os forames mentonianos. Foram fixados dois extensômetros lineares em cada intermediário convencional, de $5 \mathrm{~mm}$ de altura. Foi fundida em liga de ouro tipo IV uma infraestrutura padronizada na forma de barra, com secção transversal de $6 \mathrm{~mm} \times 3,8 \mathrm{~mm}$ e $13 \mathrm{~mm}$ de extremidade livre em ambos os lados. Deste modo, poderia ser fixada em diferentes combinações de implantes e receber uma carga oclusal, de até $90 \mathrm{~N}$, em locais distintos, já pré-determinados por esferas metálicas. Foi afirmado pelos pesquisadores que a rigidez da mandíbula está relacionada com as dimensões e propriedades do tecido ósseo e que quanto mais fina a cortical, maior a tendência de ocorrer deformação mandibular funcional.

Taylor (1998) avaliando os tipos de problemas encontrados na implantodontia observou na literatura que a desadaptação dos componentes protéticos tem um importante papel nas falhas mecânicas e salientou que a conexão mantida pelo parafuso do intermediário com o implante, é uma região sujeita aos altos níveis de tensão por estar localizada perto da crista alveolar, sendo esta a região na qual são dissipadas as forças mastigatórias. 
Rubo et al. (1999) utilizando um modelo computadorizado estudaram a distribuição de estresse entre os implantes através de um programa de análise de elemento finito, simulando uma prótese implantossuportada em uma mandíbula humana, foram simuladas as seguintes variáveis: densidade do osso trabecular, comprimento dos intermediários e implantes, extensão do cantilever, número e arranjo dos implantes, grau de curvatura da mandíbula e a liga usada na confecção da infraestrutura (prata-paládio e cobalto-cromo). Foi simulada a carga oclusal utilizando $100 \mathrm{~N}$ de carga. Foi observada uma tendência de melhor distribuição do estresse entre os implantes e intermediários localizados em uma mandíbula mais estreita, com uma extensão em cantilever menor, implantes longos e infraestrutura mais rígida. A distribuição do estresse não foi influenciada pela densidade do osso trabecular. Maior foi o estresse resultante sobre os intermediários quanto menor o número de implantes. Segundo os resultados encontrados pelos pesquisadores a distribuição de estresse sobre a infraestrutura foi independente da curvatura da mandíbula, sendo menor quando a liga utilizada foi mais rígida e os implantes e intermediários eram mais longos.

Já os pesquisadores Korioth e Johann (1999) estudaram com a utilização da análise tridimensional de elemento finito a transmissão de estresse para o osso adjacente aos implantes variando a forma da infraestrutura e avaliaram a incidência de cargas laterais e oclusais em 5 formas de infraestruturas e o estresse gerado no sistema. Utilizaram um modelo com 5 implantes simulando uma mandíbula edêntula e 2 materiais oclusais da infraestrutura: metal e resina acrílica. O modelo foi submetido a simulação de cargas oclusais, somente vertical e somente lateral bilateralmente. Foram calculados estresses máximos e mínimos para cada intermediário e estes variaram significativamente tanto entre cada intermediário como entre as diferentes infraestruturas. Os intermediários mais distais desenvolveram os maiores níveis de estresse, geralmente compressivos, e forças de tensão ocorreram no intermediário vizinho. Os níveis mais baixos de estresse foram obtidos com a infraestrutura de forma retangular, ao receber carga vertical. Porem, os resultados mostraram que materiais com menor módulo de elasticidade parecem aumentar de maneira não uniforme a transmissão de cargas nos implantes. Foi observado que uma infraestrutura menos rígida pode reduzir a transmissão de estresse para os implantes mais anteriores, em relação aos demais, quando 
submetida a cargas oclusais posteriores. Concluíram que os estresses desenvolvidos nos intermediários podem ser significativamente afetados pela forma da infraestrutura, pelas diferentes condições de incidência de carga e, em menor grau, pelas propriedades do material da infraestrutura.

Hollweg (2000) observou a passividade da adaptação de infraestruturas simulando uma prótese total fixa mandibular sobre um modelo mestre com 5 implantes. Foram confeccionados corpos de prova de paládio-prata e cobalto-cromo e posicionados sobre um modelo mestre. Nas faces mesial e distal de cada intermediário foram fixados extensômetros lineares elétricos para capturar a deformação gerada durante o aperto dos parafusos de fixação. Ainda tenha verificado a geração de tensões quando da aplicação de torque nos intermediários, foi observado que houve um nível de passividade semelhante entre as infraestruturas fundidas em cobalto-cromo e prata-paládio. Sugeriu a utilização de ligas em cobalto-cromo para a realização de pesquisas clínicas.

Rubo e Souza (2001) apresentaram uma revisão sobre os métodos computacionais aplicados à bioengenharia. Os progressos ocorridos nos últimos anos permitiram uma aproximação entre Odontologia e Ciências de Computação. Deste modo, tornou-se possível a análise e solução de problemas complexos encontrados no tratamento dos pacientes. Os recursos utilizados envolvem, entre outros, a análise por fotoelasticidade, o Método de Elemento Finito e a extensometria. Os pesquisadores relatam as aplicações dos métodos na resolução de carregamentos em próteses implantossuportadas, assim como as potencialidades que esses recursos oferecem.

Sahin e Çehreli (2001) analisaram a importância do assentamento passivo das infra-estruturas em próteses sobre implantes. Adaptação passiva é sinônimo de uma "adaptação ideal”. Uma conexão rígida entre os implantes osseointegrados e a infra-estrutura induzem tensões em cada componente exposto à força. Teoricamente, uma infraestrutura deveria proporcionar uma adaptação passiva, o que seria indução de tensão zero nos componentes do complexo implante osso periimplantar na ausência de cargas. Entretanto, uma adaptação realmente passiva é impossível de ser obtida. Todos os procedimentos prévios clínicos e laboratoriais utilizados na confecção de infraestruturas são inadequados para propiciar tal 
adaptação. Falhas e complicações protéticas como afrouxamento e fratura dos parafusos, fratura do intermediário, da infraestrutura e material de cobertura têm sido documentadas e relacionadas à desadaptação das infraestruturas. Estudos clínicos longitudinais comprovando falhas nos implantes atribuídas especificamente à falta de adaptação da infraestrutura não existem. Uma adaptação marginal aceitável entre os componentes não significa a obtenção de uma adaptação passiva. Sugerem que o método ideal para se determinar a passividade de uma infraestrutura seria a análise com a utilização de "strain gages" (extensômetros) da tensão gerada em cada intermediário e/ou componente protético antes e após o apertamento dos parafusos e/ou cimentação da mesma.

Janson (2002) avaliou a deformação sofrida pelas infraestruturas de próteses fixas implantossuportadas com extremidade livre, confeccionadas em ligas de $\mathrm{PdAg}$ e CoCr, quando estas foram submetidas a uma carga estática de $100 \mathrm{~N}$ aplicada a 10, 15 e 20 mm de distância do implante terminal utilizando extensômetros lineares elétricos. Extensômetros foram colados à distal do implante terminal nas superfícies inferior e superior da infraestrutura. Foi observado que infraestruturas confeccionadas em liga de CoCr sofriam menor deformação que as confeccionadas com liga de PdAg, mesmo quando a força era aplicada a uma distância maior do implante terminal. Fundamentado nestes dados concluiu-se que as ligas de $\mathrm{CoCr}$ têm boa perspectiva de utilização em próteses sobre implantes, visando uma melhor distribuição de forças.

Na revisão de literatura de Taylor e Agar (2002) conclui-se que muitos princípios e parâmetros considerados foco de atenção das próteses implantossuportadas, foram alterados com o tempo e novas idéias e conceitos foram sendo gradativamente estabelecidos Antes de 1982 quando a conferência de Toronto foi realizada, o tratamento com implantes não era aceito como uma alternativa em relação aos procedimentos protéticos tradicionais. Afiançaram que conceitos e princípios empíricos considerados no tratamento de dentes naturais foram extrapolados para as próteses implantossuportadas. Foi considerado pelos pesquisadores a importância da redução no custo do tratamento com implantes a fim de se permitir que a população em geral tenha acesso a este tipo de tratamento reabilitador. 
Akça Çehreli e Iplikçioglu (2002) analisaram o estresse por elemento finito tridimensional com leituras de extensômetros lineares elétricos em vitro, nas mesmas situações, obtiveram um aumento estatisticamente significante $(P<0,05)$ nos valores de tensão quando a avaliação foi realizada com extensômetros lineares elétricos nos diversos tipos de forças. Foi concluído que há diferenças relativas à quantificação das tensões entre os dois sistemas, porém há um consenso mútuo na determinação do tipo de tensões de tração e compressão induzidas pelas forças aplicadas.

Goodacre et al. (2003) fizeram um levantamento de artigos de 1981 a 2001 os quais descreviam complicações com implantes osseointegráveis e prótese sobre implante. Devido ao levantamento realizado, 14 complicações mecânicas foram identificadas na literatura, com uma incidência de 30\% para perda de retenção de overdentures a $1 \%$ para fratura de implantes, onde $7 \%$ relataram afrouxamento do parafuso protético, $6 \%$ Afrouxamento do parafuso do intermediário, $4 \%$ fratura do parafuso protético, $3 \%$ fratura da infraestrutura e $2 \%$ fratura do parafuso do intermediário.

Em um estudo laboratorial avaliando a mudança da adaptação de próteses implantossuportadas frente a aplicação de forças cíclicas $(200 \mathrm{Ncm}$ com $50.000 \mathrm{e}$ 200.000 ciclos), Hecker e Ecker (2003) simularam a situação de uma prótese fixa mandibular com cinco implantes e cantilever, avaliando a adaptação das próteses antes e após a aplicação de cargas cíclicas na região anterior e também no cantilever de $18 \mathrm{~mm}$. Os resultados demonstraram significante diminuição da interface de desadaptação quando as forças foram aplicadas na região anterior da infraestrutura, já quando as forças foram aplicadas no cantilever distal, uni ou bilateralmente, não foi observada diminuição significante na desadaptação dos componentes da prótese. Concluirão que as aplicações de forças cíclicas em infraestruturas de prótese sobre implante causam mudanças na adaptação entre a prótese e o intermediário.

Ishigaki et al. (2003) estudaram a biomecânica de distribuição de forças ao redor de implante simulando a mastigação na região de primeiro molar inferior, utilizando para tanto um modelo de elemento finito tri-dimensional. O estudo demonstrou que comparativamente ao modelo de dentes naturais, o implante mostrou maior concentração de estresse na região do colo do implante, 
especialmente na região vestibular, onde o tipo de oclusão influenciou na distribuição de forças.

Para obter as características da transmissão de forca de implantes ocluindo em dentes naturais ou implantes, Hekimoglu, Anil e Çehreli (2004) compararam deformações sob cargas estáticas e dinâmicas. Regiões do primeiro molar maxilar e mandibular de uma dentadura plástica dentiforme de ambas as arcadas foram cortadas. Pilares cimentos-retidos para restaurações de implantes unitários foram conectados a implantes com $45 \mathrm{Ncm}$ de torque como recomendado pelo fabricante. Simulação do ligamento periodontal foi fornecida em torno do dente natural recentemente extraído. Implantes e dentes foram alinhados verticalmente nas cavidades preparadas na dentadura plástica dentiforme de ambas as arcadas. Então, impressões transferidas de silicone de condensação foram feitas dos implantes e dentes naturais de ambas as arcadas. Uma mistura de resina acrílica de metil-metacrilato autopolimerizavel foi vertida nas impressões dos espaços ocupados previamente por dentes artificiais e diretamente em torno dos implantes e o dente natural foi coberto com polivinilsiloxano para obter modelos experimentais. Essa aplicação resultou em uma rígida ancoragem de implantes em resina acrílica ao passo que o dente foi integrado no modelo com um ligamento periodontal simulado. Uma coroa metalo-cerâmica foi fabricada no dente e em cada implante e foi cimentada com um cimento provisório. Três strain gages lineares foram unidos no lado vestibular de cada implante e do dente natural na resina acrílica e mensurado sob $75 \mathrm{~N}$ e $100 \mathrm{~N}$ de carga axial estática e lateral dinâmica em situações de carga separadas usando o sistema de aquisição de dados em uma média de amostra de $100 \mathrm{~Hz}$. Os dados do dente natural e implantes foram comparados para cada carga pelo teste (Kruskal-Wallis) seguido pelo teste de comparação múltipla $(\alpha=0.05)$. Deformações compressivas foram induzidas em torno do dente natural e implantes como um resultado de carga axial estática, ao passo que combinações de deformações compressivas e tensão foram observadas durante a carga dinâmica lateral. Deformações em torno do dente natural foram significantemente menores que o implante antagonista e implantes ocluindo do lado contralateral para a maioria das regiões sob condições de carga $(P<0.05)$. Existiu uma tendência geral para 0 aumento das deformações em torno do implante opondo ao dente natural sob cargas maiores e particularmente sob carga dinâmica lateral. 
Em um estudo prospectivo de 5 anos Kreissl et al. (2007), determinaram a incidência de problemas técnicos em próteses parciais fixas implantossuportadas e 0 grau de sucesso deste tipo de prótese. Foram avaliadas 112 PPFs confeccionadas em 205 implantes, obtendo uma média de $94,5 \%$ de sobrevivência dos implantes em função. As PPFs tiveram $80 \%$ de sucesso, em 5 anos de avaliação, com $6.7 \%$ de afrouxamento de parafusos, $3,9 \%$ de quebra dos parafusos, $5,7 \%$ de fratura de porcelana, e fratura de infraestrutura foi raro, um evento com $1 \%$. Observaram que a maior incidência de falhas ocorreu em PPFs com cantilever com um índice de sucesso de $68,6 \%$, seguido por coroas unitárias $(77,8 \%)$, e próteses contíguas explintadas $(86,1 \%)$.

Empregando o modelo de elemento finito, Bonneta, Postaireb e Lipinskia (2009) avaliaram o estresse gerado nos componentes e no osso mandibular de prórese total fixa implanto suportada por quatro implantes ("All-on-four"), utilizando para isto modelos de elemento finito tridimensionais com osso de características isotrópicas e anisotrópicas. Analisaram também a posição do bolo alimentar durante a mastigação e sua relação com as tensões transmitidas. Observaram resultados significantemente diferentes de estresse e tensão entre os modelos isotópico e anisotrópico (ortotrópico). O bolo alimentar na posição molar (cantilever) foi o mais danoso em relação ao estresse e tensão transmitidas para a prótese, para o implante e consequentemente para o osso peri-implantar. Foi verificado que a inclinação do implante aumentou o estresse gerado no osso. Concluíram que o modelo de elemento finito com osso isotrópico é de fundamental importância para as simulações numéricas, e que o modelo de prótese suportada por quarto implantes ("All-on-four") deve ser revisado.

Jacques et al. (2009) verificaram a distribuição de estresse em componentes de prótese fixa implantossuportada em função de ligas metálicas de cromo-cobalto e prata-paládio, através de um estudo no qual utilizaram corpos de prova simulando infraestruturas de prótese total fixa mandibular com cantilever sobre um modelomestre. Aplicaram uma carga estática vertical de $100 \mathrm{~N}$ na extremidade livre, a uma distância de 10, 15 e $20 \mathrm{~mm}$ para distal do intermediário terminal e mediram distribuição de forças através do uso de extensômetros. Os resultados demonstraram um padrão de distribuição de forças da liga cromo-cobalto em grandes extensões de cantilever semelhante à liga de prata-paládio com cantilever 
curto. Além disso, observaram que o intermediário mais próximo do ponto de aplicação da carga foi o que registrou a maior deformação específica, independente do local de aplicação de força no cantilever e da liga utilizada. Concluíram que o emprego de uma liga de cobalto-cromo na confecção de infraestruturas para prótese sobre implantes pode permitir braços de cantilever mais extensos.

Suedam et al. (2009) verificaram a distribuição de estresse em componentes de prótese fixa implantossuportada em função da altura dos intermediários $(4 \mathrm{~mm}$, $5,5 \mathrm{~mm}$ e $7 \mathrm{~mm}$ de altura) e de ligas metálicas de cromo-cobalto e prata-paládio, através de um estudo no qual utilizaram corpos de prova simulando infraestruturas de prótese total fixa mandibular com cantilever sobre um modelo-mestre. Aplicaram uma carga estática vertical de $100 \mathrm{~N}$ na extremidade livre, a uma distância de $15 \mathrm{~mm}$ para distal do intermediário terminal para cada altura de intermediário e para cada tipo de liga, medindo a distribuição de forças através do uso de extensômetros. Os resultados demonstraram que o intermediário mais próximo do ponto de aplicação da carga foi o que registrou a maior deformação específica, independente da altura do intermediário e da liga utilizada. Observaram também que o aumento na altura dos intermediários promoveu o aumento da tensão gerada no intermediário próximo à aplicação da carga e que esta deformação é influenciada pelo tipo de liga utilizada na confecção da infraestrutura.

Moretti Neto (2009) visando a obtenção de dados relacionados á adaptação passiva em prótese implantossuportada, analisaram a quantidade de deformação que ocorre no intermediário da prótese após o aperto do parafuso tanto do cilindro de paládio-prata como de cobalto-cromo. Um modelo mestre foi usado para simular uma mandíbula humana com cinco implantes. Extensômetros foram colados nas faces mesial e distal de cada intermediário. Os intermediários foram montados sobre as réplicas dos implantes e os parafusos foram apertados com um torque de $20 \mathrm{Ncm}$ e as leituras foram gravadas. Após este passo, os parafusos tanto dos cilindros de paládio-prata como de cobalto-cromo foram apertados com um torque de $10 \mathrm{Ncm} \mathrm{e}$ as leituras também foram gravadas. Estas medições foram repetidas por cinco vezes. Não houve diferença estatisticamente significante entre os dois grupos. Nenhuma diferença estatística foi encontrada entre as tensões geradas tanto pelos cilindros de paládio-prata como os de cobalto-cromo. No entanto, existiram diferenças com relação à qualidade da tensão. A deformação gerada pelo aperto 
dos parafusos dos cilindros de cobalto-cromo foi de compressão e o aperto dos parafusos dos cilindros de Paládio-Prata gerou forças de compressão e tração.

Rubo e Souza (2010) aplicando elementos finitos 3D, avaliaram as variáveis clínicas que influenciam na distribuição de forças em prótese total implanto suportada mandibular, tais como: densidade do osso trabecular, comprimento dos intermediários e implantes, extensão do cantilever, número e arranjo dos implantes, grau de curvatura da mandíbula e a liga usada na confecção da infraestrutura (pratapaládio e cobalto-cromo). Para simular a carga oclusal, empregaram uma carga de $100 \mathrm{~N}$. Observaram que o estresse aumenta à medida que o implante se aproxima do ponto de aplicação de força. Quanto maior o cantilever, maior o estresse e quanto menor o módulo de elasticidade do osso cortical, maior o estresse gerado. $O$ aumento do comprimento dos intermediários levou à diminuição do estresse gerado nos implantes e na infraestrutura. A diminuição do estresse não foi verificada com implantes maiores do que $13 \mathrm{~mm}$. Uma infraestrutura mais rígida permite uma melhor distribuição de forças. Concluíram que as propriedades físicas dos diversos materiais envolvidos afetam a maneira como o estresse é distribuído em uma prótese total implantossuportada mandibular.

Empregando strain gages, Nishioka et al. (2010) quantificaram in vitro as tensões desenvolvidas durante o aperto do parafuso de fixação de próteses fixas implantossuportadas variando o tipo de conexão dos implantes (hexágono externo e interno) e também o tipo de cilindro protético utilizado. Os implantes foram inseridos em um bloco de poliuretano com características semelhantes ao osso mandibular. Intermediários do tipo micro-unit foram instalados com torque de $20 \mathrm{~N}$ sobre três implantes hexagono externo e três hexagono interno em cada bloco. Cilindros protéticos usindados de cobalto-cromo e de plástico, forma parafusados no modelo e receberam uma matriz padronizada para confecçãos das infra-estruturas em cera, que foram fundidas em liga de cobalto-cromo. Quatro strain gages foram colados na superficie do bloco no sentido horizontal, nas regiões mesial e distal de cada implante. Utilizando um torquímetro manual as infra-estruturas foram parafusadas sobre os intermediáros com torque de $10 \mathrm{Ncm}$. Não foram encontradas diferenças estatisticamente significantes quanto ao tipo de conexão ou cilindro utilizado. Desta forma, as conexões do tipo hexágono externa e interna, cilindros fundidos e 
usinados, apresentaram comportamento mecânico similar em condições de fixação do parafuso.

Em um estudo recente, Hollweg et al. (2010), estudaram a deformação que ocorre nos pilares dos implantes com a fixação de infra-estruturas, confeccionadas em liga de cobalto-cromo e prata-paládio. As amostras ( $n=5$ para cada liga), simulando uma infra-estrutura de prótese mandibular protocolo implantossuportada foram fabricados e aparafusados sobre pilares standard posicionados em um modelo mestre contendo cinco réplicas dos implantes. Dois extensômetros lineares foram fixados sobre as faces mesial e distal de cada pilar para capturar deformação durante o aperto dos parafusos de retenção. Uma combinação de forças de compressão e tração foi observada em ambos os pilares para infra-estruturas cobalto-cromo e prata-paládio. Não houve evidência de diferenças significativas nas médias das deformações do pilar em nove das dez faces dos pilares. Apesar de visualmente as infra-estruturas apresentarem bem adaptadas, não necessariamente transmissão de carga aos pilares ocorre de maneira uniforme. O uso de ligas de cobalto-cromo para estruturas de próteses implantossuportadas podem ser consideradas clinicamente aceitáveis como a liga prata-paládio.

\subsection{BIOLOGIA ÓSSEA E TENSÕES AO REDOR DOS IMPLANTES}

Os pesquisadores McDowell e Regli (1961) descreveram um procedimento para analisar a flexão da mandíbula que ocorre da posição de repouso para a de máxima abertura e máxima protrusão. Os 20 pacientes estudados indicaram que houve uma diminuição da distância na região dos molares de 0,4mm e 0,5mm nas duas condições, com um valor máximo registrado de $1,5 \mathrm{~mm}$.

Enlow (1968) estudou os possíveis modos de operação da Lei de Wolff, tentando relacioná-los com as alterações morfológicas geradas. Considerou que não há indícios de uma relação direta entre tensão e aposição óssea progressiva e que a tensão pode estar associada tanto com reabsorção como com deposição. Na região onde ocorrem forças de tensão, estímulos bioelétricos e indução celular, poderia haver crescimento ósseo. 
Chamay e Tschantz (1971) confrontaram a distribuição de tensões na diáfise ulnar de cães com a quantidade de hipertrofia gerada por sobrecarga. Concluíram que, sob tração, o osso atrofia por reabsorção periostal e osteólise intracortical. Sob compressão, o osso hipertrofia por aposição periostal e endostal. Sob compressão estática, a hipertrofia é localizada somente nas áreas contendo lesões plásticas. Sob compressão intermitente, a hipertrofia é maior e aumenta até que o osso se adapte à sobrecarga mecânica.

Os pesquisadores Pugh, Rose e Radin (1973) afirmaram que o tecido ósseo remodela sua estrutura segundo a carga que the é imposta. A variação desta carga poderá determinar uma remodelação construtiva ou destrutiva. A ausência de carga no implante poderia resultar em atrofia semelhante à reabsorção alveolar após exodontia. Uma sobrecarga oclusal poderia resultar em necrose e perda do implante. Para efeito de cálculo, o osso pode ser considerado puramente elástico a baixas taxas de deformação.

Carter e Hayes (1977) fizeram testes de compressão em osso humano e bovino com uma larga variação de densidade, com o objetivo de estabelecer relações entre a densidade e resistência à compressão, módulo de elasticidade e taxa de deformação do osso. Tanto a resistência como o módulo de elasticidade foram proporcionais à taxa de deformação. $\mathrm{O}$ osso compacto apresenta porosidade de aproximadamente 5 a $30 \%$, enquanto o osso trabecular varia de 30 a $90 \%$.

Por meio de uma revisão sobre fisiologia e metabolismo ósseo em que conceituam diversos eventos que ocorrem em nível celular, Roberts et al. (1987) apresentaram entre eles: 1) Modelação - atividade superficial específica (aposição ou reabsorção) que produz uma mudança no tamanho e/ou forma de um osso. É um processo não pareado, significando que a ativação celular (A) procede independentemente da formação $(F)$ ou reabsorção $(R)$; 2) Remodelação - definida como renovação ou reestruturação interna de osso pré-existente. É um fenômeno pareado, primariamente em nível tecidual. A ativação $(A)$ de células ósseoprecursoras resulta em uma sequência de: a) reabsorção ativa $(R)$; b) quiescência ou reversão $(Q)$; e c) formação $(F)$. A remodelação inclui todas as mudanças localizadas em osteons individuais ou trabéculas, renovação, hipertrofia, atrofia ou reorientação. 
Rieger; Mayberry e Brose (1990) examinaram a magnitude das tensões no tecido ósseo ao redor de seis implantes endósseos de diferentes formas através do MEF bi-dimensional. Sugeriam que há um valor ótimo de tensão em que ocorre um equilíbrio entre reabsorção e formação. Segundo os estudos com o MEF, a reabsorção em forma de cálice, resultante de sobrecarga é possível em alguns implantes. Recomendaram pesquisas adicionais, utilizando modelos tridimensionais, para todos os implantes disponíveis.

Clelland et al. (1993) analisaram a influência de intermediários angulados na geração de estresse próximo a um implante através de um estudo associando resina fotoelástica e uso de extensômetros. Implantes do Sistema Steri-Oss (3.8mmx10mm) foram incluídos numa resina fotoelástica, sobre os quais

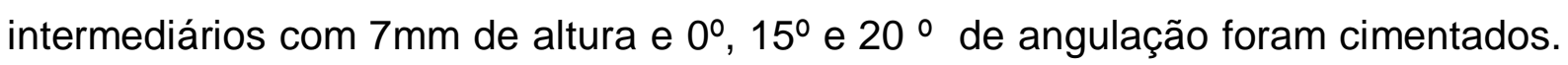
Uma carga vertical de $178 \mathrm{~N}$ foi aplicada em cada intermediário. O estresse compressivo praticamente duplicou no lado do implante oposto à carga aplicada, à medida que a angulação dos intermediários aumentava de 0 a 20 graus. Apesar de haver um aumento estatisticamente significante do estresse, conforme o aumento da angulação do intermediário, os três ângulos de intermediários produziram estresses aparentemente dentro dos limites de adaptação fisiológica do tecido ósseo.

Os conceitos da lei de Wolff e as adaptações estruturais que ocorrem no osso sob determinados estímulos mecânicos foram revisados por Frost (1994). A remodelação baseada na unidade multicelular básica pode induzir a remoção ou conservação do osso, mas não pode ser adicionado. As atividades básicas de crescimento, modelação e remodelação determinam a arquitetura e resistência do osso. Locais onde o pico ósseo de deformação permanece abaixo de $50 \mu \varepsilon$ significa que está sob efeito de desuso. Deformações acima de $1500 \mu \varepsilon$ tendem a uma remodelação lamelar pela reconfiguração. Entretanto, com microdeformações iguais ou superiores a $4.000 \mu \varepsilon$, as avarias não possibilitam a recuperação pelos mecanismos convencionais de reparo, resultando em danos teciduais irreversíveis.

Hoshaw; Brunski e Cochran (1994) fizeram um estudo para investigar a hipótese de que cargas mecânicas nos implantes, e conseqüentemente campos de tensão e deformação, influenciam a modelação e remodelação óssea na interface osso/implante. Instalaram dois implantes Brånemark ${ }^{\mathrm{TM}}$ em vinte tíbias de cachorro e 
os deixaram sem carga por 1 ano. Após a reabertura, os implantes foram submetidos à carga por 12 semanas. Foram feitas análises histológicas e os resultados foram comparados com simulações em MEF. Encontraram: 1) perda óssea próxima à porção coronária do implante; 2) uma porcentagem menor de tecido mineralizado na córtex; e 3) diminuição da freqüência de marcadores fluorocrômicos na córtex adjacente ao implante após a carga. O MEF indicou maior tensão na região da superfície do periósteo adjacente aos implantes submetidos à carga. Concluíram que os resultados dão suporte à premissa de que a perda óssea observada ao redor do pescoço dos implantes era consequência de modelação e remodelação óssea secundárias, causadas por microlesões resultantes da carga.

Segundo os pesquisadores Duncan e Turner (1995) a transdução mecânica desempenha um papel crucial na fisiologia de muitos tecidos, inclusive o ósseo. 0 processo de transdução mecânica pode ser dividido em 4 partes: 1) estimulação mecânica, em que as forças mecânicas provocam deformação celular; 2) estimulação bioquímica, em que enzimas são produzidas; 3) transmissão de sinal, através de osteoblastos, osteócitos e células da linhagem óssea; e 4) resposta celular, dependente da magnitude, duração e taxa da carga aplicada.

Van Zyl et al. (1995) por meio de uma análise tridimensional de elemento finito, verificaram a distribuição de estresse no tecido ósseo circundante aos implantes, os quais suportavam uma prótese total fixa com extremidade livre bilateral. Uma força estática vertical de $100 \mathrm{~N}$ era aplicada ao longo de toda a extensão dos cantilevers, a partir de $7 \mathrm{~mm}$ do implante terminal, até $25 \mathrm{~mm}$, em pontos localizados a cada $2 \mathrm{~mm}$. Os resultados deste estudo demonstraram que os estresses distribuídos nas áreas mesiais e distais dos implantes foram, consideravelmente, inferiores aos estresses transmitidos às porções vestibulares e linguais. Os autores concluíram que extensões em cantilever superiores a $15 \mathrm{~mm}$, podem propiciar uma maior produção de estresse na cortical lingual e, em menor grau, na cortical vestibular, o que poderia colocar em risco a integridade dos implantes.

Sertgöz e Güvener (1996) estudaram a distribuição de estresse na interface implante/tecido ósseo através de uma análise tridimensional de elemento finito, onde foram utilizados três comprimentos diferentes de cantilevers e implantes. Foram 
criados modelos de simulação de uma prótese fixa implantossuportada por seis implantes, embutidos em um modelo de osso mandibular (cortical e esponjoso) e com cantilevers posteriores bilaterais. Um total de nove modelos de simulação apresentavam três diferentes comprimentos de cantilevers (7, 14 e 28mm) e três comprimentos de implantes (7, 15 e 20mm). Uma força de $75 \mathrm{~N}$ era aplicada, em direção perpendicular, na porção central e na região correspondente ao elemento mais posterior da extremidade livre. Uma força horizontal de $25 \mathrm{~N}$ era aplicada na superfície vestibular do elemento mais posterior do cantilever. As análises revelaram que os estresses máximos concentraram-se na interface tecido ósseo / implante mais distal, localizada no lado de aplicação da carga. O estresse de tração máximo foi observado nas regiões mesial e distal do tecido ósseo, quando uma carga vertical era aplicada, e nas regiões vestibular e lingual, sob carga horizontal. $O$ aumento do comprimento do cantilever resultou na elevação dos valores de estresse na interface implante/tecido ósseo. No entanto, o comprimento do implante não teve efeito significativo na distribuição do estresse nesta interface.

Tamatsu et al. (1996) pesquisaram o módulo de elasticidade de pequenos espécimes de osso obtidos a partir de quatro mandíbulas secas de homens adultos. Através da realização do teste de três pontos, os autores concluíram que o módulo de elasticidade da mandíbula variou de acordo com local e com a orientação de obtenção dos espécimes. O osso apresentou características anisotrópicas, refletindo a complexidade da estrutura óssea mandibular. Quando os espécimes foram obtidos das regiões paralelas ao plano mandibular, os valores do módulo de elasticidade dos espécimes mais inferiores eram geralmente mais elevados do que aqueles dos obtidos das regiões mais superiores, indicando maior rigidez desta região. Obtiveram valores de módulo de elasticidade, na região de incisivos, de 16,9 \pm 2,7 GPa, 15,4 \pm 4,9 GPa e 13,9 $\pm 3,4 \mathrm{GPa}$ nas regiões inferior, média e superior, respectivamente. Para a região de pré-molares foram obtidos valores de 19,4 $\pm 2,5$ GPa, 18,8 $\pm 3,5$ GPa e 12,6 \pm 4,2 Gpa, respectivamente.

Ivanoff; Sennerby e Lekholm (1996) estudaram a influência da mono ou da bicorticalização de implantes de 10 e de $16 \mathrm{~mm}$ de comprimento por 3,75mm de diâmetro instalados em tíbia de coelho e submetidos a testes de remoção. Os implantes de $10 \mathrm{~mm}$ não atingiam a cortical oposta, enquanto os de $16 \mathrm{~mm}$ sim. Concluíram que após seis semanas os implantes bicorticais necessitavam de torque 
duas vezes maior que os monocorticais, e que após 12 semanas necessitavam de torque três vezes maior. Apresentaram estes resultados para validação da técnica de bicorticalização.

Papavasiliou et al. (1997) analisaram a influência do grau de osseointegração no sucesso do tratamento com implantes. Determinaram, através de análise tridimensional de elemento finito, o nível de estresse na interface de implante com quatro graus de osseointegração $(100,75,50$ e 25\%) e cinco padrões de osseointegração (com localização alternada, somente cervical, apical, vestibular e lingual). Simularam uma coroa unitária submetida a carga axial e oblíqua de 10Mpa. Observaram que forças oblíquas oclusais elevaram o estresse na interface entre $5 \mathrm{a}$ 20 vezes e estes foram sempre maiores na região de crista óssea. Menores níveis de estresse foram encontrados com a osseointegração na região cervical (crista óssea) associada à carga axial.

Com o seu estudo histomorfométrico Barbier e Schepers (1997) instalaram implantes em cães Beagle, que após três meses de cicatrização, receberam próteses fixas com e sem cantilever, simulando cargas axiais e não axiais. Os cães receberam marcadores fluorocrômicos uma semana, três semanas e cinco semanas após a instalação das próteses e então foram sacrificados. A remodelação óssea ao redor dos implantes sob cantilever foi mais intensa em todos os períodos, mas a diferença diminuiu ao final. Além disso, foram observados osteoclastos em determinados locais ao redor destes implantes com próteses em cantilever que poderiam estar relacionados com perda óssea marginal, se o período de acompanhamento do experimento fosse mais longo. Em contraste, quase nenhum osteoclasto, células inflamatórias, ou reabsorção marginal, foram encontrados nos implantes carregados axialmente. Nos implantes que receberam carga axial, o osso se tornou mais denso na cervical, enquanto a atividade de remodelação em direção apical diminuiu, sugerindo que a ancoragem destes implantes se dava primariamente em função do osso cortical. Nos implantes sob carga não axial, essa diminuição era menos pronunciada, indicando uma ancoragem mais importante em osso medular.

Os pesquisadores, Mish; Qu e Bidez (2000) tentaram estabelecer uma relação entre a densidade, o módulo de elasticidade e a força compressiva final do 
osso trabecular de mandíbulas humanas, e determinar a influência que as placas corticais têm nestes valores. Para realização do trabalho foram utilizadas nove mandíbulas humanas frescas, entre as idades de 56 e 90 anos, as quais foram cortadas na região anterior (incisivos e caninos), média (pré-molares), e em secções distais (molares). Foram obtidos 76 espécimes cilíndricos do osso trabecular com medula óssea "in situ", que foram preparados e testados com compressão no sentido vertical. Estes testes foram executados a uma taxa constante de tensão de $0.01 \mathrm{~s}(-1)$ com e sem a presença das placas corticais. Obtiveram valor de densidade de 0.85 a $1.53 \mathrm{~g} / \mathrm{cm}^{3}$, com um valor médio de $1.14 \mathrm{~g} / \mathrm{cm}^{3}$ (DP = 0.15). Os resultados de módulo de elasticidade foram de 24.9 a $240.0 \mathrm{MPa}$, com um valor médio de 96.2 MPa (DP = 40.6) no osso trabecular com as placas corticais. Sem as placas corticais o módulo de elasticidade variou de 3.5 a $125.6 \mathrm{MPa}$, com um valor médio de 56.0 MPa (DP = 29.6). A força compressiva final do osso trabecular variou de 0.22 a 10.44 MPa, com um valor médio de 3.9 MPa (DP=2.7). Concluíram que o osso trabecular na mandíbula humana possui significativamente maior densidade, módulo de elasticidade e força compressiva final na região anterior do que nas regiões médias ou distais da mandíbula, e que a ausência das placas corticais diminui o módulo de elasticidade do osso.

Melsen e Lang (2001) analisaram as reações teciduais ao redor de implantes após aplicação de forças ortodônticas relacionando-as a deformações do osso trabecular definidas em MEF. Encontraram que a carga influencia significantemente tanto o turnover como a densidade do osso ao redor dos implantes. Mesmo implantes não submetidos à força mantiveram as características do processo alveolar. Por outro lado, o grau de osseointegração parece ser independente da carga sobre o implante.

Por meio de uma revisão de literatura sobre a aplicação da análise de elemento finito em Implantodontia; Geng, Tan e Liu (2001) discutiram sobre os achados encontrados com essa metodologia quanto à interface osso-implante, a conexão prótese-implante e próteses implantossuportadas por vários implantes. Relataram que as propriedades dos materiais simulados influenciam a distribuição e a manutenção dos esforços no modelo de elemento finito e, por isso, resultados de muitos estudos não podem ser generalizados para situações clínicas. O osso, por exemplo, não é um material isotrópico. Significa que tem diferentes propriedades 
quando medido em diferentes direções e a maioria dos estudos avaliados considera os materiais homogêneos e com propriedades lineares. Ligas metálicas com baixo módulo de elasticidade promovem esforços mais intensos na interface osso-implante e recomendaram a utilização de ligas metálicas rígidas para uma melhor distribuição dos esforços. A distribuição dos esforços em próteses suportadas por vários implantes é de grande complexidade, incluindo os seguintes fatores mecânicos: inclinação e posição dos implantes, forma e extensão da infraestrutura, material da prótese, comprimento do cantilever, interface entre componentes protéticos e implantes e interface osso-implante.

Oh et al. (2002) analisaram trabalhos na literatura a respeito das causas de perda precoce de osso peri-implantar, onde encontraram seis possíveis causas descritas na literatura: 1. Trauma cirúrgico, 2. Sobrecarga oclusal, 3. Peri-implantite, 4. Micro-desadaptação do intermediário, 5. Selamento biológico e 6. Características superficiais da porção do implante que fica em contato com a crista óssea. A sobrecarga oclusal é considerada pelos autores como a maior causadora de falhas em implantes. Uma sobrecarga oclusal que ultrapasse o limiar de homeostasia do osso pode levar a uma progressiva reabsorção óssea marginal, podendo ocorrer até mesmo a falha da osseointegração. Segundo os autores, a reabsorção ocorrida após o primeiro ano em função é resultado da adaptação funcional da musculatura oral, associada ao aumento da densidade óssea, reduzindo a sobrecarga oclusal ou aumentando a resistência óssea à sobrecarga.

Shain, Cehreli e Yalçin (2002) realizaram uma revisão de literatura sobre a influência das forças funcionais sobre os implantes osseointegrados e discorrem que a sobrecarga mecânica pode acarretar em falhas biológicas, afirmando que quando uma sobrecarga é aplicada em um implante osseointegrado o osso circunjacente a este implante sofre uma deformação (de 2000 a 3000 "microstrain”). Quando uma sobrecarga patológica ocorre (acima de 4000 "microstrain") o estresse e a tensão gerados excedem o limiar fisiológico tolerado pelo osso e ocorrem microfraturas na interface implante-osso. A aplicação de repetidas cargas podem levar a falha por fadiga da interface, diminuindo a densidade óssea peri-implantar e levar a formação de defeitos ósseos tipo crateras. Segundo este autor as falhas tardias em implantes, após a instalação das próteses, são observadas e estão correlacionadas com complicações biomecânicas e que os mecanismos relacionados com estas falhas 
ainda não são totalmente entendidos e a literatura a respeito das influências dos vários fatores biomecânicos é inconclusiva.

Wyatt e Zarb (2002) estudaram a reabsorção óssea peri-implantar proximal de próteses parciais fixas sobre implantes Brånemark no período de um ano após a instalação das prótese e nos anos seguintes. Obtiveram uma media de $0.33 \mathrm{~mm}$ de perda óssea após o primeiro ano de função e após o primeiro 0,00mm de perda óssea proximal. Puderam observar que homens jovens com prótese com extensão em cantilever tiveram uma maior perda óssea no primeiro ano de função, o que estaria relacionado à maior carga oclusal transmitida ao osso.

Stegaroiu et al. (2004) analisaram a distribuição de estresse no osso circunjacente, com a utilização de extensômetros lineares elétricos, ao implante restaurado com coroas metálicas recobertas com de três diferentes materiais: compômero, resina acrílica e liga de ouro, com a aplicação de força lateral estática e dinâmica sem impacto de $100 \mathrm{Ncm}$. O estudo demonstrou que os diversos materiais de cobertura das próteses tiveram a mesma influência no estresse transmitido ao osso circunjacente a uma prótese implantossuportada unitária.

Çehreli et al. (2004) por meio da fotolelasticidade e da utilização de 'strain gages ', avaliou o estresse gerado no osso ao redor de implantes com diversos tipos de conexões, desde hexágono externo, interno até cone morse. Foram aplicadas forcas de $100 \mathrm{~N}$ a $150 \mathrm{~N}$ no longo eixo dos implantes e com 20 graus de angulação. De acordo com os resultados observados, concluíram que todos os implantes apresentaram características similares de distribuição de forças, onde o desenho da conexão protética não é um fator decisivo que afeta a magnitude do estresse transmitido ao osso.

Weiner et al. (2004) estudaram a resposta sensorial do nervo alveolar inferior frente a aplicação de forças em implantes osseointegrados na mandíbula de cães. Relataram que: a aplicação de forças vibratórias nos implantes resultou na geração de potencial de ação no nervo alveolar inferior, o limiar para geração de potenciais de ação é maior nos implantes do que o dos dentes naturais adjacentes e que a latência da resposta é similar tanto no dente como no implante. 
Petrie e Williams (2005) com um modelo de elemento finito analisaram e compararam sistematicamente a relação e a interatividade do diâmetro, comprimento e o formato das roscas do implante nas tensões geradas na crista óssea, com a aplicação de uma força vertical de $200 \mathrm{~N}$ e obliqua de $40 \mathrm{~N}$. Ao total obtiveram 16 formatos de implantes. Concluíram que quanto maior o diâmetro do implante e maior o seu comprimento, menor é o estresse gerado na crista óssea circundante ao implante. Consideraram que o travamento do implante aumentou a tensão gerada na crista especialmente em implantes curtos e estreitos. Concluíram que, para a diminuição da tensão gerada na crista óssea peri-implantar, é indicada a utilização de implantes de diâmetros largos e relativamente longos, onde os implantes sem roscas demonstraram ser a escolha mais favorável. Implantes curtos com roscas na região da crista peri-implantar devem ser evitados, especialmente em osso de baixa densidade.

Heckmann et al. (2006) estudaram o estresse gerado no osso devido à fixação parafusada ou cimentada de próteses parciais fixas implanto suportadas de três elementos, com a utilização de um modelo de elemento finito, associando estudos 'in vitro` e 'in vivo` com extensômetros elétricos lineares. Concluíram que o estresse gerado na crista óssea devido ao tipo de fixação da prótese não constitui um risco devido ao fato de estar dentro do limite fisiológico do osso.

Akça, Uysal e Çehreli (2006) analisaram a correlação entre a máxima força de mordida e o nível de perda óssea marginal em pacientes com prótese parcial fixa implanto suportada, com 0 uso de radiografias periapicais digitais, em um acompanhamento de 24 meses. Observaram que a força de mordida máxima para PPF implantossuportadas (média de $356,61 \mathrm{~N}$ ) foi maior do que em região dentada (média de $275,48 \mathrm{~N}$ ), o que não foi influenciado pelo sexo. A perda óssea marginal após o período de acompanhamento das próteses em função foi de $0,28 \mathrm{~mm}$ na mesial e de 0,097mm na distal. Concluíram que o uso de próteses implantossuportadas aumenta a força de mordida, porem não prejudica a estabilidade da crista óssea e consequentemente do implante.

Isidor (2006) relacionou forças em implantes osseointegrados e reabsorção óssea peri-implantar encontrou resultados conflitantes, onde os estudos experimentais em animais demonstravam que a força oclusal poderia levar a perda 
marginal de osso ao redor dos implantes e até mesmo à perda completa da osseointegração. Nos estudos clínicos, uma associação entre as condições de força e a perda marginal de osso ao redor dos implantes, ou a perda completa da osseointegração tem sido relatadas, porém nenhuma relação causal foi convincentemente demonstrada.

Chung et al. (2007) avaliaram os fatores envolvidos na perda óssea tardia peri-implantar. Foram avaliados 339 implantes colocados em 69 pacientes. Os implantes foram divididos de acordo com: 1. características de superfície, 2. comprimento, diâmetro, 3. quantidade de mucosa queratinizada, 4. localização no arco dental, 5. tipo de prótese, 6. tipo de dentição oposta. Os efeitos clínicos destes fatores foram avaliados radiograficamente e clinicamente, obtendo o índice de placa, quantidade de mucosa queratinizada, sangramento, profundidade a sondagem e média de perda óssea anual. Concluíram que implantes curtos, implantes largos, implantes que suportam próteses parciais fixas, e implantes em fumantes foram associados com grande perda óssea anual, onde o comprimento dos implantes foi o fator mais favorável à sua manutenção na boca.

Kozlovsky et al. (2007) analisaram o impacto da sobrecarga oclusal na crista óssea peri-implantar em regiões com tecido peri-implantar sadio e inflamado em cães beagle. Observaram que em tecido saudável a sobrecarga oclusal aumentou ligeiramente o grau de reabsorção da crista óssea, porém não no sentido apical da base do implante. Já a sobrecarga agravou a reabsorção da crista óssea periimplantar nas regiões inflamadas. Concluíram que o controle de placa e da carga recebida pelo implante são fatores fundamentais para a longevidade do tratamento.

Hälg, Schmid e Hämmerle (2008) em uma pesquisa clínica analisaram a perda óssea peri-implantar e as complicações técnicas de PPFs com e sem cantilever. Foram analisados 54 pacientes com 54 PPFs suportadas por 78 implantes, 27 com cantilever e 27 sem cantilever todas suportadas por dois implantes na região posterior da maxila ou da mandíbula. Depois de um período médio de observação de 5,3 anos avaliaram um nível de perda óssea para próteses com cantilever de 0,23 $\mathrm{mm}$ e 0,09 $\mathrm{mm}$ para próteses sem cantilever, não obtendo diferença estatisticamente significante. Cinco complicações técnicas foram encontradas no grupo de próteses com cantilever e nenhuma no grupo sem 
cantilever. Concluíram que de acordo com o estudo, PPFs com cantilever não levam a maior perda óssea peri-implantar quando comparadas com PPFs convencionais.

Matsunaga et al. (2010) investigaram o papel biomecânico do osso trabecular ao redor dos implantes dentais na mandíbula. O modelo do estudo foi feito utilizando os dados de tomografia computadorizada de micro-tirada de um cadáver em implantes osseointegrados quem tinha estado em vigor por 15 anos antes da morte. A análise morfológica e tridimensionais (3D), análise de elementos finitos foram realizadas para calcular o caminho de carregamento peri-implante do modelo em que a estrutura trabecular foi devidamente simulada. Os pesquisadores encontraram que como foi visto através da análise multiescala utilizando o método de homogeneização, a arquitetura do osso trabecular ao redor implantes foi isotrópico para a maior parte. A maior stress no osso esponjoso foi observado no carregamento perpendicular e estresse produzido em trabéculas diminuiu aproximando de carga horizontal. Foi concluido pelos pesquisadores que a arquitetura do osso esponjoso ao redor do implante era geralmente isotrópico. A análise 3D de elementos finitos mostraram que trabéculas do osso esponjoso ao redor dos implantes dispersa o estresse, formando caminhos de transferência de carga. Os resultados sugerem que o osso trabecular desempenha um papel importante no apoio funcional pressão exercida através do implante.

Sallan, Kheiralla e Aldawakly (2010) estudaram as tensões na região periimplantar de implantes com diâmetro reduzido utilizados na restauração em cristas ósseas com pouca espessura, através de diferentes desenhos da infra-estrutura. Além disso, a influência do local de aplicação de carga vertical de oclusão foi avaliada utilizando strain gages. Dois modelos simulando o arco mandibular de extremidade livre unilateral foram fabricados. Dois implantes de tamanho padrão (3,75 x 13mm), foram inseridos em um modelo na posição de segundo pré-molar e primeiro molar para suportar próteses fixas de três unidades com cantilever distal (liga de níquel-cromo). Enquanto no outro modelo, o implante padrão e o miniimplante $(3,0 \times 13 \mathrm{~mm})$ foram colocados na posição de segundo pré-molar e segundo molar, respectivamente, para suportar próteses fixas de três unidades com o pôntico suspenso entre os pilares (níquel-cromo). Quatro extensômetros foram fixados no sentido vertical nas faces, lingual, mesial e distal adjacente aos implantes. As próteses foram cimentadas temporáriamente. Uma carga vertical de $300 \mathrm{~N}$ foi 
aplicada no meio da barra horizontal unida as unidades da prótese no centro. Os valores de microstrains foram registrados e analisados. As infra-estruturas com cantilever registraram microstrains superiores do que com pôntico entre os pilares para ambas as condições de carregamento. No entanto, para ambos os casos, quando a carga foi aplicada na barra distribuindo as forças igualmente em todas as unidades ao mesmo tempo, apresentaram os menores valores de microstrain do que aplicando a carga apenas nos pônticos. Os pesquisadores encontraram que o implante convencional apresentou valores de menor tensão que os mini-implantes. 

3-Proposicão 



\section{PROPOSIÇÃo}

A proposta deste trabalho é medir a deformação gerada no intermediário e no osso peri-implantar simulado pelo poliuretano, de uma coroa de prótese fixa suportada por um implante frente à aplicação de uma carga axial de $300 \mathrm{~N}$, com a utilização de extensômetros lineares elétricos, a fim de analisar:

1. A influencia do tipo cilindro protético utilizado para a confecção da infraestrutura.

2. Correlacionar as deformações geradas na região peri-implantar com a teoria de Frost 

4- Material e Métodos 



\section{MATERIAL E MÉTODOS}

Nesta pesquisa foi utilizado um modelo mestre em poliuretano, também usado nas pesquisas de Suedam (2009) e Moretti Neto (2010). Do modelo foi utilizado o seguinte:

- 01 implante Brånemark System ${ }^{\circledR}$ Mk III Groov de 3,75mm de diâmetro por $13 \mathrm{~mm}$ de comprimento (Nobel Biocare, Göteborg, Sweden)

- 01 intermediário multi-unit de 5mm de altura (Nobel Biocare, Göteborg, Sweden)

- Modelo mestre confeccionado em poliuretano, com características isotrópicas, simulando o osso mandibular, validado por estudos anteriores. (MORETTI NETO et al., 2011; MYIASHIRO et al. 2011).

\subsection{MODELO EXPERIMENTAL}

O modelo experimental utilizado foi o mesmo usado nas pesquisas de Suedam (2009) e Moretti Neto (2010), cuja confecção se deu como segue:

O modelo foi confeccionado em poliuretano F 16 (espuma rígida) para vazamento de presa rápida (AXSON, Cergy, França). Este material é composto por dois líquidos: Poliol (parte A) e Isocianato (parte B) com densidade de 1,05 g/. $\mathrm{cm}^{3}$ após sua polimerização, segundo dados do fabricante.

Com auxílio de uma matriz metálica confeccionada em alumínio (figura 4.1), foi construído um modelo de Poliuretano (Axson, Cergy, França) em forma de $U$ simulando o arco mandibular. Dois implantes Brånemark System ${ }^{\circledR}$ Mk III RP, ref 28887 e lote 659900 (Nobel Biocare, Göteborg, Sweden) de 3,75mm de diâmetro por $13 \mathrm{~mm}$ de comprimento foram posicionados na matriz paralelos entre si (figura 4.2). Em seguida o poliuretano foi proporcionado e manipulado e por fim injetado na matriz, resultando num contato íntimo. O modelo obtido apresentava as seguintes dimensões: $13 \mathrm{~mm}$ de diâmetro interno, $52 \mathrm{~mm}$ de diâmetro externo, 35mm de 
comprimento, $13 \mathrm{~mm}$ de largura e $19 \mathrm{~mm}$ de altura (figura 4.3 e 4.4 ). Os dois implantes paralelos entre si estavam posicionados $14,0 \mathrm{~mm}$ distantes de centro a centro com o centro do implante mesial distante $7,0 \mathrm{~mm}$ da linha média.

Embora o modelo experimental apresentasse dois implantes, na presente pesquisa somente um deles foi aproveitado como veremos a seguir.

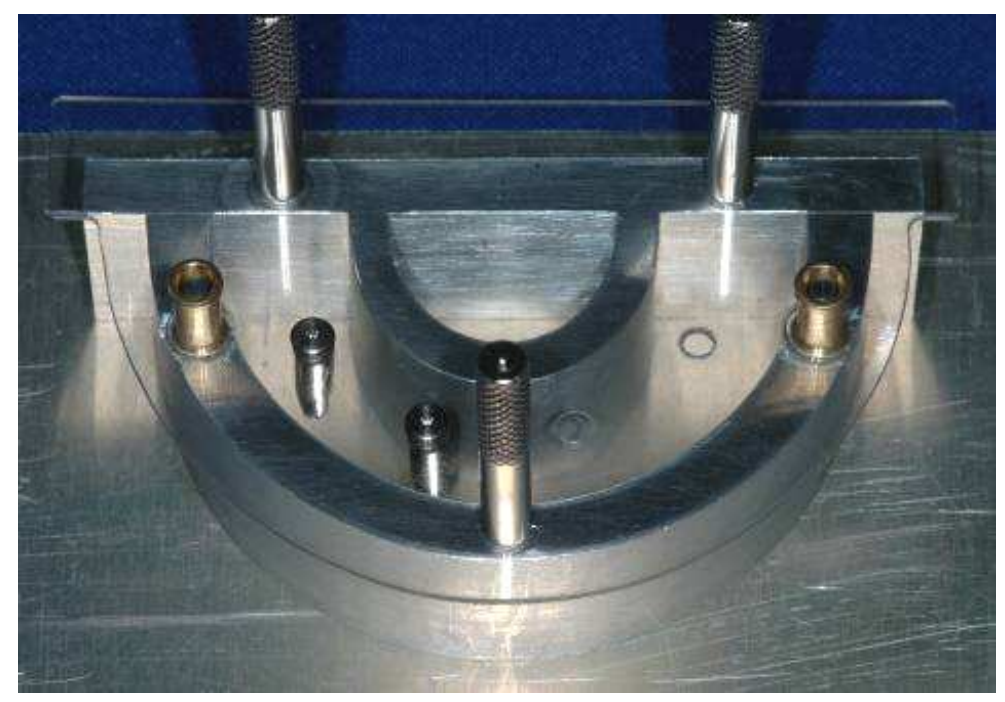

Figura 4.1 - Vista ântero-superior da matriz metálica com a tampa de acrílico e os dois implantes posicionados.

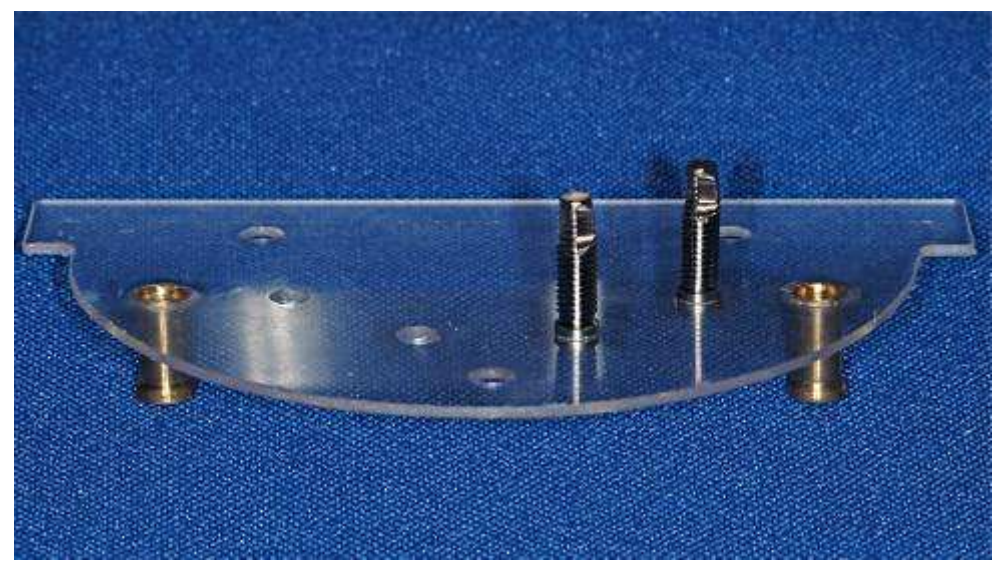

Figura 4.2 - Vista interna da tampa com os implantes posicionados. 


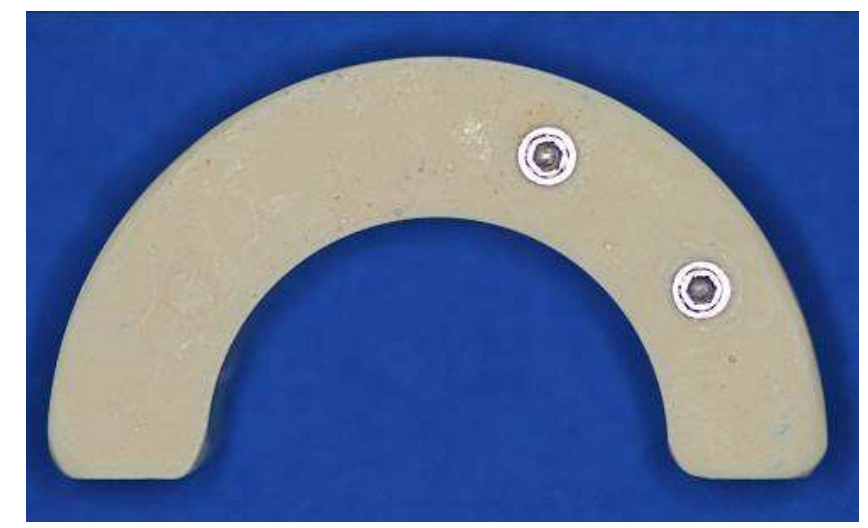

Figura 4.3 - Vista superior do modelo de PU, com os implantes.

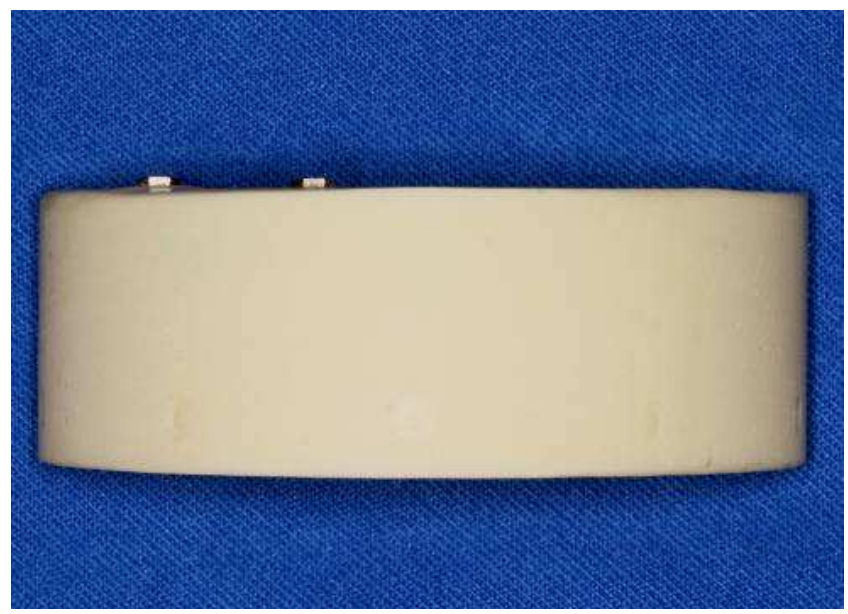

Figura 4.4 - Vista anterior do modelo de PU, com os implantes.

\subsection{OBTENÇÃO DOS CORPOS DE PROVA}

Para a confecção dos corpos de prova foram utilizadas duas ligas diferentes (tabela 4.1), uma de cobalto-cromo (Dan Ceramalloy, Nihon Shika Kinzoku CO) e outra de paládio-prata (Pors-on ${ }^{\circledR}$ 4, Degussa S.A., São Paulo, Brasil). Foram utilizados quatro cilindros protéticos de ouro (Nobel Biocare, Göteborg, Sweden, REF 29043, lote 109020) que foram sobre-fundidos com a liga de paládio-prata, quatro cilindros protéticos com cinta usinada de cobalto-cromo (Conexão Sistema de Prótese Ltda. São Paulo, Brasil, REF. 14400599, lote 7023110) fundidos com a liga de cobalto-cromo e quatro cilindros protéticos de acrílico (Conexão Sistema de Prótese Ltda. São Paulo, Brasil, REF. 14400199, lote 7013087) fundidos com a liga 
de cobalto-cromo. Desta forma três grupos de corpos de prova ficaram estabelecidos: Grupo com liga de ouro, Grupo com liga de cobalto-cromo e sobrefundição em cilindro usinado e o Grupo com fundição completa dos cilindros em liga de cobalto-cromo.

Tabela 4.1 - Especificações das ligas utilizadas, segundo os fabricantes.

\begin{tabular}{|c|c|c|c|}
\hline LIGA & CONTEÚDO & $\begin{array}{l}\text { INTERVALO DE } \\
\text { FUSÃO (ํㅜ) }\end{array}$ & $\begin{array}{c}\text { PESO } \\
\text { ESPECÍFICO } \\
\left(\mathrm{g} / \mathrm{cm}^{3}\right)\end{array}$ \\
\hline $\begin{array}{c}\text { Dan Ceramalloy } \\
\text { (Nihon Shika } \\
\text { Kinzoku CO.) }\end{array}$ & $\begin{array}{c}\mathrm{Ni} 56 \% \mathrm{Cr}-20 \% \\
\mathrm{Co}-12 \%\end{array}$ & $1205-1250$ & 8,0 \\
\hline $\begin{array}{c}\text { Pors-on 4 } \\
\text { (Degussa S.A.) }\end{array}$ & $\begin{array}{c}\mathrm{Pd}-57,8 \% \mathrm{Ag}- \\
30 \%\end{array}$ & $1175-1275$ & 11,40 \\
\hline
\end{tabular}

\subsubsection{Enceramento e inclusão dos corpos de prova.}

Para realizar as fundições das infra-estruturas de cada grupo, inicialmente um cilindro protético foi posicionado sobre um análogo do componente micro-unit e a partir daí o enceramento foi realizado. Este enceramento recebeu a forma anatômica de um pré-molar e a partir dele uma matriz foi confeccionada com silicona Zetalabor (Zhermack Spa, Badia Polesine, Itália) para que os próximos enceramentos apresentassem as mesmas características anatômicas com relação as suas dimensões promovendo assim uma padronização dos corpos de prova dos três grupos (figura 4.5).

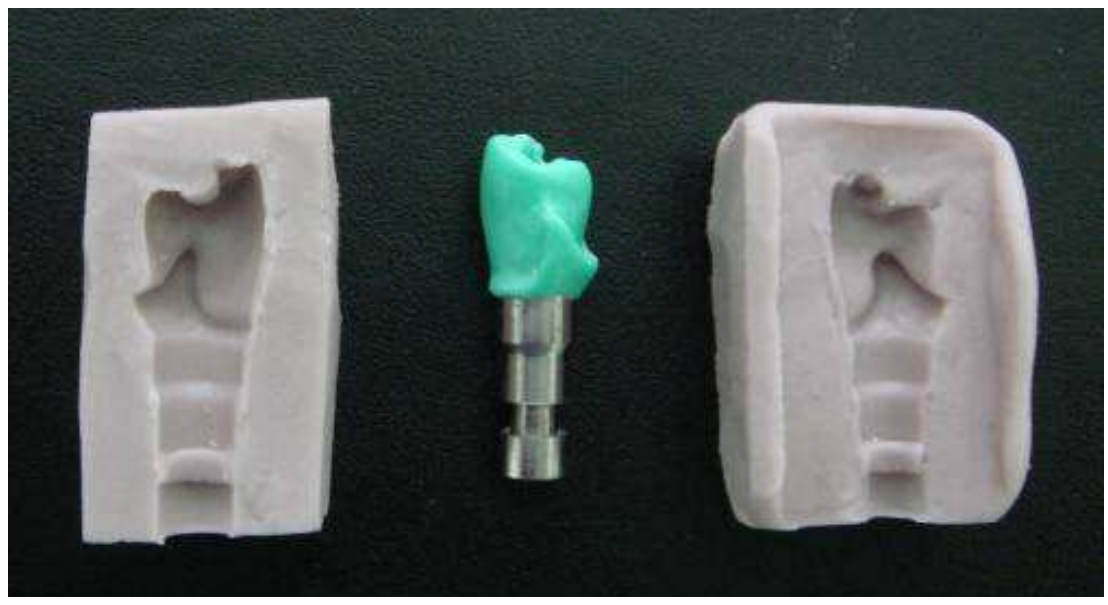

Figura 4.5- Padronização dos corpos de prova. Matriz em silicona e enceramento do pré-molar terminado. 
Após o enceramento de todos os quatro corpos de prova de cada um dos três grupos, estes foram unidos em conjunto aos canais de alimentação e fixados a uma base formadora de cadinho. Neste momento foi aplicado um agente redutor de tensão superficial e revestimento foi vertido para o interior do anel sob vibração para que o material envolvesse todos os padrões dos corpos de prova sem que bolhas pudessem estar presentes.

\subsubsection{Sobrefundição dos corpos de prova.}

Após completar 30 minutos da espatulação do revestimento, os anéis de fundição foram levados ao forno para eliminação da cera. A partir da temperatura ambiente, foi iniciado o ciclo de aquecimento convencional até atingir-se a temperatura de $250^{\circ} \mathrm{C}$ a qual foi mantida por 30 minutos. Em uma segunda fase a temperatura do forno foi aumentada de $250^{\circ} \mathrm{C}$ para $560 / 600^{\circ} \mathrm{C}$ e mantida por 40 minutos com a finalidade de se eliminar o carvão e carbono residuais aderidos nas paredes do revestimento. Por fim, para o aquecimento interno do anel, a temperatura alcançou $850 / 900^{\circ} \mathrm{C}$ por 60 minutos. Após estes procedimentos a fundição foi realizada respeitando-se as características técnicas das ligas utilizadas para a formação dos três grupos.

\subsubsection{Acabamento das infra-estruturas.}

Com o resfriamento dos anéis em temperatura ambiente, as sobrefundições puderam então ser removidas do revestimento. Procedimentos laboratoriais padrão foram utilizados para realizar esta etapa do trabalho. Para a limpeza dos corpos de prova e para preparar sua superfície para receber a cobertura cerâmica foi empregado jato de óxido de alumínio de $50 \mu \mathrm{m}$ de partícula e posteriormente acabamento com pedras de óxido de aluminio para o preparo do metal. Estes procedimentos foram realizados de forma a evitar o aprisionamento de ar o que poderia ocasionar o aparecimento de bolhas durante a fase de aplicação da porcelana. 
Durante estes procedimentos, os corpos de prova foram fixados sobre um análogo a fim de minimizar possíveis danos na região da interface intermediário/cilindro protético.

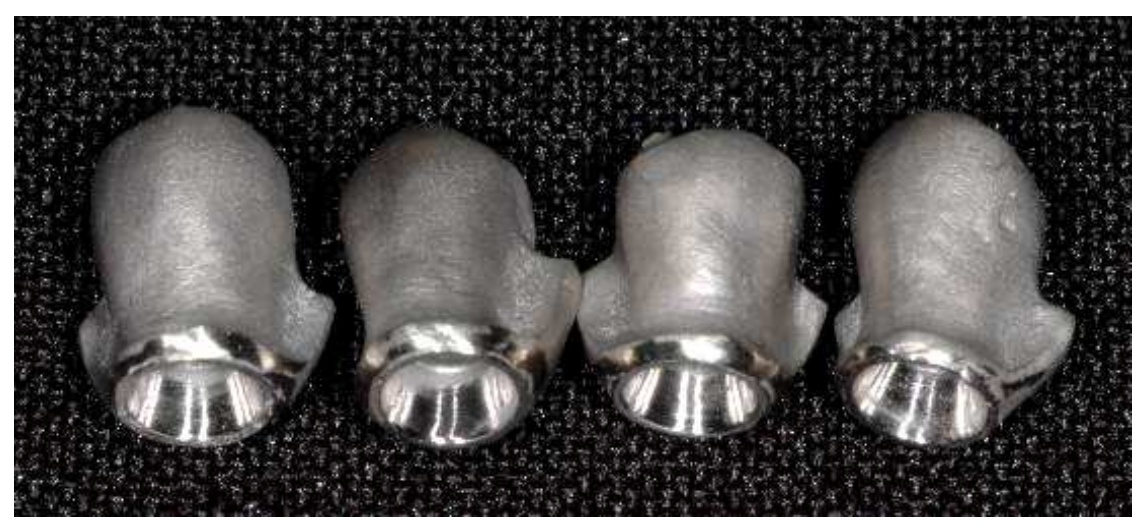

Figura 4.6 - Corpos de prova cilindro protético de ouro - liga de paládio-prata.

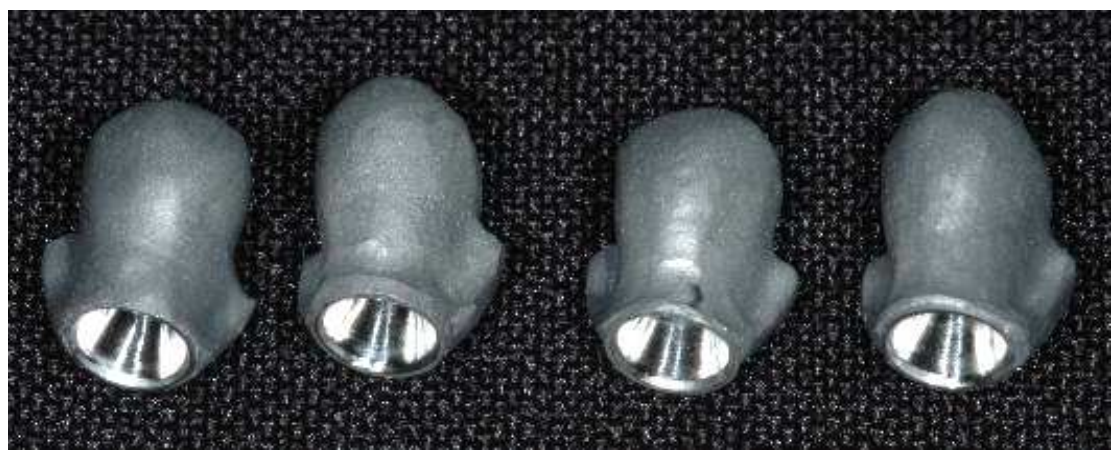

Figura 4.7 - Corpos de prova cilindro protético usinado - liga de cobalto-cromo.

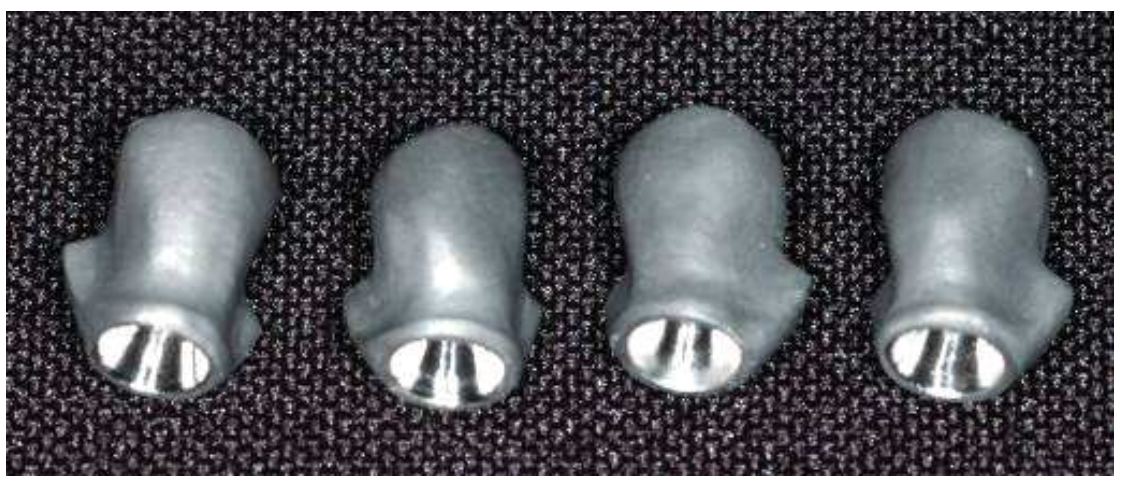

Figura 4.8 - Corpos de prova cilindro protético de acrílico - liga de cobalto-cromo. 


\subsubsection{Etapas da cobertura cerâmica.}

Para a oxidação do metal, as infra-estruturas foram levadas ao forno de cerâmica pré-aquecido a $600^{\circ} \mathrm{C}$ e esta temperatura foi elevada em incrementos de $55^{\circ} \mathrm{C}$ até atingir $900^{\circ} \mathrm{C}$ permanecendo assim por 5 minutos sob vácuo parcial. Após esta fase, foi realizada a queima das camadas de opaco usada para mascarar a infra-estrutura metálica. As temperaturas utilizadas em todas as fases de aplicação da porcelana sofrem variações de uma porcelana para outra, portanto, foi prudente seguir as recomendações do fabricante. Neste trabalho foi utilizada a cerâmica Duceram Kiss (Degudent, Hanau-Wolfgang, Alemanha). Para este sistema cerâmico a aplicação do opaco seguiu o seguinte protocolo: no opacificador em pasta, a temperatura inicial do forno foi $575^{\circ} \mathrm{C}$ permanecendo nesta temperatura por sete minutos e aumentada em incrementos de $55^{\circ} \mathrm{C}$ atingindo a temperatura final de 930 C e mantida por três minutos. Após o resfriamento foi realizada a queima da camada de opaco em pó. A temperatura inicial do forno foi de $575^{\circ} \mathrm{C}$ permanecendo nesta temperatura por cinco minutos e aumentada em incrementos de $55^{\circ} \mathrm{C}$ atingindo a temperatura final de $930^{\circ} \mathrm{C}$ e mantida por dois minutos. Após a aplicação do opaco, duas camadas de cervical foram aplicadas de maneira semelhante: temperatura inicial do forno de $575^{\circ} \mathrm{C}$ mantendo-se nesta temperatura por sete minutos, elevação da temperatura em incrementos de $55^{\circ} \mathrm{C}$ até atingir a temperatura de $920^{\circ} \mathrm{C}$ mantida por um minuto. Para a aplicação das duas camadas cerâmicas (dentina) as peças foram levadas ao forno com temperatura inicial de $575^{\circ} \mathrm{C}$ mantendo-se nesta temperatura por seis minutos. A seguir a temperatura foi elevada em $55^{\circ} \mathrm{C}$ até atingir $910^{\circ} \mathrm{C}$ permanecendo nesta temperatura por um minuto. Para a segunda camada de porcelana (dentina) as peças foram levadas ao forno com temperatura inicial de $575^{\circ} \mathrm{C}$ mantida por quatro minutos, após o que a temperatura foi elevada em $55^{\circ} \mathrm{C}$ até atingir $900^{\circ} \mathrm{C}$ permanecendo nesta temperatura por um minuto. Na realização do glaze os corpos de prova foram introduzidos no forno pré-aquecido à temperatura de $575^{\circ} \mathrm{C}$ por três minutos e aumentado a temperatura em incrementos de $55^{\circ} \mathrm{C}$ até atingir $890^{\circ} \mathrm{C}$ permanecendo nesta temperatura por um minuto. Todas as fases da aplicação estratificada da porcelana exceto a queima do glaze foram realizadas sob vácuo de $50 \mathrm{hPa}$. 


\subsection{CONSTITUIÇÃO DOS GRUPOS}

Os doze corpos de prova foram alocados em três grupos onde o tipo da liga e o tipo de cilindro protético utilizados foram variáveis determinantes.

Grupo 1. foram utilizados quatro cilindros protéticos de ouro sobre-fundidos com liga de paládio-prata e cobertura cerâmica. (Fig.4.9)

Grupo 2.foram utilizados quatro cilindros protéticos com cinta de cobaltocromo sobre-fundidos com liga de cobalto-cromo e cobertura cerâmica. (Fig.4.10)

Grupo 3. foram utilizados quatro cilindros protéticos de acrílico fundidos com liga de cobalto-cromo e cobertura cerâmica. (Fig 4.11)

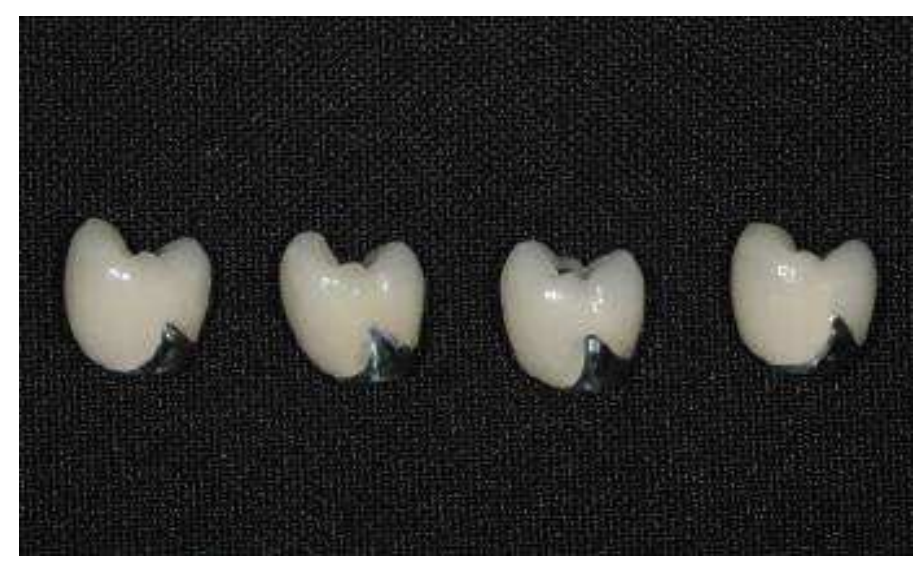

Figura 4.9 Grupo 1: Cilindro de ouro, sobre-fundidos com a liga de paládio-prata e cobertura cerâmica * Pors-on ${ }^{\circledR} 4$ - Degussa S.A., São Paulo, Brasil.

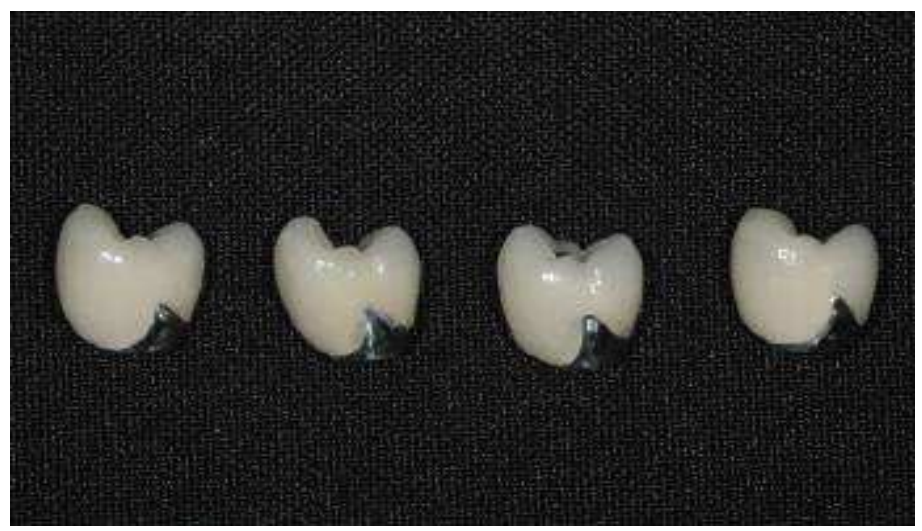

Figura 4.10 Grupo 2: Cilindro de acrílico fundido com a liga de NiCoCr e c obertura cerâmica *Dan Ceramalloy, Nihon Shika Kinzoku CO. 


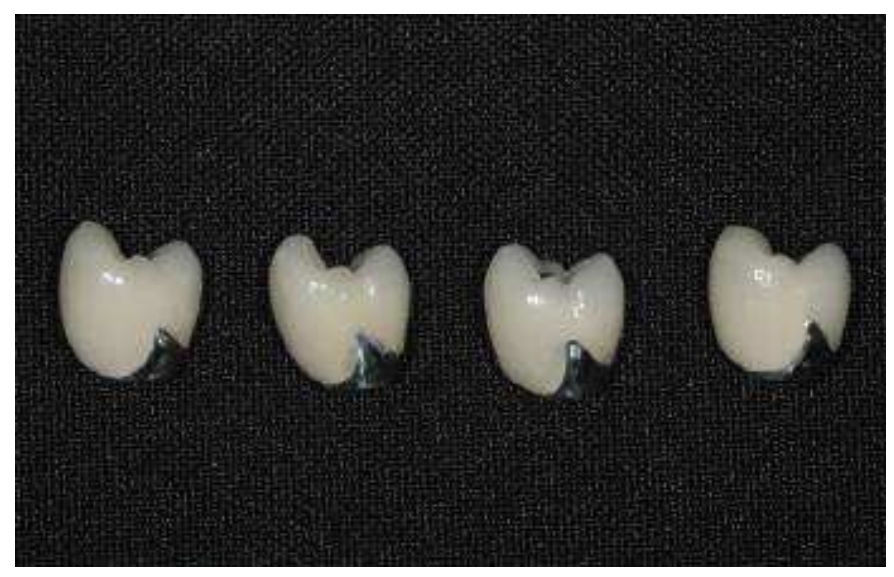

Figura 4.11 Grupo 3: Cilindro de CoCr usinado, sobre-fundidos com a liga de NiCoCr e cobertura cerâmica *Dan Ceramalloy, Nihon Shika Kinzoku CO.

\subsection{FIXAÇÃO DOS CORPOS DE PROVA}

Uma base metálica (figuras 4.12 e 4.13 ) foi desenvolvida para fixação e estabilização do modelo experimental onde os testes foram realizados. Esta fixação se fez necessária para que não ocorressem movimentações do conjunto no momento da aplicação das forças para a fixação dos corpos de prova sobre o intermediário. A utilização desta base metálica rígida também tem o intuito de não interferir na deformação do modelo de PU e de não absorver as forças aplicadas durante os testes.

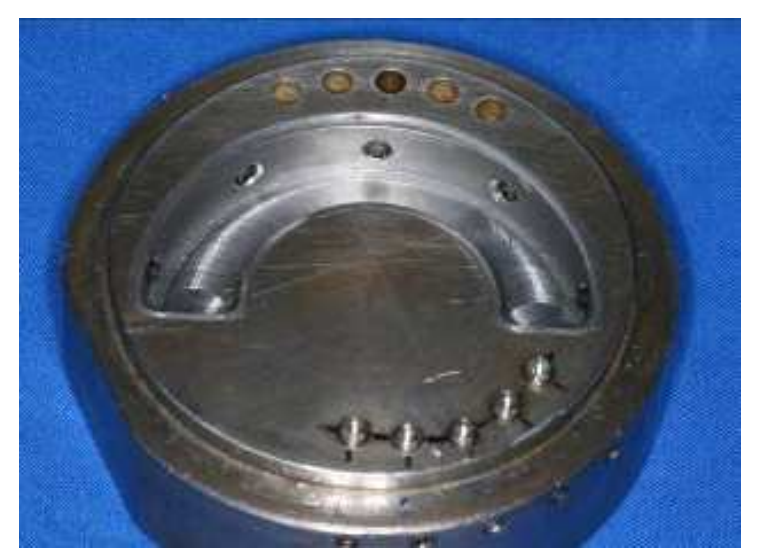

Figura 4.12 - Imagem da base metálica visualizando o local de assentamento do modelo de PU com os três parafusos de retenção e estabilização. 


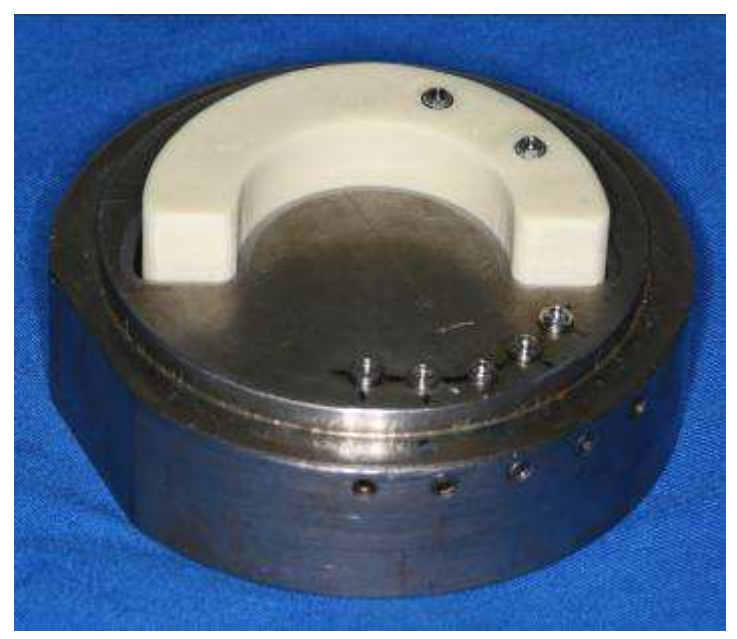

Figura 4.13 - Imagem da base metálica com o modelo de PU posicionado, notando o perfeito assentamento da superfície lingual do modelo na superfície interna da base metálica.

Os intermediários multi-unit de $5,0 \mathrm{~mm}$ de altura foram posicionados e parafusados com um torque de $20 \mathrm{Ncm}$, através de um dispositivo eletrônico de controle de torque (Nobel Biocare Torque Controller ${ }^{\mathrm{TM}}$, Gotemburgo, Suécia).

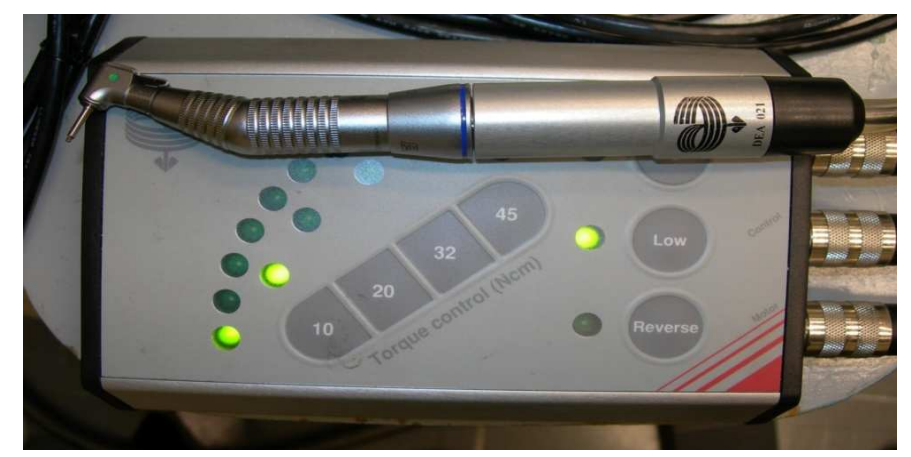

Figura 4.14 - Imagem do torquimetro eletrônico Nobel Biocare Torque Controller ${ }^{\mathrm{TM}}$

\subsection{COLAGEM DOS EXTENSÔMETROS LINEARES ELÉTRICOS}

A superfície externa do modelo de PU e dos intermediários foi limpa com acetona, para remover qualquer resíduo que pudesse interferir no processo de fixação dos extensômetros lineares elétricos. Para a realização deste experimento quatro extensômetros lineares elétricos (KFG -02-120-C1-11, Strain Gages, Kyowa Electronic Instruments Co., Ltda., Tóquio, Japão) (Figuras 4.15) foram fixados na superfície oclusal do modelo de PU e três na superfície lateral do intermediário 
equidistantes entre si. Com uma cola a base de cianoacrilato (Strain Gage Cement CC - 33 A -Kyowa Electronic Instruments Co., Ltda., Tóquio, Japão), os extensômetros foram colados, quatro ao redor do implante nas faces mesial, distal, vestibular e lingual e três na superfície lateral do intermediário (figura 4.16).

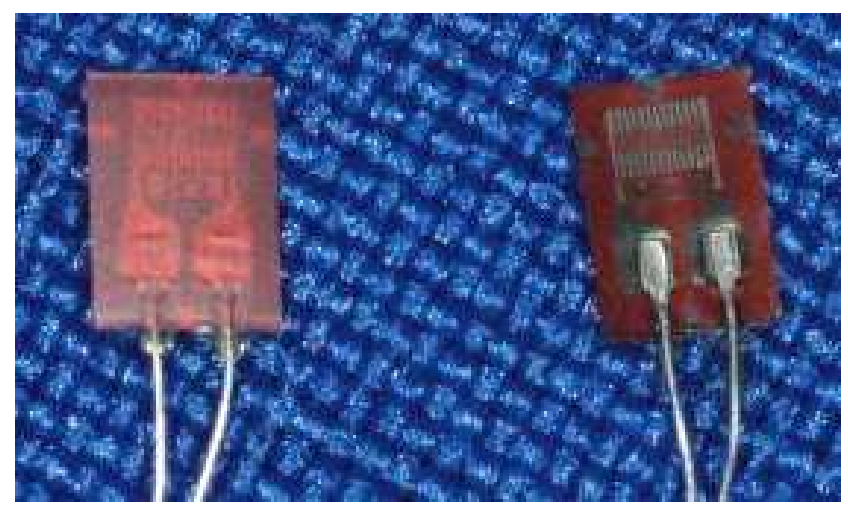

Figura 4.15 - Superfícies interna e externa dos extensômetros lineares elétricos.

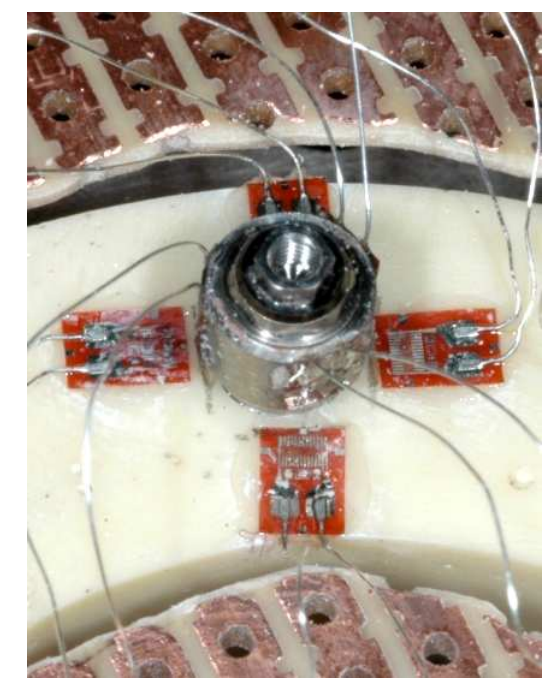

Figura 4.16 - Modelo de PU com os intermediários e com os extensômetros lineares elétricos colados na superfície oclusal do modelo ao redor dos dois implantes.

As terminações dos extensômetros lineares elétricos foram soldadas em uma placa de circuito elétrico que foi afixada sobre a superfície do modelo mestre (figura 4.17). Cada um dos extensômetros lineares elétricos foi conectado a um canal de um dispositivo de aquisição de dados (NIDAQ-9172, National Instruments Corp., Austin, Texas, USA (figura 4.18) capaz de medir a deformação dos extensômetros e transmiti-las para um computador com processador Intel Celerom M, 512MB por meio de uma conexão USB 2.0, onde os dados foram visualizados por meio do programa LabVIEW 8.1 para Windows (National Instruments Corp., Austin, Texas, 
USA). Obtiveram-se assim os valores numéricos da deformação sofrida no modelo de PU e intermediário. Após cada infra-estrutura ser posicionada sobre os intermediários no modelo de $\mathrm{PU}$, os parafusos de titânio foram apertados com uma chave hexagonal manual até oferecerem resistência, para confirmação da adaptação da infra-estrutura. A seguir, foi empregado um torque de $10 \mathrm{Ncm}$, através do dispositivo eletrônico de controle de torque e as deformações foram registradas e gravadas para posterior tratamento estatístico.

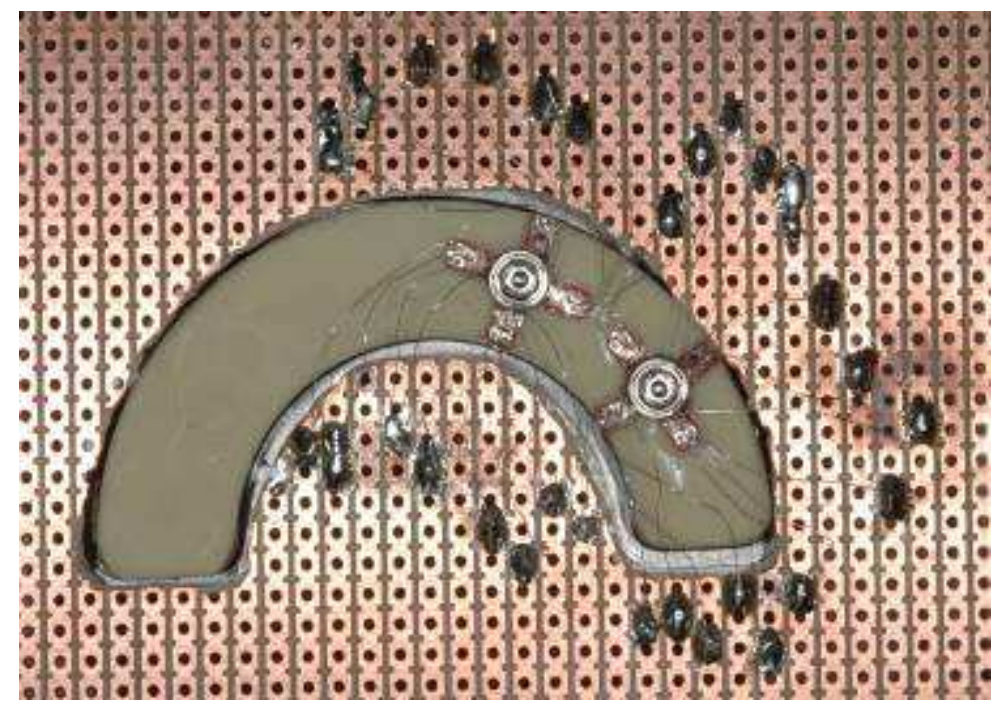

Figura 4.17 - Placa de circuito com extensômetros soldados.

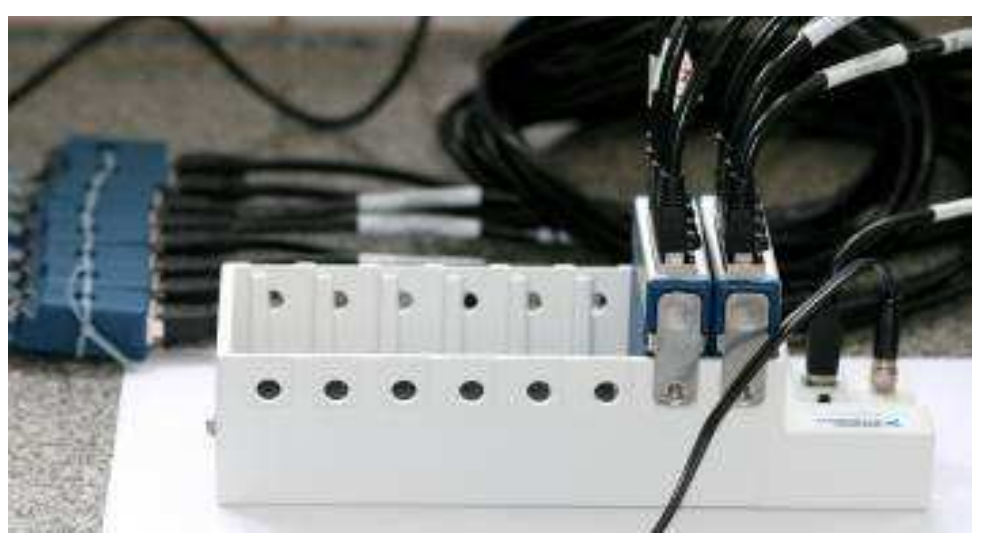

Figura 4.18 - Imagem do dispositivo de aquisição de dados com os canais de extensometria conectados. 


\subsection{REALIZAÇÃO DO TESTE}

Para a realização dos testes foi utilizada a máquina universal de ensaio EMIC (Equipamentos e Sistemas de Ensaio Ltda). Este é um aparelho de conceito electromecânico que atua em conjunto com o software instalado em um microcomputador, e um sistema de instrumentação eletrônica dotado de canais de medição de forças (Figura 4.19).

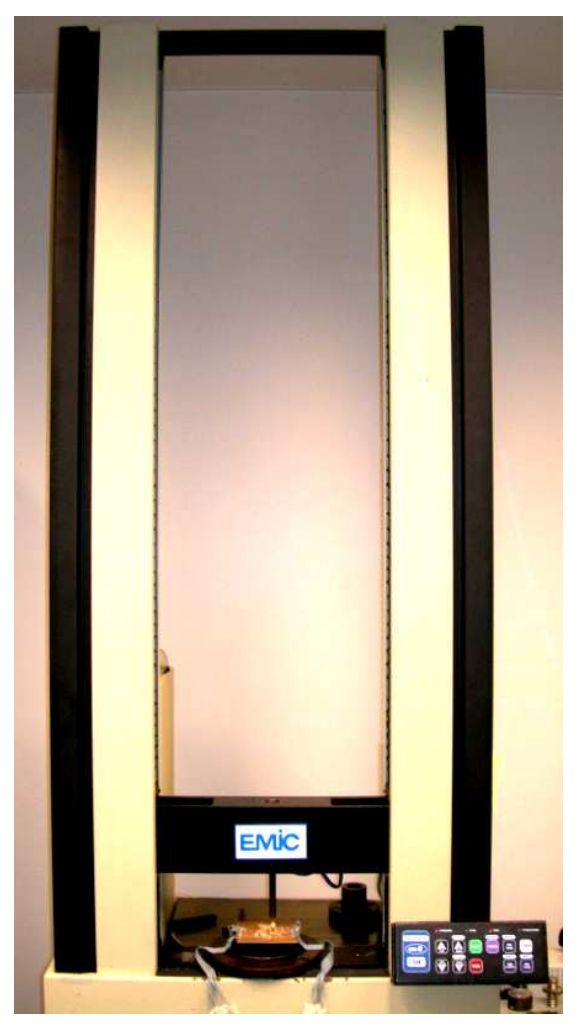

Figura 4.19 - Imagem da Maquina de ensaio univeral da empressa EMIC ${ }^{\mathrm{TM}}$

O conjunto base metálica/modelo de poliuretano foi colocado através de um dispositivo que permite a sua movimentação em todas as direções no plano horizontal, permitindo o correto posicionamento da ponta aplicadora de carga e colocado na maquina de ensaio universal EMICTM(Figuras 4.20,4. 21). 


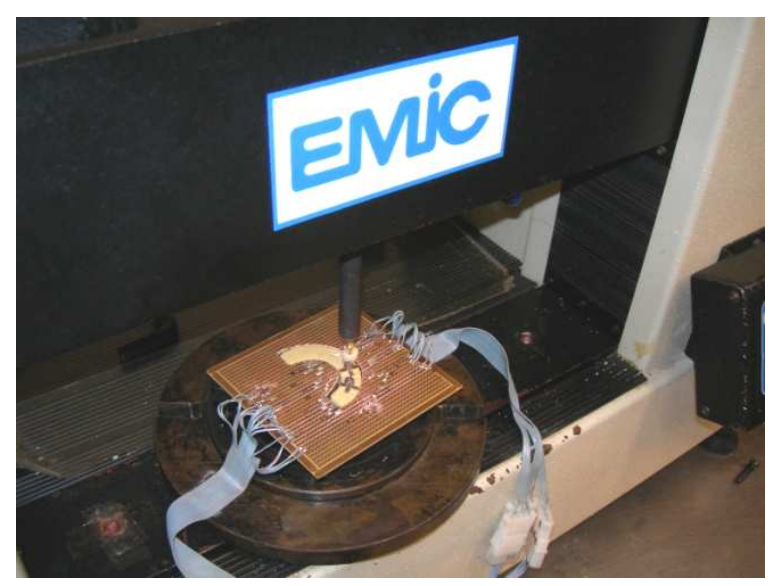

Figura 4.20 - Imagem superior do modelo experimental na base colocado na maquina de ensaio universal EMICTM

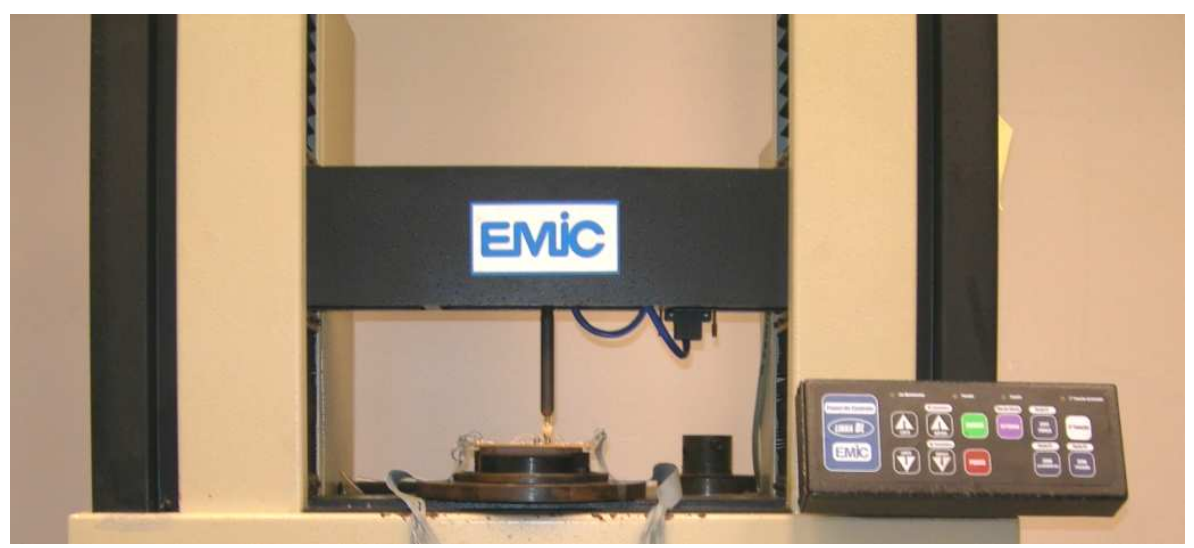

Figura 4.21 - Imagem lateral do modelo experimental na sua base colocado nas maquina de ensaio universal EMIC ${ }^{\mathrm{TM}}$

Uma ponta em aço comum, na forma de lápis, foi fixada à célula de carga e uma força axial de $300 \mathrm{~N}$ foi aplicada, a uma velocidade de $0,5 \mathrm{~mm} / \mathrm{min}$, no ponto central oclusal de cada corpo de prova. A força escolhida para realização do teste foi de $300 \mathrm{~N}$ de acordo com os valores de força de mordida encontrados por Akça, Uysal e Çehreli (2006) para próteses implantossuportadas.

Foram realizadas cinco aplicações de carga para cada situação; em cada aplicação de força foi realizada a leitura da microdeformação gerada no modelo de PU ao redor dos dois implantes, captadas pelos extensômetros colados nas faces mesial, distal, vestibular e lingual, e nas três fases escolhidas do intermediário. 


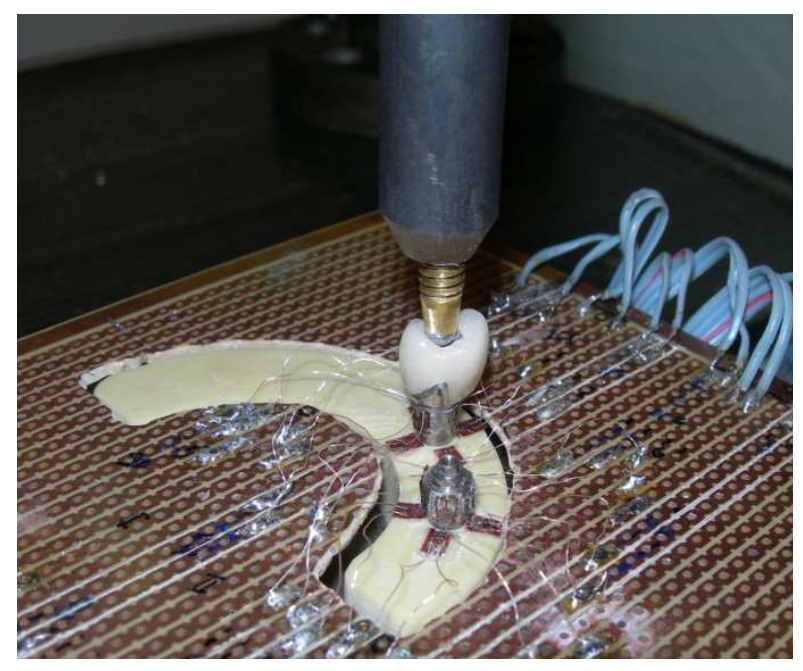

Figura 4.22 - Imagem da aplicação de carga com a ponta de aço

Sobre o implante foi fixado um intermediário Multi-unit abutment Brånemarck System® RP 5 mm (Nobel Biocare, Göteborg, Sweden, REF 29183, lote 662959) com torque de $20 \mathrm{Ncm}$ aplicados com auxílio de um dispositivo eletrônico de controle de torque (Nobel Biocare Torque Controller ${ }^{\mathrm{TM}}$, Gotemborg, Sweden).

Os testes de deformação foram realizados para os três grupos e dois momentos diferentes. Em um primeiro momento as leituras de deformação foram realizadas após a fase laboratorial de fundição das infra-estruturas.

Para o grupo que utilizou cilindro de ouro e liga de paládio-prata as infraestruturas foram fixadas com parafuso protético para multi-unit (Nobel Biocare, Göteborg, Sweden - REF 29285, lote 669883) apertados com torque de $10 \mathrm{Ncm}$ aplicados com auxílio de um dispositivo eletrônico de controle de torque (Nobel Biocare Torque Controller ${ }^{\mathrm{TM}}$, Gotemborg, Sweden).

Para dar fidelidade e consistência aos dados de deformação foram realizadas cinco repetições do aperto dos parafusos de cada corpo de prova e os parafusos trocados após cada teste. A leitura da microdeformação gerada no modelo de PU ao redor do implante e do intermediário, captadas pelos extensômetros colados nas faces mesial, distal, vestibular e lingual e na face lateral do intermediário. 
Ao todo, foram empregados sete extensômetros lineares elétricos colados no modelo de PU e no intermediário para cada teste, os quais foram conectados a sete canais do dispositivo de aquisição de dados (figura 4.23).

- Canal 1 (Int) - superfície do intermediário;

- Canal 2 (Int') - superfície do intermediário;

- Canal 3 (Int”) - superfície do intermediário;

- Canal 4 (Distal) - superfície do modelo do lado distal;

- Canal 5 (Lingual) - superfície do modelo do lado lingual;

- Canal 6 (Mesial) - superfície do modelo do lado mesial;

- Canal 7 (Vestibular) - superfície do modelo do lado vestibular.

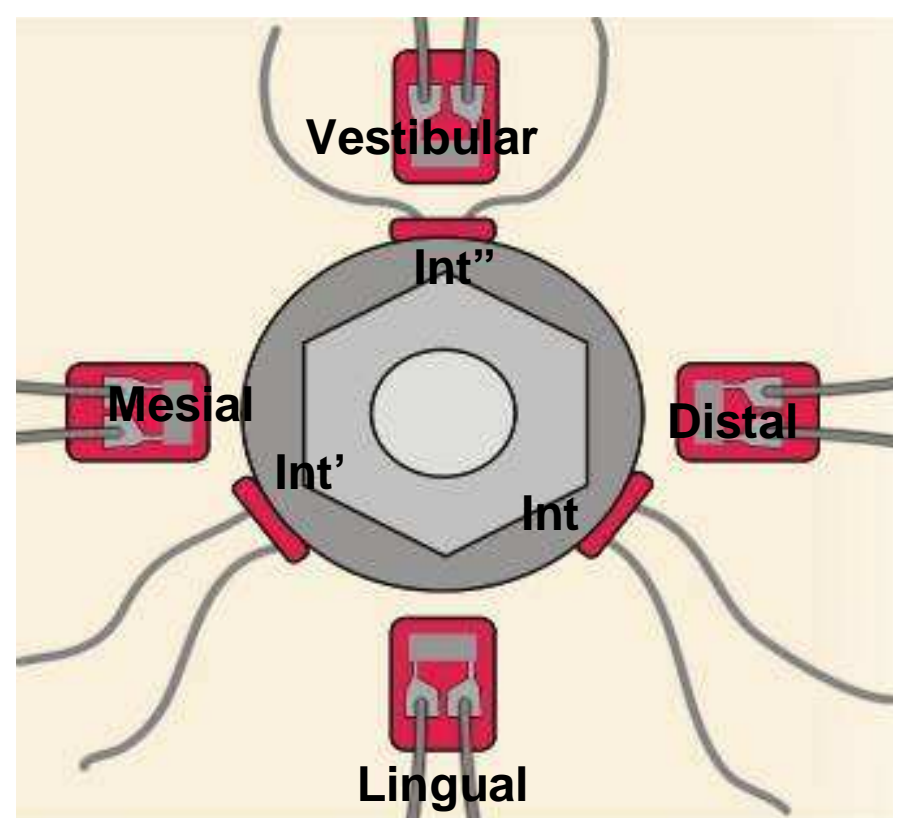

Figura 4.23 - Desenho representativo da disposição dos extensômetros lineares elétricos no intermediário (I) no modelo de PU.

Através do programa LabVIEW 8.1 os dados foram visualizados no monitor do computador e armazenados, obtendo-se dados numéricos de microdeformação $(\mu \varepsilon)$ com uma frequência de $20 \mathrm{MHz}$ durante todo o tempo necessário para ocorrer a estabilização da deformação em todos os canais. 


\subsection{AQUISIÇÃO DOS DADOS}

O extensômetro linear elétrico ou "strain gage" é um dispositivo elétrico capaz de medir a tensão sofrida por um objeto. A tensão $(\varepsilon)$ representa a quantidade de deformação de um corpo quando submetido a uma determinada força, que pode ser de tração (+) ou de compressão (-).

Quando um material é tensionado ele sofre um alongamento, denominado de deformação absoluta $(\Delta \mathrm{L})$, que é proporcional à força nele aplicada. A proporção entre a variação do comprimento $(\Delta \mathrm{L})$ de um corpo e seu tamanho inicial $(\mathrm{L})$ corresponde à deformação específica $(\varepsilon)$, expressa pela fórmula:

$$
\varepsilon=\frac{\Delta \mathrm{L}(\mathrm{mm})}{\mathrm{L}(\mathrm{mm})}
$$

Como as unidades de medida de $\Delta \mathrm{L}$ e $\mathrm{L}$ são as mesmas, pode-se entender que a deformação específica é uma medida adimensional, isto é, não representa uma unidade. Indica apenas que o número por ele representado refere-se a um valor de deformação específica, ou a uma porcentagem de deformação. A medida de deformação fornecida pelos extensômetros é representada por "micro strain" $(\mu \varepsilon)$, em que o micron $(\mu)$ corresponde à potência de $1 \times 10^{-6}$ ou 0,000001 .

Os extensômetros constituem-se resistências elétricas nas quais percorre uma corrente elétrica de baixa intensidade através de um circuito elétrico de ponte de Wheatstone. Quando sofre qualquer deformação, a resistência elétrica do extensômetro é alterada, gerando uma tensão de saída nos terminais da ponte. Esses sinais elétricos são enviados pelos canais para a placa de aquisição de dados.

Esta, por sua vez, transforma os sinais elétricos em sinais digitais, enviandoos para a placa de leitura instalada no computador. Através do programa LabVIEW 8.1 para Windows (National Instruments Corp., Austin, Texas, USA), os dados são transformados em valores de deformação específica, permitindo a visualização das deformações em tempo real. 
Após o aperto dos intermediários com torque de $20 \mathrm{Ncm}$, as infra-estruturas foram posicionadas e apertadas com torque de $10 \mathrm{Ncm}$. Os extensômetros realizaram a medida dos valores respectivos à tensão sofrida tanto pelo intermediário como pelo modelo de poliuretano após o apertamento dos parafusos.

Todos os dados foram gravados no computador como arquivos de extensão TXT. Em seguida, transferidos como arquivos de extensão XLS para o programa EXCEL, a fim de que fosse realizada a análise e seleção dos dados.

Os valores de deformação medidos por cada um dos extensômetros lineares elétricos passam por 3 fases distintas:

- Na fase inicial ocorre variação de baixa magnitude, que corresponde ao período compreendido entre o momento em que se liga a aparelhagem e o momento de estabilização das leituras; esta variação é da ordem de $+16,648$ a $-16,648 \mu \varepsilon$ e corresponde ao limite de sensibilidade dos extensômetros lineares elétricos.

- $\quad \mathrm{Na}$ fase intermediária observam-se as leituras compreendidas entre o momento em que se inicia o aperto dos parafusos até atingir o torque de $10 \mathrm{Ncm}$; a deformação é crescente em função do tempo.

- Na fase final, os valores de deformação estabilizam-se e permanecem em um patamar de deformação máxima para a carga aplicada (Figura 4.24). 


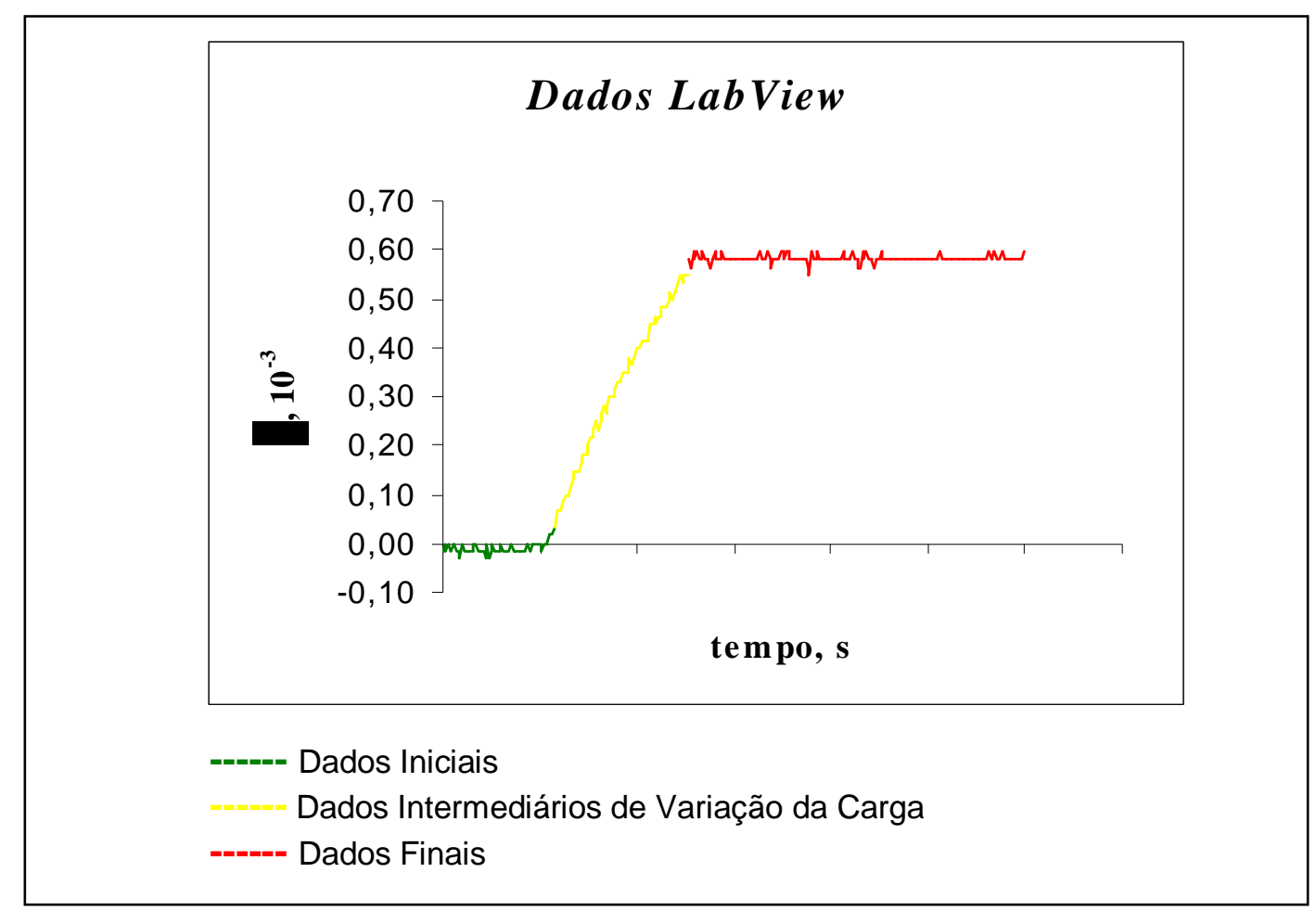

Figura 4.24 - Fases das variações dos valores de deformação.

Foram realizadas cinco repetições para o aperto dos parafusos para cada corpo de prova. As leituras foram realizadas a uma freqüência de $20 \mathrm{MHz}$ por um período de 3 minutos corridos após o início do aperto dos parafusos. Durante este período o programa nos forneceu em torno de 300 leituras de deformação para cada experimento. Para efeito de cálculo da deformação média final, foram utilizados os 100 últimos valores de deformação, os quais corresponderam à terceira fase de aquisição de dados quando as leituras de deformação estavam estabilizadas. 


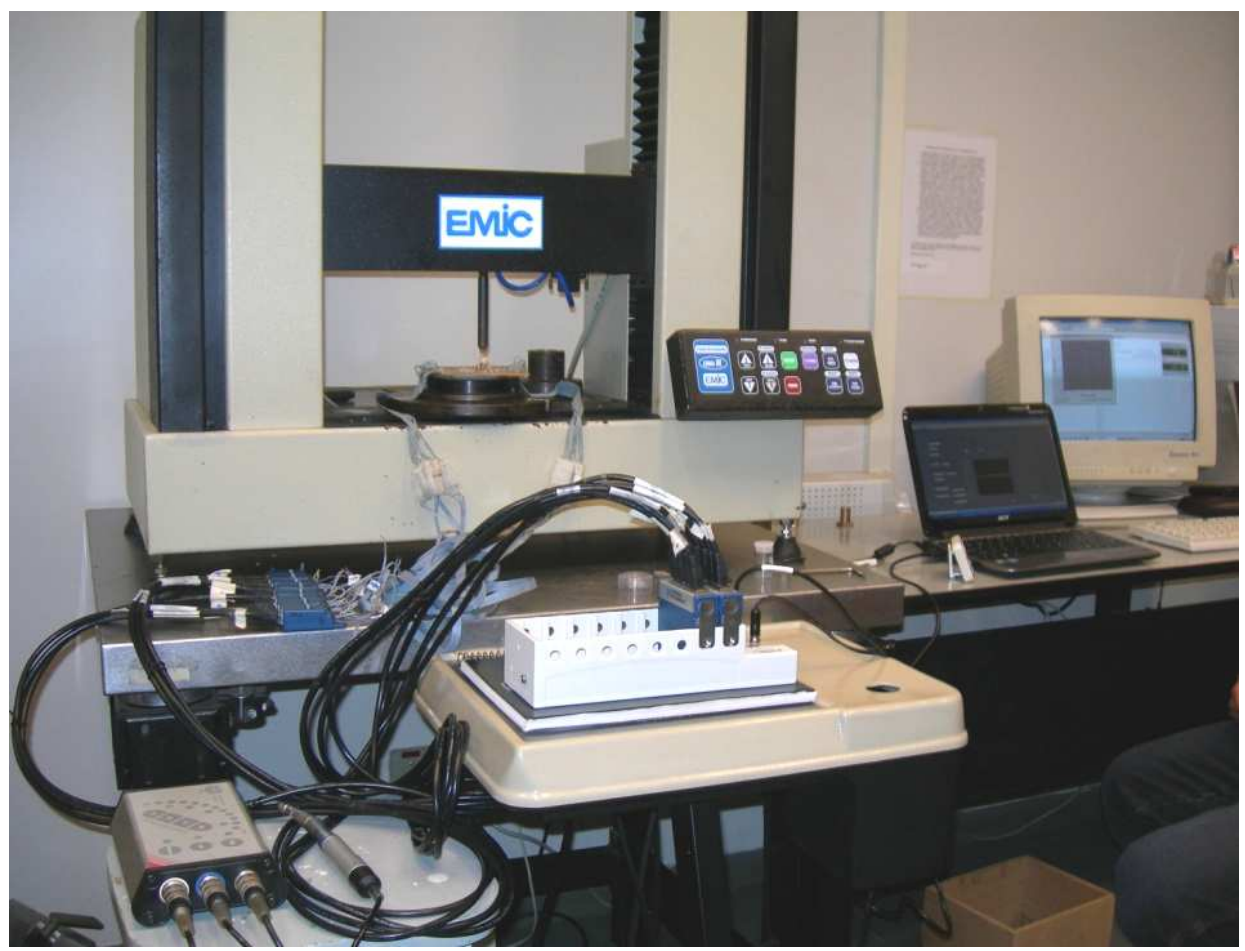

Figura 4.25 - Vista panorâmica de toda a montagem para a aplicação de carga e a aquisição dos dados 
5- Resultados 



\section{RESULTADOS}

Foram realizados os testes de micro-deformação por meio da extensometria relativos aos 12 corpos de prova divididos em 3 grupos de 4 corpos assim distribuidos:

- Grupo 1. Prótese unitária com cilindro protético usinado de Au sobre-fundidos com a liga de paládio-prata e cobertura cerâmica.

- Grupo 2. Prótese unitária com cilindro protético calcinável fundido com a liga de NiCoCr e cobertura cerâmica.

- Grupo 3. Prótese unitária com cilindro de CoCr usinado, sobre-fundidos com a liga de NiCoCr e cobertura cerâmica.

Todos os dados numéricos obtidos na etapa inicial foram expressos por tração (valores positivos) e compressão (valores negativos). Cada uma das cinco repetições de aplicação de força $(300 N)$ foi registrada. A média final e o desvio padrão dos resultados das deformações geradas pelos três extensômetros nas faces laterais do intermediário Inter, Inter', Inter"= (SG1, SG2, SG3) e nas faces distal, lingual, mesial e vestibular do osso simulado pelo poliuretano (SG4, SG5, SG6, SG7), estão nas tabelas 1 a 3 (APÊNDICE A).

Foram utilizados para a estatística os valores absolutos de micro-deformação que representam a tensão durante o experimento, não levando em consideração se as leituras correspondiam à tração ou compressão.

Porém, nas tabelas 4 a 6 (APÊNDICE B) encontram-se os dados obtidos nas microdeformações com os valores positivos e negativos de tração e compresão como foram obtidos inicialmente.

Foi realizada a média total entre os valores médios absolutos encontrados nos extensômetros lineares elétricos localizados no poliuretano e no intermediário para cada corpo de prova (Gráfico 5.1). No eixo das abscissas (y), tem-se a deformação, em "microstrains" $(\mu \varepsilon)$, enquanto no eixo das coordenadas (x) estão 
representados os canais de extensometria, onde os primeiros três canais correspondem a lateral do intermediário, Inter, Inter', Inter" = (SG1, SG2, SG3) e os quatro últimos canais correspondem às regiões peri-implantares distal, lingual, mesial e vestibular (SG4, SG5, SG6, SG7) do osso simulado pelo poliuretano

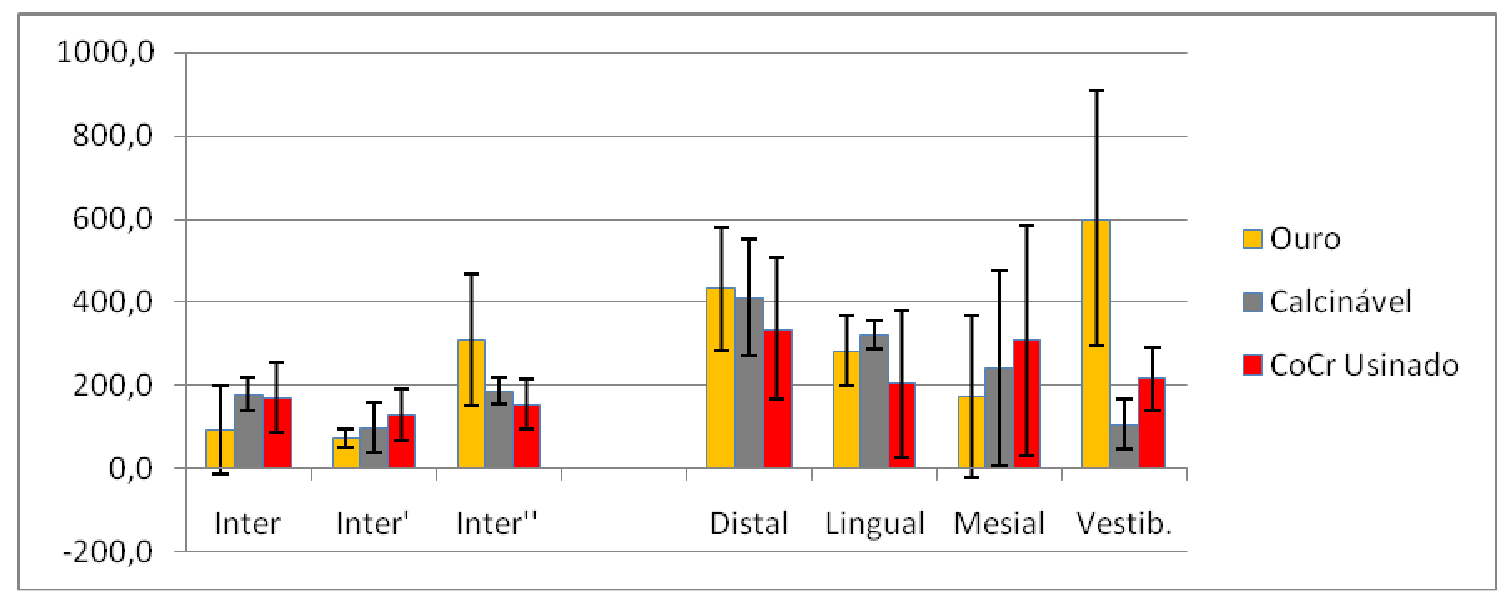

Gráfico 5.1- Gráfico de médias e desvio padrão de micro-deformação $(\mu \varepsilon)$ para todos os corpos de prova no intermediário e no poliuretano.

Para diferenciar individualmente cada grupo pelo tipo de cilindro utilizado na confecção dos três grupos ( $\mathrm{Au}$, Calcinável, $\mathrm{CoCr}$ ), as médias e o desvio padrão dos valores obtidos de micro-deformação $(\mu \varepsilon)$ para cada grupo, foram feitos os gráficos $5.2,5.3$ e 5.4 .

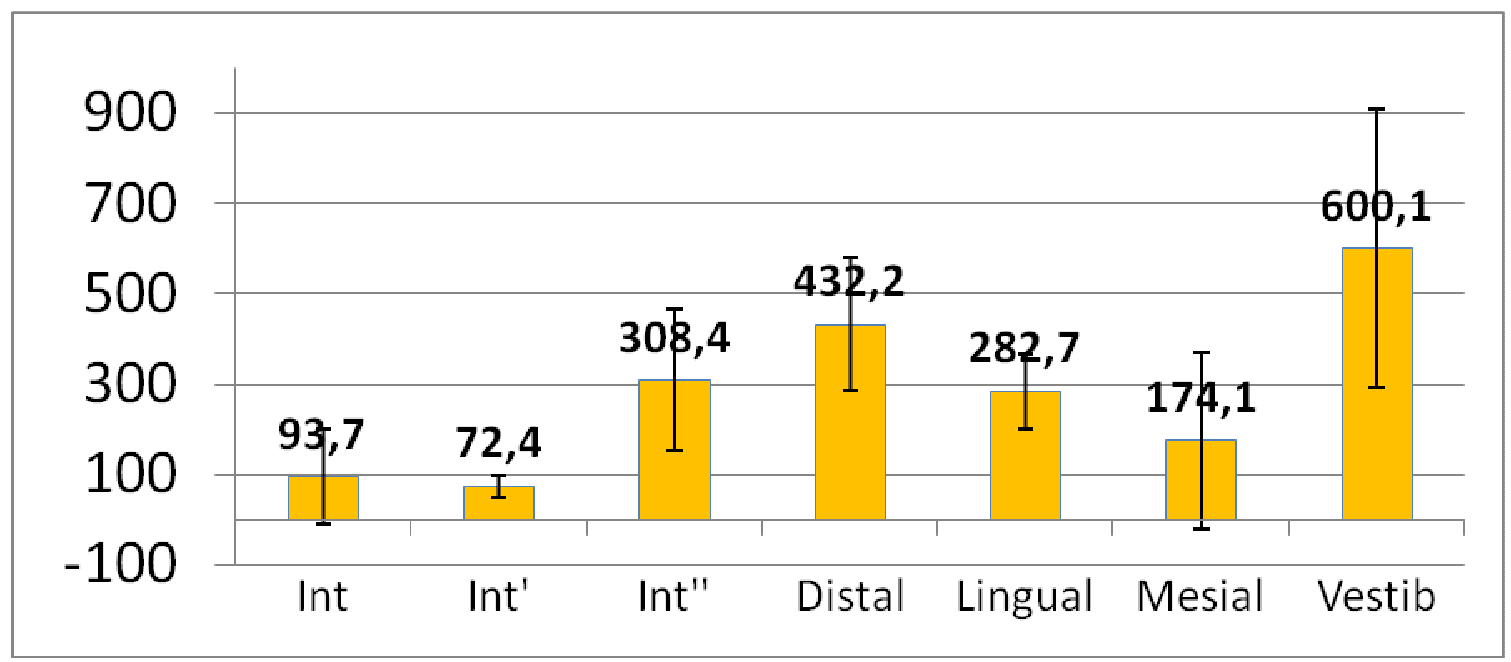

Gráfico 5.2- Gráfico das médias de microdeformação $(\mu \varepsilon)$ captadas pelos canais de extensometria no intermediário e no poliuretano para o grupo de cilindro de Au 


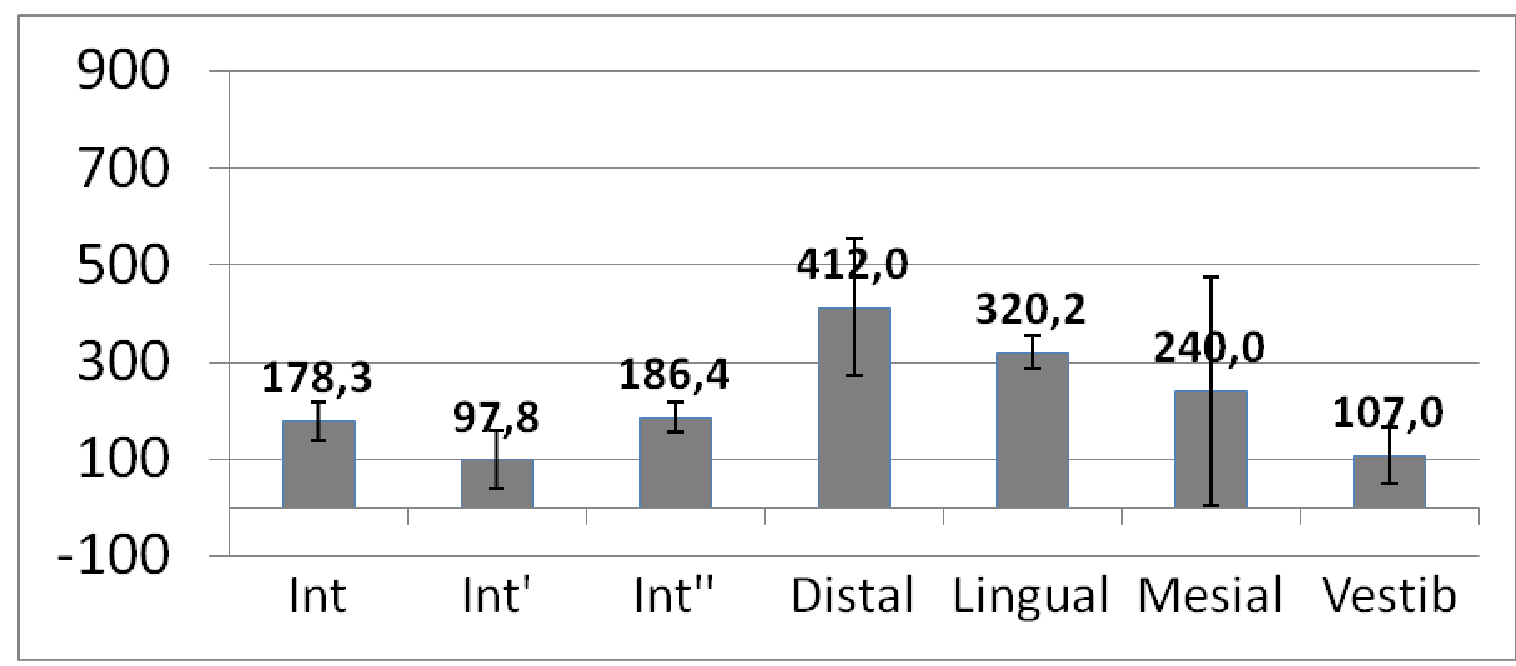

Gráfico 5.3- Gráfico das médias de microdeformação $(\mu \varepsilon)$ captadas pelos canais de extensometria no intermediário e no poliuretano para o grupo de cilindro Calcinável.

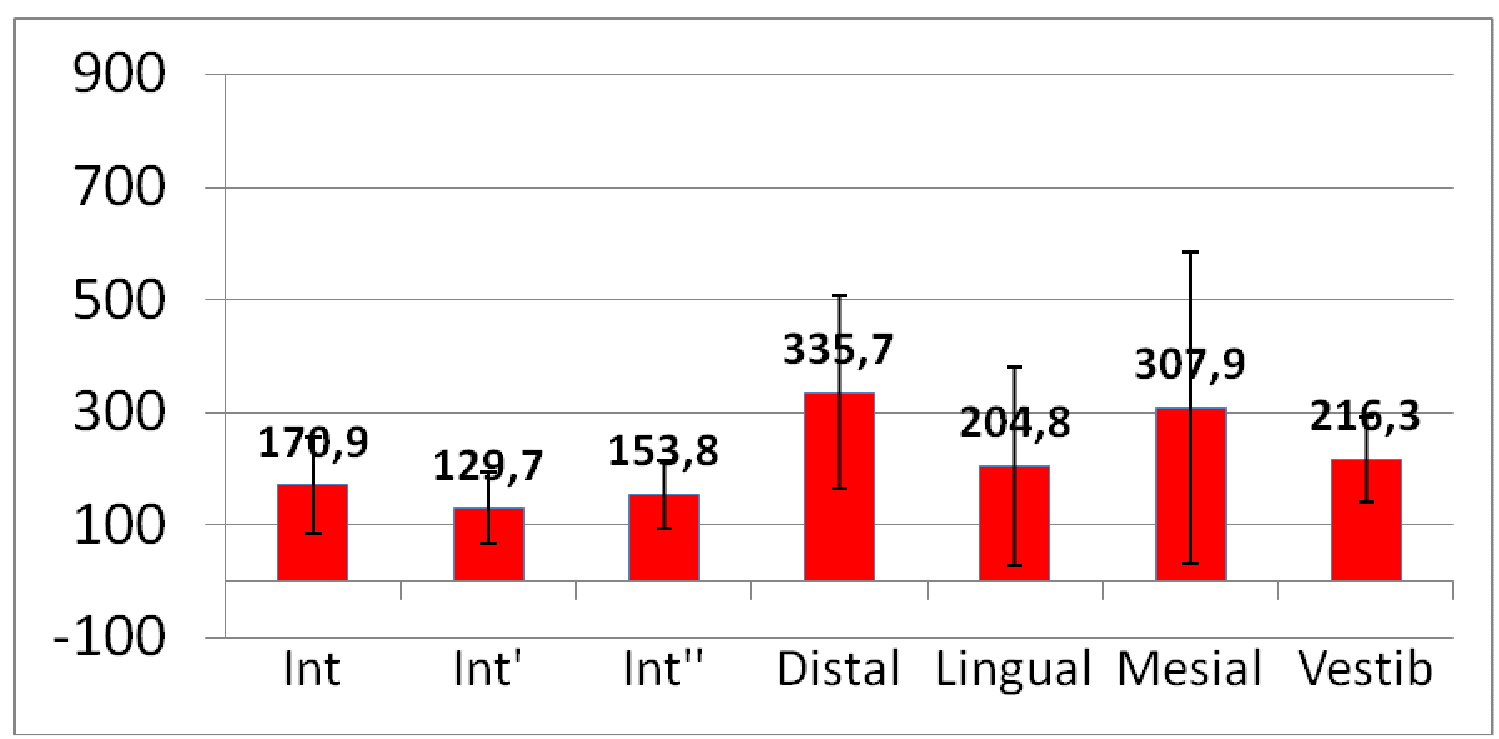

Gráfico 5.4- Gráfico das médias de microdeformação $(\mu \varepsilon)$ captadas pelos canais de extensometria no intermediário e no poliuretano para o grupo de cilindro de CoCr.

A fim de se analisar todos os dados do experimento em relação às possíveis variáveis presentes no estudo foram realizados inicialmente dois testes estatísticos em cada situação de aplicação de carga. Para verificar a presença de diferenças estatisticamente significantes foi aplicada a análise de variância (ANOVA) a dois critérios, onde a primeira variável é o tipo de material do cilindro utilizado na confecção da infraestrutura da coroa (Au, Calcinavel, CoCr), e a segunda variável, a localização do extensômetro na região peri-implantar (Distal, Lingual, Mesial, Vestibular) e no intermediário (Inter, Inter',Inter”). O nível de significância escolhido foi o valor convencional de $5 \%$. 
Tabela 5.1: - ANOVA a dois critérios para as duas variáveis pesquisadas, material e localização. Valor da probabilidade menor que 0,05 significa estatisticamente significante $(p<0,05)$.

\begin{tabular}{|c|c|c|c|c|c|c|}
\hline \multirow[t]{2}{*}{ Fonte de Variação } & \multicolumn{2}{|c|}{ Graus de Liberdade } & \multicolumn{2}{|c|}{ Quadrado Médio } & \multirow[t]{2}{*}{ "F" } & \multirow[t]{2}{*}{ Probabilidade } \\
\hline & Efeito & Resíduo & Efeito & Resíduo & & \\
\hline Material & 2 & 9 & 35831,49 & 9099,955 & 3,937546 & 0,0591 \\
\hline Localização & 6 & 54 & 115315,3 & 23001,61 & 5,013357 & 0,0004 \\
\hline Interação & 12 & 54 & 52207,57 & 23001,61 & 2,269735 & 0,0204 \\
\hline
\end{tabular}

Posteriormente foi aplicado o teste de Tukey para verificar de quais variáveis apresentam diferenças estatisticamente significantes (Tabela 5.2).

Tabela 5.2 -TESTE DE TUKEY. Os valores localizados em cada linha com a mesma letra não apresentam diferença estatisticamente significante (nível de significância de 0,05). A interação foi apenas observada no SG vestibular com valores estatisticamente significantes.

\begin{tabular}{ccccccccc}
\hline & Int & Int' & Int” & Distal & Lingual & Mesial & Vestibular \\
\hline Au & 93,7 a & 72,4 a & 308,4 ab & 432,2 ab & 282,7 ab & 174,1 a & 600,1 b \\
Calcinável & 178,3 ab & 97,8 a & 186,4 ab & 412 b & 320,2 ab & 240 ab & 107 a \\
CoCr & 170,9 a & 129,7 a & 153,8 a & 335,7 a & 204,8 a & 307,9 a & 216,3 a \\
\hline
\end{tabular}


6-Discussão 



\section{DISCUSSÃO}

Entre os problemas biomecânicos relacionados com o insucesso dos tratamentos de próteses implantossuportadas, os pesquisadores tem encontrado que a sobrecarga oclusal tem sido identificada como a causa primária da perda óssea peri-implantar, perda de implantes e da prótese (HEKIMOGLU et al., 2004; ADELL et al., 1981; NAERT et al., 1992; ISIDOR, 1996; ZARB; SCHMITT, 1990).

Um dos fatores que influencia o resultado dos tratamentos com implantes é a quantidade e qualidade óssea, que variam muito conforme os diferentes tipos de pacientes (Sahin, Çehreli e Yalçin, 2002). A utilização de mandíbulas humanas frescas é uma alternativa com maiores dificuldades para a realização de estudos biomecânicos in vitro, esta alternativa entretanto apresenta algumas complicações, pela dificuldades de padronização por suas características elásticas e anisotrópicas, assim como também a dificuldade de colagem de extensômetros em razão da umidade e oleosidade. Estudos in vitro tem utilizado materiais considerados isotrópicos e homogêneos para uma adequada padronização dos testes (AKÇA, ÇEHRELI; IPLIKÇIOGLU, 2002; ÇEHRELI et al., 2004; KIM; JACOBSON; NATHANSON, 1999). De acordo com Bonneta, Postaireb, Lipinskia (2009), o uso de modelos isotrópicos, são fundamentais para o estudo biomecânico de simulações numéricas, e como demonstrado em estudos prévios, o poliuretano possui as características necessárias e foi o material de escolha para confecção do modelo simulando a região mandibular conforme utilizado em pesquisas anteriores (MORETTI NETO et al., 2011; MYIASHIRO et al., 2011).

Conforme afirmaram Kim et al. (1999), existe a possibilidade de serem estabelecidas correlações entre os resultados obtidos com modelos artificiais e os encontrados em situações clínicas. Fundamentado no processo de osteogênese e osteólise, o tecido ósseo está em constantes ciclos de remodelação. Foi indicado por estudos clínicos e laboratoriais que este equilíbrio fisiológico depende diretamente da estimulação mecânica (FROST, 1994). Segundo Wiskott e Belser (1999), para o equilíbrio fisiológico tecidual são necessárias intensidades adequadas de deformação. Assim para evitar reabsorções ósseas, são necessárias deformações acima da faixa de $100 \mu \varepsilon$ (Wiskott e Belser, 1999). Porém quando há 
queda desse estímulo ocorre um desequilíbrio na remodelação óssea, prevalecendo a reabsorção. No entanto para que a injúria permanente exista, os valores devem

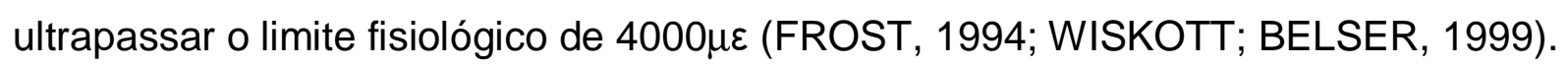

O presente estudo buscou avaliar, em um modelo experimental, a microdeformação no intermediário e no osso simulado pelo poliuretano, no momento de aplicação de carga axial de $300 \mathrm{~N}$. A força foi escolhida para realização do teste de acordo com os valores de força de mordida encontrados por Akça, Uysal e Çehreli (2006) para próteses implantossuportadas.

Para registrar estas deformações foram utilizados extensômetros elétricos colados nas superfícies laterais do intermediário o qual foi pesquisado por (RUBO et al., 1999), através de análise de elemento finito, o que determinou serem estas áreas as mais susceptíveis ao estresse diante de uma carga oclusal. Para o osso simulado pelo poliuretano, os extensômetros foram colados nas superfícies distal, lingual, mesial e vestibular do poliuretano ao redor do implante como pesquisado por outros autores (SUEDAM, 2009, e MORETTI, 2010).

Os dados de microdeformação registrados pelos extensômetros elétricos são valores extremamente pequenos, e assim a compressão ou o alongamento relativo são expressos em $\mu \varepsilon$ (microdeformação), que corresponde a $10^{-6} \varepsilon$. Mil unidades de microdeformação $(1.000 \mu \varepsilon)$ correspondem ao alongamento ou compressão de $0,1 \%$ da estrutura sendo medida ou registrada. (FROST, 1994; WISKOTT; BELSER, 1999).

Os registros de microdeformação das forças aplicadas também podem ser caracterizados qualitativamente. As forças compressivas recebem como prefixo 0 sinal negativo, e as forças de tracionamento, recebem como prefixo o sinal positivo. Como os sinais caracterizam as forças deformantes, para a análise estatística utilizamos nesta pesquisa os valores absolutos. Além disso, para a realização dos testes estatísticos o mais importante é a quantidade de deformação sofrida pelo corpo estudado (intermediário ou osso simulado) independente da qualidade da deformação (tração ou compressão), por isso os valores absolutos de deformação foram utilizados (Karl et al. 2008). 
Como pudemos avaliar, as forças de deformação que atuaram sobre 0 intermediário mostraram uma variação entre os corpos de prova analisados. Os valores obtidos de microdeformação após aplicação da carga axial de 300N nas 12 amostras variou entre $13,0 \mu \varepsilon$ e $454,7 \mu \varepsilon$ para os corpos de prova com cilindro protético usinado de Au. Encontramos valores entre 53,0 $\mu \varepsilon$ e 208,7 $\mu \varepsilon$ para os corpos de prova de Prótese unitária com cilindro protético calcinável fundido com a liga de NiCoCr. E por fim valores entre 47,0 $\mu \varepsilon$ e $245,1 \mu \varepsilon$ para os corpos de prova de Prótese unitária com cilindro de CoCr usinado.

No osso simulado pelo poliuretano, encontramos valores absolutos de microdeformação após aplicação da carga axial de 300N entre 50,7 $\mu \varepsilon$ e 907,4 $\mu \varepsilon$ nos corpos de prova com cilindro protético usinado de Au. Para os corpos de prova com cilindro protético calcinável fundido, a deformação ocorrida foi em valores absolutos entre $19,5 \mu \varepsilon$ e $580,3 \mu \varepsilon$. Por fim, para os corpos de prova de com cilindro de CoCr usinado, encontramos valores entre 9,4 $\mu \varepsilon$. e 535,3 $\mu \varepsilon$.

Os valores das médias absolutas de microdeformação do osso simulado pelo poliuretano encontrados neste estudo in vitro se encontram dentro da janela fisiológica descrita por (Frost 1994) ao descrever a lei de Wolff e as adaptações estruturais que ocorrem no osso sob determinados estímulos mecânicos. Entre os conceitos revisados por Frost no seu artigo, a remodelação baseada na unidade multicelular básica pode induzir a remoção ou conservação do osso, mas este não pode ser adicionado. Todas as atividades básicas de crescimento, modelação e remodelação determinam a arquitetura e resistência do osso. Nos lugares onde o pico ósseo de deformação permanece abaixo de $50 \mu \varepsilon$ denota que está sob efeito de desuso. As deformações acima de $1500 \mu \varepsilon$ tendem a uma remodelação lamelar pela reconfiguração. Porém, com microdeformações iguais ou superiores a $4.000 \mu \varepsilon$, os prejuízos não possibilitam a recuperação pelos mecanismos convencionais de reparo, resultando em danos teciduais irreversíveis para o osso.

Diante dos resultados encontrados nesta pesquisa, todos os valores médios de deformação se mantiveram dentro dos padrões de normalidade, na janela fisiológica de descrita por Frost (1994) entre $50 \mu \varepsilon$ e $1500 \mu \varepsilon$, independente do tipo de cilindro utilizado. 
Foi encontrado na nossa pesquisa que os valores de microdeformação para o intermediário e para o osso simulado quando comparados os materiais utilizados para confecção das coroas (cilindros ouro, calcinável e cobalto-cromo) não apresentaram diferença estatística significante, porém, como foi mostrado na tabela 5.6 o resultado ficou muito perto do valor de probabilidade $(p=0,059)$. Tendo em conta a localização dos extensômetros, no intermediário e no osso simulado pelo poliuretano, encontramos diferença estatisticamente significante $(p=0,0004)$ dentro dos mesmos tipos de cilindros, o que ficou confirmado com a analise do teste de Tukey. Desta forma, no cilindro de ouro ouve diferença estatisticamente significante entre a média do extensômetro vestibular $(600,1 \mu \varepsilon)$ em relação ao mesial $(174,1$ $\mu \varepsilon)$. No cilindro calcinável existiu diferença estatisticamente significante entre a média do strain gauges vestibular $(107 \mu \varepsilon)$ e distal $(412 \mu \varepsilon)$. No entanto, com relação ao cilindro de cobalto cromo não verificamos diferenças estatisticamente significantes quanto as posições no poliuretano, indicando uma melhor uniformidade na distribuição das tensões.

Com relação às deformações no intermediário observamos que em todos os tipos de cilindros pesquisados, os valores encontrados não apresentaram diferenças estatisticamente significantes variando entre $72,4 \mu \varepsilon$ a $308,4 \mu \varepsilon$.

Outro dado importante observado na análise de variância foi o resultado estatisticamente significante para interação entre localização e material, indicando que em alguma localização existiu diferença entre materiais. Com o teste de Tukey, verificamos que a diferença ocorreu na vestibular do poliuretano nos corpos de prova com cilindro protético usinado de $\mathrm{Au}(600,1 \mu \varepsilon)$ em relação aos confeccionados com cilindros calcináveis $(107 \mu \varepsilon)$ e aos usinados de cobalto-cromo $(216,3 \mu \varepsilon)$. Estes dados do comportamento dos cilindros de ouro seriam alvo de futuras pesquisas, alterando as cargas e os locais de aplicação, para assim observar seu comportamento.

As coroas confeccionadas com cilindro de CoCr usinado, sobre-fundidos com a liga de NiCoCr e cobertura cerâmica tiveram o comportamento mais estável com relação à uniformidade na distribuição das tensões no intermediário e no osso simulado quando comparados com os outros dois grupos (Au e Calcinável), o que 
permite recomendar este tipo de cilindro em tratamentos de próteses unitárias implantossuportadas. 

7-Conclusões 



\section{CONCLUSÕES}

Levando-se em consideração os resultados encontrados de deformação do intermediário e o osso simulado pelo poliuretano frente à aplicação de carga axial de $300 \mathrm{~N}$ em coroas unitárias parafusadas com cilindros de ouro, cilindros calcináveis, e cilindros de cobalto-cromo podemos concluir que:

1. A utilização dos três tipos de cilindro não altera o resultado final de distribuição de tensão no intermediário após o carregamento axial de 300N.

2. Quando aplicada uma carga axial de $300 \mathrm{~N}$ em coroas unitárias parafusadas com os diferentes tipos de cilindros pesquisados, foram encontrados valores de microdeformação $(\mu \varepsilon)$ para o osso simulado pelo poliuretano dentro dos valores da janela fisiológica de equilibrio, proposta pela teoria de Frost. 

Referências 



\section{REFERÊNCIAS}

Adell R, Lekholm U, Rockler B, Brånemark PI. A 15-year study of osseointegrated implants in the treatment of the edentulous jaw. Int J Oral Surg. 1981; 10(6):387416.

Akça K, Çehreli MC, Iplikçioglu H. A comparison of three-dimensional finite element stress analysis with in vitro strain gauge measurements on dental implants. Int $\mathrm{J}$ Prosthodont. $2002 ; 15(2): 115-121$.

Akça K, Uysal S, Çehreli MC. Implant-tooth-supported fixed partial prostheses: correlations between in vivo occlusal bite forces and marginal bone reactions. Clin Oral Impl Res. 2006; (17): 331-336.

Barbier I, Schepers E. Adaptive bone remodeling around oral implants under axial and nonaxial loading conditions in the dog mandible. Int J Oral Maxillofac Implants. $1997 ; 12(2): 215-223$.

Bidez MW, Misch CE. Force transfer in implant dentistry: basic concepts and principals. Journal of Oral Implantol. 1992; 23:264-74.

Bonneta AS, Postaireb M, Lipinskia P. Biomechanical study of mandible bone supporting a four-implant retained bridge. Finite element analysis of the influence of bone anisotropy andfoodstuff position. Med Eng Phys. 2009; 31(7):806-815

Brånemark PI, Zarb GA, Albrektsson T. Tissue-integrated prosthesis.

Osseointegration in clinical dentistry. Chicago: Quintessence;1987.129p.

Burguete RL, Johns RB, King T, Patterson EA. Tightening characteristics for screwed joints in osseointegrated dental implants. J Prosthet Dent. 1994; 71(6):592-599.

Carlson B, Carlson GE. Prosthodontic complications in osseointegrated dental implant tratment. Int J Oral Maxillofac Implants. 1994;9 (1):90-94.

Carr AB, Brunski JB, Hurley E. Effects of fabrication, finishing end polishing on preload in prosteses using conventional gold and plastic cylinders. Int J Oral Maxillofac Implants. 1996;11(5):589-599. 
Carr AB, Gerard DA, Larsen PE. The response of bone in primates around unloaded dental implants supporting prostheses with different levels of fit. J Prosthet Dent. $1996: 76,(5): 500-509$.

Carter DR, Hayes WC. The compressive behavior of bone as a two-phase porous structure. J Bone Joint Surg. 1977;59(7):954-962.

Çehreli M, Duyck J, De Cooman M, Puers R, Naert I. Implant design and interface force transfer. A photo-elastic and strain-gauge analysis. Clin Oral Impl Res. $2004 ; 15(2): 249-257$.

Çehreli MC, Iplikçioglu H, Bilir ÖG. The influence of the location of load transfer on strains around implants supporting four unit cement retained fixed prostheses: in vitro evaluation of axial versus off-set loading. J Rehabil. 2002; 29(4):394-400.

Chamay A, Tschantz $P$. Mechanical influences in bone remodeling. Experimental research on Wolff's Law. J Biomechanics. 1972;5:173-180.

Chung DM, Oh TJ, Lee J, Misch CE, Wang HL. Factors affecting implant bone loss: A retrospective analisys. Int J Oral Maxilofac Implants 2007; 22:117-126.

Clelland NL, Gilat A, McGlumphy EA, Brantley WA. A photoelastic and strain gauge analysis of angled abutments for na implant system. Int $\mathrm{J}$ Oral Maxillofac Implants. 1993; 8(5):.541-548.

Clelland NL, Van Putten MC. Comparison of strains produced in a bone simulant between conventional cast and resin-luted implant frameworks. Int J Oral Maxillofac Implants. 1996;12(6):793-799.

Duncan RL, Turner $\mathrm{CH}$. Mechanotransduction and the functional response of bone to mechanical strain. Calcif Tissue Int. 1995;57(5):344-358.

Ekfeldt A, Carlsson GE, Börjesson G. Clinical evaluation of single-tooth restorations supported by osseointegrated implants: a retrospective study. Int J Oral Maxillofac Implants. 1994;9:179-183.

Enlow DH. Wolff's law and the factor of architectonic circumstance. American $\mathrm{J}$ Orthodontics. 1968;54(11):803-822 
Frost HM. Wolff's law and bone's structural adaptations to mechanical usage: an overview for clinicians. Angle Orthod. 1994;64(3):175-188.

Geng JP, Tan KB, Liu GR. Application of finite element analysis in implant dentistry: a review of the literature. J Prosthet Dent. 2001; 85(6):585-598.

Glantz PO, Rangert B, Svensson A, Stafford GD, Arnuidarson B, Randik, et al. On clinical loading of osseointegrated implants: a methodological and clinical study. Clin Oral Implants Res. 1993; 4(2):99-105.

Goodacre CJ, Bernal G, Rungcharassaeng K, Kan JY. Clinical complications with implant and implant prostheses. J Prosthet Dent. 2003;90(2):121-132.

Hälg GA, Schmid J, Hämmerle CHF. Bone level changes at implants supporting crowns or fixed partial dentures with or without cantilevers. Clinical Oral Implants Research. 2008;19(10):983-999.

Hecker DM, Ecker SE. Cyclic loading of implant-supported prostheses: Changes in component fit over time. J Prosthet Dent. 2003;89(4):346-351.

Heckmann SM, Karl M, Wichmann MG, Winter W, Graef F, Taylor TD. Loading of bone surrounding implants through three-unit fixed partial denture fixation: a finiteelement analysis based on in vitro and in vivo strain measurements. Clin Oral Impl Res. 2006;17:345-350.

Hekimoglu C, Anil N, Çehreli MC. Analysis of strain around endosseous implants opposing natural teeth or implants. J Prosthet Dent. 2004;92(5):441-446.

Hobkirk JA, Havthoulas TK. The influence of mandibular deformation implant numbers and loading position on detected forces in abutment supporting fixed implant superstructures. J Prosth Dent. 1998;8(2):164-174.

Hollweg $\mathrm{H}$. Análise da passividade de adaptação de infra-estruturas para prótese fixa implanto-suportada, através do uso de extensômetros. 2000. 71p. Tese (Doutorado em odontologia) - Faculdade de Odontologia de Bauru, Universidade de São Paulo, Bauru, 2000.

Hollweg H, Jacques LB, Silva Moura M, Bianco VC, Capello Sousa EA, Rubo JH. Deformation of implant abutments after framework connection - a study with strain gauges. Journal of Oral Implantology. 2010. AAID-JOI-D-10-00068R1 
Hoshaw SJ, Brunski, j.b.; Cochran, g.v.b. Mechanical loading of Brånemark implants affects interfacial bone modeling and remodeling. Int J Oral Maxillofac Implants. 1994; 9(3):345-360.

Hulterström M, Nilsson U. Cobalt-chromium as a framework material in implantsupported fixed prostheses: A 3-year follow-up. Int J Oral Maxillofac Implants. 1994:9(4):449-454.

Isa ZM, Hobkirk JA. The effects of superstructure fit and loading on individual implant units: part I. the effects of tightening the gold screws and placement of a superstructure with varying degrees of fit. Eur J Prosthodont Restorat Dent. 1995; 3(6):247-253.

Ishigaki S, Nakano T, Yamada S, Nakamura T, Takashima F. Biomechanical stress in bone surrounding an implant under simulated chewing. Clin Oral Implants Res. 2003;14:97-102.

Isidor F. Influence of forces on peri-implant bone. Clin Oral Impants Res. $2006 ; 17(2): 8-18$.

Ivanoff CJ, Sennerby I, Lekholm U. Influence of mono- and bicortical anchorage on the integration of titanium implants. A study in the rabbit tibia. Int J Oral Maxillofac Implants. 1996;25(3):229-235.

Jacques LB, Moura MS, Suedam V, Souza EA, Rubo JH. Effect of cantilever length and framework alloy on the stress distribution of mandibular-cantilevered implantsupported prostheses. Clin Oral Implants Res. 2009; 20(7):737-741.

Janson, VRP. Análise da deformação gerada em infra-estruturas de prótese fixa implanto-suportada, através do uso de extensômetros. 2002. 76 p. Dissertação (Mestrado) - Faculdade de Odontologia de Bauru, Universidade de São Paulo, Bauru, 2002.

Jemt T. In vivo measurements of precision of fit involving implant supported prostheses in the edentulous jaw. Int J Oral Maxillofac Implants. 1996; 11(2):151158.

Jemt T. Failures and complications in 391 consecutively inserted fixed prostheses supported by branemark implants in edentulous jaws: a study of treatment form the time of prosthesis placement to the first annual checkup. Int $\mathrm{J}$ Oral Maxillofac Implants. 1991;6(3):270-276. 
Jemt T, Carlsson L, Boss A, Jörneús L. In vivo load measurements on osseointegrated implants supporting fixed or removable prostheses: a comparative pilot study. Int J Oral Maxillofac Implants. 1991; 6(4):.413-417.

Jornéus I, Jemt T, Carlsson I. Loads and design of screw joints for single crowns supported by osseointegrated implants. Int J Oral Maxillofac Implants. 1992;7(3):353359.

Karl M, Wichmann MG, Winter W, Graef F, Taylor T, Heckmann SM. Influence of fixation mode and superstructure span upon strain development of implant fixed partial dentures. J Prosthodont. 2008;17(1):3-8.

Kim WD, Jacobson Z, Nathanson D. In vitro stress analyses of dental implants supporting screw retained and cement retained prostheses. Implant Dent. 1999; 8(2):141-151.

Kansu G, Aydin AK. Evaluation of the biocompatibility of various dental alloys: part 1toxic potentials. Europ J Prosthodont Restorat Dent. 1996; 4(3):155-161.

Korioth TWP, Johann AR. Influence of mandibular superstructure shape on implant stresses during simulated posterior biting. J Prosthet Dent. 1999; 89(1):67-72.

Kozlovsky A, Tal H, Laufer BZ, Leshem R, Rohrer MD, Weinreb M, Artzi Z. Impact of implant overloading on the peri-implant bone in inflamed and non-inflamed periimplant mucosa. Clin Oral Impl Res. 2007;18:601-610.

KreissI ME, Gerds T, Muche R, Heydecke G, Strub JR. Technical complications of implant-supported fixed partial dentures in partially edentulous cases after an average observation period of 5 years. Clin Oral Impl Res 2007;18:720-726.

Matsunaga, Shirakura Y, Ohashi T, Nakahara K, Tamatsu Y, Takano N, et al. Biomechanical Role of Peri-Implant Cancellous Bone Architecture. Int J Prosthodont. 2010;23:333-338.

McDowell JA, Regli CP. A quantitative analysis of the decrease in width of the mandibular arch during forced movements of the mandible. J Dent Res 1961; 40(6):1183-1185.

Melsen B, Llang NP. Biological reactions of alveolar bone to orthodontic loading of oral implants. Clin Oral Impl Res 2001;12(2):144-152. 
Millington NL, Leung T. Inaccurate fit of implant superstructures. Part 1: stresses generated on the superstructure relative to the size of fit discrepancy. Int $\mathrm{J}$ Prosthodont. $1995 ; 8(6): 511-516$.

Millington, ND, Leung T. Stress on an implant superstructure in relation to its accuracy of fit. J Dent Res. 1992; 71:529.

Miyashiro M, Suedam V, Moretti Neto RT, Ferreira PM, Rubo JH. Validation of an experimental polyurethane model for biomechanical studies on implant supported prosthesis - tension tests. J. Appl Oral Sci. 2011;19(3):244-248

Misch CE, Qu Z, Bidez MW. Mechanical properties of trabecular bone in the human mandible: implications for dental implant treatment planning and surgical placement. J Oral Maxillofac Surg. 2000; 58(2):247-248.

Moretti Neto RT. Avaliação da deformação do intermediário e região perimplantar de próteses implanto-suportada unitárias parafusada. Estudo através da extensometria. 2010. Tese (Doutorado em odontologia) - Faculdade de odontologia de Bauru, Universidade de São Paulo, Bauru. 2010.

Moretti Neto RT, Hiramatsu DA, Suedam V, Conti PC, Rubo JH. Validation of an experimental polyurethane model for biomechanical studies on implant-supported prosthesis - compression tests. J Appl Oral Sci. 2011;19(1):47-51

Moretti Neto RT, Silva MM, Capello Souza EA, Rubo JH. Implant Abutment Deformation During Prosthetic Cylinder Screw Tightening: An In Vitro Study Int J Prosthodont. 2009; 22:391-395.

Naert I, Quirynen M, Van Steenberghe D, Darius P. A study of 589 consecutive implants supporting complete fixed prostheses. Part II: Prosthetic aspects. J Prosthetic Dent. 1992; 68(6):949-956.

Nishioka RS, Nishioka LN, Abreu CW, De Vasconcellos LG, Balducci I. Machined and plastic copings in three-element prostheses with different types of implantabutment joints: a strain gauge comparative analysis. J Appl Oral Sci. 2010 Jun;18(3):225-230.

Oh TJ, Yoon J, Misch CE, Wang HL. The causes of early implant bone loss: myth or science? J Periodontol. 2002,73(3):322-33. 
Papavasiliou G, Kamposiora P, Bayne SC, Felton DA. 3D-FEA of ossointegration percentages and patterns on implants-bone interfacial estresses. J Dent. 1997;25(6):485-491.

Patterson EA, Burguete RL, Thoi MH, Johns RB. Distribution of load in an oral prosthesis system: an in vitro study. Int J Oral Maxillofac Implants, v. 10, n. 5, p. 55260, Sep./Oct. 1995.

Petrie CS, Williams JL. Comparative evaluation of implant designs: influence of diameter, length, and taper on strains in the alveolar crest. A three-dimensional finiteelement analysis. Clin Oral Implants Res. 2005;16:486-494.

Pugh JP, Rose RM, Radin El. Elastic and viscoelastic properties of trabecular bone: dependence on structure. J Biomechanics. 1973; 6:475-485.

Rangert B, Jemt T, Jörneus I. Forces and moments on Brånemark Implants. Int J Oral Maxillofac Implants. 1989;4(3):241-247.

Rangert B, Sullivan R, Jemt TM. Load factor control for implants in the posterior partially edentulous segment. Int J Oral Maxillofac Implants. 1997;12:360-370.

Rieger MR, Mayberry M, Brose MO. Finite element analysis of six endosseous implants. J Prosthet Dent. 1990; 63(6):671-676.

Roberts WE, Turley PK, Brezniak N, Fielder PJ. Bone physiology and metabolism. J Calif Dent Assoc. 1987;15(10):54-61.

Rubo JH, Zarb GA, Lei XY, Curran JH. Finite element analysis of stress distribution on dental implants: a study of seven clinical variables. Part II -stresses on implants, abutments and frameworks. Int J Prosthodont. 1999;12,(6):567.

Rubo JH, Souza EAC. Métodos computacionais aplicados à bioengenharia: solução de problemas de carregamento em prótese sobre implantes. Rev FOB. 2001;9(3/4):97-103.

Rubo JH, Souza EAC. Finite-Element Analysis of Stress on Dental Implant Prosthesis. Clin Dent Implant. 2010; 12(2):105-113. 
Sahin S, Çehreli MC, Yalçin E. The influence of functional forces on the biomechanics of implant-suported prostheses - a review. J Dent. 2002;30:271-282.

Sahin S, Çehreli MC. The significance of passive framework fit in implant prosthodontics: current status. J Implant Dent. 2001;10(2):85-90.

Sallam H, Kheiralla LS, Aldawakly A. Microstrains around standard and mini implants supporting different bridge designs. Oral Implantol. 2010. 10.1563/AAID-JOI-D-1000020

Setz J, Krämer A, Benzing U, Weber H. Complete dentures fixed on dental implants: chewing patterns and implant stress. Int J Oral Maxillofac Implants. 1989;4(2):10711.

Sergoz A, Guvener S. Finite element analysis of the effect of cantilever and implant length on stress distribution in implant-supported fixed prostheses. J Prosthet Dent. 1996;76(2):165-169.

Sertgöz A. Finite element analysis study of the effect of superstructure material on stress distribution in an implant-supported fixed prosthesis. Int J Prosthodont,. 1997;10(1):19-27.

Shackleton J. Carr L, Slabbert JC, lownie JF, Becker JP. Prosthodontic complications and problems of fixture-supported prostheses. J Dent Res 1992;71(4):1113. /Abstract n. 89/

Skalak R. Biomechanical considerations in osseointegrated prostheses. J Prosth Dent 1983;49(6):843-848.

Spiekermann H. et al. Biomechanics. In: Color Atlas of Dental Medicine Implantology. New York, Thieme Medical Publishers, p. 81-89, 1995.

Stegaroiu R, Khraisat A, Nomura S, Miyakawa O. Influence of superstructure materials on strain around an implant under 2 loading conditions: a technical investigation. Int J Oral Maxilifac Implants. 2004;19(5):735-742.

Suedam V, Souza EA, Moura MS, Jacques LB, Rubo JH. Effect of abutment's height and framework alloy on the load distribution of mandibular cantilevered implantsupported prosthesis. Clin Oral Implants Res. 2009;20(2):196-200. 
Suedam V. Avaliação da deformação gerada na região Peri-implantar de prótese fixa implantossuportada, com a utilização de extensômetros lineares elétricos. 2009. 134p. Tese (Doutorado em odontologia) - Faculdade de odontologia de Bauru, Universidade de São Paulo, Bauru, 2009.

Tamatsu Y, Kaimoto K, Arai M, Ide Y. Properties of the elastic modulus from buccal compact bone of human mandible. Bull Tokyo Dent Coll. 1996;37(2):93-101.

Tan KB, Rubenstein JE, Nicholls JI, Yuodelis RA. Three-dimensional analysis of the casting accuracy of one-piece, osseointegrated implant-retained prostheses. Int $\mathrm{J}$ Prosth. 1993;6(4):346-363.

Taylor TD. Prosthodontic problems and limitations associated with osseointegration. J Prosthet Dent. 1998;79(1):74-78.

Taylor TD, Agar JR. Twenty years of progress in implant prosthodontics. J Prosth Dent. 2002; 88(1):89-95.

Taylor TD, Agar JR, Vogiatzi T. Implant Prosthodontics: current perspective future directions. Int J Oral and Maxillofac Implants. 2000;15(1):66-75.

Van Zyl PP, Grundling NL, Jooste $\mathrm{CH}$, Terblanche E. Three-dimensional finite element model of a human mandible incorporating six osseointegrted implants for stress analysis of mandibular cantilever prostheses. Int J Oral Maxilofac Implants. $1995 ; 10(1): 51-57$.

Vasconcellos DK. Efeito dos ciclos térmicos para aplicação da cerâmica na passividade de próteses implanto-suportadas, observado pela extensometria. [tese]. São José dos Campos: Faculdade de Odontologia de São José dos Campos, Universidade Estadual Paulista; 2005.

Waskericz GA, Ostrowsky JS, Parks VJ. Photoelastic analysis of stress distribution transmitted from a fixed prosthesis attached to osseointegrated implants. Int J Oral Maxillofac Implants. 1994; 9(4):405-411.

Weinberg IA. The biomechanics of force distribuition in implant-supported prostheses. Int J Oral Maxillofac Implants 1993; 8(1):19-31. 
Weiner S, Sirois D, Ehrenberg D, Lehrmann N, Simon B, Zohn H. Sensory responses from loading of implants: a pilot study. Int. J Oral Maxilofac Implants. 2004;19(1):4451.

Williams KR, Watson CJ, Murphy WM, Scott J, Gregory M, Sinobad D. Finite element analysis of fixed prosthesis attached to osseointegrated implants. Quintessence Int. 1990;21(7):563-570.

Wiskott HW, Belser UC. Lack of integration of smooth titanium surfaces: a working hypothesis based on strains generated in the surrounding bone. Clin Oral Implants Res. 1999;10(6):429-444.

Wyatt C, Zarb G. Bone level changes proximal to oral implants supporting fixed partial prostheses. Clin Oral Impl Res. 2002;13:162-168.

Yanase RT. How do you test a cast framework fit for a full-arch fixed implantsupported prosthesis. Int J Oral Maxillofac Implant. 1994;9(4):170-174.

Zarb GA, Schmitt A. The longitudinal clinical effectiveness of osseointegrated dental implants: the Toronto study. Part II: the prosthetic results. J Prosth Dent. 1990; 64(1):53-61. 
Apêndice 



\section{APÊNDICE A}

Tabela 1- Media dos resultados de microdeformação $(\mu \varepsilon)$ das cinco repetições no intermediário e osso simulado com aplicação de carga nos corpos de prova:Prótese unitária com cilindro protético usinado de Au sobre-fundidos com a liga de paládio-prata e cobertura cerâmica.

\begin{tabular}{cccccccc}
\hline & Int & Int' & Int” & Distal & Lingual & Mesial & Vestibular \\
\hline Au 01 & 13,0 & 83,4 & 250,6 & 222,1 & 355,4 & 461,3 & 369,7 \\
\hline Au 02 & 58,8 & 42,5 & 415,7 & 453,7 & 326,8 & 50,7 & 790,4 \\
\hline Au 03 & 248,5 & 67,9 & 112,4 & 488,5 & 163,6 & 129,9 & 310,0 \\
\hline Au 04 & 54,4 & 95,9 & 454,7 & 564,4 & 285,3 & 54,6 & 930,4 \\
\hline $\begin{array}{c}\text { Media final } \\
\text { Desvio }\end{array}$ & 93,7 & $\mathbf{7 2 , 4}$ & $\mathbf{3 0 8 , 4}$ & $\mathbf{4 3 2 , 2}$ & $\mathbf{2 8 2 , 7}$ & $\mathbf{1 7 4 , 1}$ & $\mathbf{6 0 0 , 1}$ \\
\hline \begin{tabular}{c} 
Padrão \\
\hline 105,3
\end{tabular} & $\mathbf{2 3 , 0}$ & $\mathbf{1 5 7 , 8}$ & 147,5 & 84,5 & 194,9 & 306,9 \\
\hline
\end{tabular}

Tabela 2- Media dos resultados de microdeformação $(\mu \varepsilon)$ das cinco repetições no intermediário e osso simulado com aplicação de carga nos corpos de prova: Prótese unitária com cilindro protético calcinável (cal) fundido com a liga de $\mathrm{NiCoCr}$ e cobertura cerâmica.

\begin{tabular}{|c|c|c|c|c|c|c|c|}
\hline & $\operatorname{lnt}$ & Int' & Int" & Distal & Lingual & Mesial & Vestibular \\
\hline Cal 01 & 208,7 & 99,5 & 184,5 & 432,9 & 304,6 & 211,0 & 134,5 \\
\hline Cal 02 & 204,9 & 53,0 & 210,5 & 506,3 & 306,5 & 95,0 & 150,0 \\
\hline Cal 03 & 124,2 & 182,2 & 143,4 & 206,1 & 371,1 & 580,3 & 19,5 \\
\hline Cal 04 & 175,3 & 56,4 & 207,2 & 502,7 & 298,6 & 73,6 & 123,8 \\
\hline Media final & 178,3 & 97,8 & 186,4 & 412,0 & 320,2 & 240,0 & 107,0 \\
\hline $\begin{array}{l}\text { Desvio } \\
\text { Padrão }\end{array}$ & 39.1 & 60,1 & 30,9 & 141,4 & 34.1 & 234.8 & 59,3 \\
\hline
\end{tabular}


Tabela 3- Media dos resultados de microdeformação $(\mu \varepsilon)$ das cinco repetições no intermediário e osso simulado com aplicação de carga nos corpos de prova: Prótese unitária com cilindro de $\mathrm{CoCr}$ usinado, sobre-fundidos com a liga de NiCoCr e cobertura cerâmica.

\begin{tabular}{|c|c|c|c|c|c|c|c|}
\hline & Int & Int' & Int" & Distal & Lingual & Mesial & Vestibular \\
\hline CoCr 01 & 47,0 & 146,4 & 204,7 & 177,8 & 459,9 & 552,8 & 127,2 \\
\hline CoCr 02 & 191,5 & 211,8 & 71,2 & 200,0 & 53,5 & 535,3 & 241,6 \\
\hline CoCr 03 & 199,8 & 73,6 & 190,5 & 463,1 & 147,4 & 134,3 & 190,6 \\
\hline CoCr 04 & 245,1 & 87,0 & 149,0 & 501,8 & 158,4 & 9,4 & 305,7 \\
\hline Media final & 170,9 & 129,7 & 153,8 & 335,7 & 204,8 & 307,9 & 216,3 \\
\hline \multicolumn{8}{|l|}{ Desvio } \\
\hline Padrão & 85,9 & 63,2 & 60,0 & 170,5 & 176,5 & 277,5 & 75,8 \\
\hline
\end{tabular}

\section{APÊNDICE B}

Tabela 4- Media dos resultados de microdeformação $(\mu \varepsilon)$ em valores de tração(+) e compressão (-) ,das cinco repetições no intermediário e osso simulado com aplicação de carga nos corpos de prova:Prótese unitária com cilindro usinado de Au sobre-fundidos com a liga de paládio-prata e cobertura cerâmica.

\begin{tabular}{|c|c|c|c|c|c|c|c|}
\hline & Int & Int' & Int" & Distal & Lingual & Mesial & Vestibular \\
\hline Au 01 & & & & & & & \\
\hline Au 02 & $-12,6$ & $-83,4$ & $-250,6$ & $-222,1$ & 355,4 & $-461,3$ & $-369,7$ \\
\hline & 58,8 & 42,5 & $-415,7$ & $-453,7$ & 326,8 & $-50,7$ & $-790,4$ \\
\hline Au 03 & $-248,5$ & $-67,9$ & $-112,4$ & $-488,5$ & 163,6 & $-129,9$ & 310,0 \\
\hline Media final & 54,4 & 95,9 & $-454,7$ & $-564,4$ & 285,3 & 54,6 & $-930,4$ \\
\hline Desvio & $-37,0$ & $-3,2$ & $-308,4$ & $-432,2$ & 282,7 & $-146,8$ & $-445,1$ \\
\hline Padrão & 144,8 & 86,7 & 157,8 & 147,5 & 84,5 & 222,9 & 556,9 \\
\hline
\end{tabular}


Tabela 5- Media dos resultados de microdeformação $(\mu \varepsilon)$ em valores de tração(+) e compressão (-) das cinco repetições no intermediário e osso simulado com aplicação de carga nos corpos de prova: Prótese unitária com cilindro calcinável (Cal) fundido com a liga de NiCoCr e cobertura cerâmica.

\begin{tabular}{cccccccc}
\hline & Int & Int' & Int" & Distal & Lingual & Mesial & Vestibular \\
\hline Cal 01 & $-208,7$ & $-99,4$ & $-184,4$ & $-432,9$ & 304,5 & $-210,9$ & 134,5 \\
\hline Cal 02 & $-204,9$ & $-52,9$ & $-210,5$ & $-506,3$ & 306,5 & $-94,9$ & 149,9 \\
\hline Cal 03 & $-124,1$ & $-182,1$ & $-143,3$ & $-206,1$ & 371,0 & $-580,2$ & $-18,4$ \\
\hline Cal 04 & $-175,2$ & $-56,4$ & $-207,2$ & $-502,7$ & 298,5 & $-73,6$ & 123,8 \\
\hline Media final & $-178,3$ & $-97,8$ & $-186,4$ & $-412,0$ & 320,2 & $-240,0$ & 97,4 \\
\hline $\begin{array}{c}\text { Desvio } \\
\text { Padrão }\end{array}$ & 39,1 & 60,1 & 30,9 & 141,4 & 34,1 & 234,8 & 78,0 \\
\hline
\end{tabular}

Tabela 6- Media dos resultados de microdeformação $(\mu \varepsilon)$ em valores de tração(+) e compressão (-) das cinco repetições no intermediário e osso simulado com aplicação de carga nos corpos de prova: Prótese unitária com cilindro de $\mathbf{C o C r}$ usinado, sobre-fundidos com a liga de NiCoCr e cobertura cerâmica.

\begin{tabular}{cccccccc}
\hline & Int & Int' & Int” & Distal & Lingual & Mesial & Vestibular \\
\hline CoCr 01 & $-47,0$ & $-146,4$ & $-204,7$ & $-177,8$ & 459,9 & $-552,8$ & $-127,2$ \\
\hline CoCr 02 & $-191,5$ & $-211,8$ & $-71,2$ & $-200,0$ & 53,5 & $-535,3$ & 241,6 \\
\hline CoCr 03 & $-199,8$ & $-73,6$ & $-190,5$ & $-463,1$ & 147,4 & $-134,3$ & 190,6 \\
\hline CoCr 04 & $-245,1$ & $-87,0$ & $-149,0$ & $-501,8$ & $-158,4$ & 8,3 & 305,7 \\
\hline Media final & $-170,9$ & $-129,7$ & $-153,8$ & $-335,7$ & 125,6 & $-303,5$ & 152,7 \\
\hline Desvio & & & & & & & 192,5 \\
\hline
\end{tabular}

